\title{
Astrocytes are necessary for blood-brain barrier maintenance in the adult mouse brain
}

Running Title: Astrocytes and the blood-brain barrier

Authors: Benjamin P. Heithoff ${ }^{1,2}$, Kijana K. George ${ }^{1,3}$, Aubrey N. Phares ${ }^{1,4}$, Ivan A. Zuidhoek $^{1,3}$, Carmen Munoz-Ballester ${ }^{1}$, Stefanie Robel ${ }^{1-4}$

${ }^{1}$ Fralin Biomedical Research Institute at Virginia Tech Carilion, Roanoke 24016, Virginia, 2Department of Biological Sciences, Virginia Tech, Blacksburg 24060, Virginia, ${ }^{3}$ Graduate Program in Translational Biology, Medicine, and Health, Virginia Tech, Roanoke 24016, Virginia, ${ }^{4}$ School of Neuroscience, Virginia Tech, Blacksburg 24060, Virginia

\section{Corresponding Author:}

Stefanie Robel

2 Riverside Circle, Roanoke VA, 24016

srobel@vt.edu 


\section{Acknowledgements}

This work was supported by the National Institute of Neurological Disorders and Stroke at the National Institutes of Health (grant number R01NS105807). We thank Katie Barnes, Maame Boateng, Deyton Cook, and Dzenis Mahmutovic for their contributions to data collection.

\section{Conflict of Interest Statement}

The authors declare no conflict of interest.

\section{Data Availability Statement}

The data supporting the findings in this study are available upon reasonable request from the corresponding author.

\section{Word Counts}

Total:

Abstract: 224

Introduction: 724

Methods: 2290

Results: 2755

Discussion: 1678

\section{Abstract (224/250 words)}

In the adult brain, multiple cell types are known to produce factors that regulate blood-brain barrier properties, including astrocytes. Yet several recent studies disputed a role for mature astrocytes at the blood-brain barrier. To determine if astrocytes contribute a non-redundant and 
necessary function in maintaining the adult blood-brain barrier, we used a mouse model of tamoxifen-inducible astrocyte ablation. In adult mice, tamoxifen induction caused sparse apoptotic astrocyte cell death within 2 hours. Indicative of BBB damage, leakage of the small molecule Cadaverine and the large plasma protein fibrinogen into the brain parenchyma indicative of BBB damage was detected as early as astrocyte ablation was present. Vessels within and close to regions of astrocyte loss had lower expression of the tight junction protein zonula occludens-1 while endothelial glucose transporter 1 expression was undisturbed. Cadaverine leakage persisted for several weeks suggesting a lack of barrier repair. This is consistent with the finding that ablated astrocytes were not replaced. Adjacent astrocytes responded with partial non-proliferative astrogliosis, characterized by morphological changes and delayed phosphorylation of STAT3, which restricted dye leakage to the brain and vessel surface areas lacking coverage by astrocytes one month after ablation. In conclusion, astrocytes are necessary to maintain blood-brain barrier integrity in the adult brain. Blood-brain barrier-regulating factors secreted by other cell types, such as pericytes, are not sufficient to compensate for astrocyte loss.

\section{Keywords}

glial scar, astrogliosis, tight junctions, contact inhibition, gliovascular unit 


\section{Main Points (250 characters)}

Mature astrocytes are necessary for maintenance of endothelial tight junctions in the adult brain. Ablated astrocytes are not replaced by proliferation or process extension of neighboring astrocytes resulting in long-term blood-brain barrier damage. 


\section{Introduction (726)}

A role for astrocytes in maintaining the blood-brain barrier (BBB) in the adult healthy brain is widely assumed, but little direct experimental evidence supports this conclusion. In fact, several recent studies ablating astrocytes suggest that astrocytes are not required to maintain BBB integrity (Kubotera et al., 2019; Schreiner et al., 2015; Tsai et al., 2012). The conclusion that astrocytes are involved in BBB initiation and maintenance is based on early work that transplanted glial progenitor cells into the developing main body cavity and the anterior chamber of the eye, which both normally lack a BBB. As a result of this transplantation, permeable vessels acquired BBB properties and dyes such as trypan blue and Evans blue could no longer pass this barrier (Janzer \& Raff, 1987; Stewart \& Wiley, 1981). Evidence for an astrocytesecreted factor responsible for initiating barrier-like properties in endothelial cells was obtained in culture studies using primary bovine brain endothelial cells in conjunction with primary postnatal astrocytes or their conditioned media. Under these conditions, endothelial cells that lose their BBB properties when cultured alone start to express higher levels of tight junction proteins, and enhanced trans-endothelial electrical resistance (TEER) can be measured suggesting a physically tighter barrier (Rubin et al., 1991; Tao-Cheng, Nagy, \& Brightman, 1987; Wolburg et al., 1994). These results were reproduced in human brain microvascular endothelial cells (HBMECs) using conditioned media from human astrocytes (Siddharthan, Kim, Liu, \& Kim, 2007) or induced pluripotent stem cell-derived astrocytes (Canfield et al., 2017). From this data, a key role for astrocytes in initiating and maintaining the BBB via secreted factors, among them sonic hedgehog (Shh) and glial derived neurotrophic factor (Igarashi et al., 1999; Xia et al., 2013) was deduced. Yet astrocytes cultured from neonates rapidly divide and reflect a more progenitor-like phenotype, which is vastly different from the mature, quiescent astrocytes 
populating the adult brain. In 2010, Armulik and Daneman challenged the notion that BBB formation during development relies on astrocytes, arguing that the BBB is already established before glial progenitor cells differentiate into astrocytes and astrocyte endfeet are formed along vessels. Instead, this study established a role for pericytes in initiating BBB formation because the barrier was found to be abnormal in PDGFRb-deficient mice, which present with reduced pericyte coverage along cerebral vessels. Given the developmentally dysfunctional vessels and BBB, this study was not able to dissect a potential role for mature astrocytes in BBB maintenance upstream of pericytes in the adult brain (Armulik et al., 2010; Daneman, Zhou, Kebede, \& Barres, 2010).

Many factors secreted by cultured astrocytes that were reported to modulate the BBB in vitro, including Sonic hedgehog (Shh), glial-derived neurotrophic factor and angiopoietin, are not present in mature astrocytes in the uninjured brain according to several astrocyte-specific transcriptome and proteome datasets (Anderson et al., 2016; Sharma et al., 2015; Y. Zhang et al., 2014). This holds true even after enriching for astrocyte endfeet transcripts (Boulay et al., 2017). A study carefully assessing Shh protein and mRNA expression patterns determined that Shh is present in very few astrocytes and the majority of Shh protein in the adult uninjured cortex is made by neurons (Sirko et al., 2013). Other factors including Fibroblast growth factor 2 (FGF2) and vascular endothelial growth factor A are expressed at low or, in the case of angiotensinogen, high levels. Many of these molecules are modulated in expression during development and after injury and their role for BBB function has mostly been explored in the context of pathology (Argaw et al., 2012; Huang et al., 2012; Lee et al., 2003; Min et al., 2015; Z. G. Zhang, Zhang, Croll, \& Chopp, 2002; Z. G. Zhang et al., 2000; Zheng et al., 2009) or in genetic models that did not distinguish developmental or cell type-specific effects in vivo (Kakinuma et al., 1998; Reuss, Dono, \& Unsicker, 2003; Wosik et al., 2007) to assess the role of mature astrocytes in BBB maintenance. 
Thus, whether astrocytes have a necessary and non-redundant role in maintenance of the BBB in the healthy adult brain is still unresolved as the above-mentioned astrocyte ablation studies used readouts that only represent massive damage to the BBB (also see discussion). To overcome these limitations, we genetically ablated astrocytes in the adult brain and employed sensitive readouts to test for BBB integrity. Here, we demonstrate that astrocytes perform necessary and non-redundant roles for maintenance and repair of the BBB. 


\section{Methods}

\subsection{Mice}

To enable inducible genetic astrocyte-specific ablation Gt(ROSA)26Sortm1(DTA)Jpmb/J mice (Jackson Labs stock \#006331) were crossed with Tg(Slc1a3-cre/ERT)1Nat (Nathans, 2010) (Jackson Labs stock \#012586). We will refer to Gt(ROSA)26Sortm1(DTA)Jpmb/J mice expressing one diphtheria toxin A (DTA) allele as DTA ${ }^{\text {tl/wt }}$ mice and to $\mathrm{Tg}(\mathrm{Slc} 1 \mathrm{a} 3-\mathrm{cre} / \mathrm{ERT}) 1 \mathrm{Nat}$ expressing the transgene heterozygously as Glast-CreERT ${ }^{\mathrm{tg} / \mathrm{wt}}$ mice.

Mice were initially purchased from The Jackson Laboratory and were then bred in-house. All animal procedures were approved and carried out according to the guidelines of the Institutional Animal Care and Use Committee of Virginia Polytechnic Institute and State University (Virginia Tech) and were performed in compliance with the National Institute of Health's Guide for the Care and Use of Laboratory Animals.

\subsection{Experimental Design}

8-12 week old mice of both sexes were used for experiments. Sex is specified in Table 1.

Diphtheria Toxin fragment A (DTA) interferes with protein synthesis, inducing apoptotic cell death in those cells that express it (Ivanova, Signore et al. 2005). DTA ${ }^{\mathrm{fl} / \mathrm{wt}}$ (fl: floxed allele, encoding loxP sites; wt: wildtype allele) mice express DTA under the Rosa26 promoter behind a stop cassette flanked by loxP sites, which interferes with DTA expression until the stop cassette is removed by Cre recombinase. Cre recombinase is fused with an estrogen receptor and expressed behind the Glast promoter and as part of a complex in Glast-CreERT ${ }^{\mathrm{tg} / \mathrm{wt}}$ mice (tg: allele carries transgene; wt: wildtype allele). This restricts expression to astrocytes and enables timed relocalization of the CreERT protein complex to the nucleus for excision of the stop cassette only after Tamoxifen (TX) administration (Fig. 1a). Glast-CreERT is expressed and 
causes Cre-mediated recombination in a limited number of astrocytes in the forebrain of adult mice (Mori et al., 2006; Srinivasan et al., 2016).

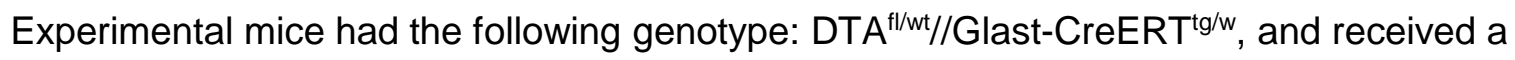

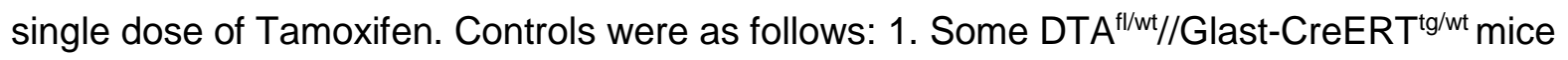
received carrier solution only, which lacked tamoxifen. 2. Mice lacking either the DTA or the

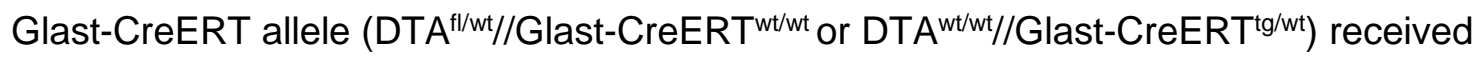

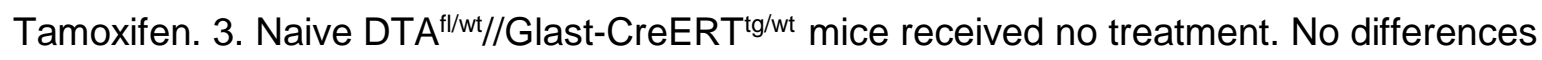
between control groups were detected and controls were hence pooled for analysis.

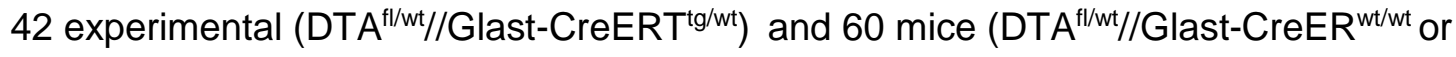

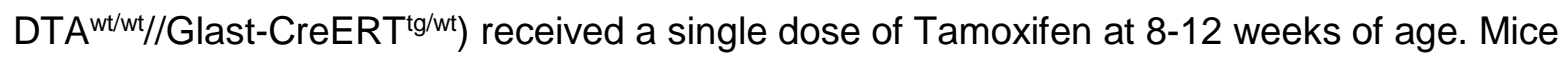
were injected with a lethal dose of Ketamine $(100 \mathrm{mg} / \mathrm{kg}) /$ Xylazine $(10 \mathrm{mg} / \mathrm{kg})$ followed by transcardial perfusion for subsequent histology at 2 and 6 hours post ablation (hpa) as well as 1 , 3, 5, 11 and 28 days post ablation (dpa) (Fig. 1b). Some mice were injected retro-orbitally with Cadaverine to assess blood-brain barrier integrity.

\subsection{Tamoxifen administration}

Tamoxifen (Sigma, cat \#T6548) was dissolved at $40 \mathrm{mg} / \mathrm{mL}$ in a mixture of $10 \% 200$-proof ethanol and $90 \%$ Corn oil (Sigma, cat \#C2867) for $2 \mathrm{~h}$ while shaking at $37^{\circ} \mathrm{C}$. The tamoxifen solution was administered via oral gavage at $330 \mathrm{mg} / \mathrm{kg}$ once.

\subsection{Cadaverine administration}

To assess blood-brain barrier function Alexa Fluor-555 Cadaverine (950 Da,1 mg; Invitrogen, Catalog \#A30677) was injected into the retro-orbital sinus of each mouse. Cadaverine $(1 \mathrm{mg})$ was dissolved in $300 \mathrm{uL}$ of sterile saline. Each mouse was injected with a volume of $100 \mathrm{uL}(0.33 \mathrm{mg})$. Mice were perfused transcardially with Phospho-Buffered Saline (PBS) followed by 4\% paraformaldehyde (PFA) 30 minutes after Cadaverine injection. 


\subsection{BrdU administration}

For the assessment of astrocyte proliferation, intraperitoneal injections of BrdU/saline (50 $\mathrm{\mu g} / \mathrm{g}$ body weight) were administered to experimental and control mice twice daily for 5 days, starting on the day of Tx administration. Mice were sacrificed at $2 \mathrm{hpa}, 6 \mathrm{hpa}, 1 \mathrm{dpa}, 3 \mathrm{dpa}$, or 5 dpa.

\subsection{Histology}

Brains were collected after transcardial perfusion and post-fixed in 4\% PFA overnight. Sagittal slices were cut at $50 \mu \mathrm{m}$ thickness using a vibratome (Campden $5100 \mathrm{mz}$ ). Immunohistochemistry used the primary antibodies (listed in Table 2) in PBS with 10\% goat serum $0.5 \%$ Triton $\mathrm{X}-100$ at $4^{\circ} \mathrm{C}$ overnight. Slices were washed in PBS and incubated in secondary antibody (listed in Table 2 ) solution of PBS with $10 \%$ goat serum and $0.5 \%$ Triton X100 for $1-2 \mathrm{~h}$ at room temperature. 4,6-diamidino-2-phenylindole (DAPI) was included in the secondary antibody solution as needed. Slices were washed in PBS three times for ten minutes each and then mounted onto glass microscope slides with Aqua Poly/Mount (Polysciences, catalog \#18606).

For immunohistochemistry against BrdU, antigen retrieval was performed using 1x citrate buffer ( $\mathrm{pH} 6.0$, Thermo Fisher, Catalog \#005000) at $95^{\circ} \mathrm{C}$ for 20 minutes followed by incubation in primary antibody solution overnight at $4^{\circ} \mathrm{C}$. This was followed by one 10 minute wash in $0.5 \%$ Triton X/ PBS and two 10 minute washes in PBS. Slices were mounted on glass slides, covered with Aqua Poly/Mount and a glass coverslip. Slices stained for phosphorylated Stat-3 underwent antigen retrieval in $10 \mathrm{mM}$ Tris- $\mathrm{HCl}, 1 \mathrm{mM}$ EDTA at $\mathrm{pH} 9.0$ at $90^{\circ} \mathrm{C}$ for 20 minutes. Slices were washed in PBS for 1 hour before incubating in primary antibody solution overnight at $4^{\circ} \mathrm{C}$.

For tight junction (ZO-1) staining, slices were subjected to antigen retrieval using $100 \mathrm{mg}$ pepsin in $10 \mathrm{mM}$ hydrochloric acid $(\mathrm{HCl})$ for 20 minutes at $37^{\circ} \mathrm{C}$. Next, slices were washed twice in PBST (PBS with $150 \mathrm{uL} \mathrm{L}^{-1}$ Tween-20) and then incubated in $3 \% \mathrm{H}_{2} \mathrm{O}_{2}$ for 10 minutes. Finally, 
slices were washed 3 times in PBS for ten minutes each and then incubated in primary antibody solution for a minimum of 48 hours at $4^{\circ} \mathrm{C}$.

Images of mice were taken using a Nikon A1R confocal microscope with Nikon 4x, 10x or 20x air objectives or Nikon Apo 40x/1.30 and 60x/1.40 oil immersion objectives.

\subsection{Data Analysis}

\subsubsection{Quantification of astrocyte loss}

Astrocyte loss was assessed in the cortical gray matter of experimental and control mice using immunohistochemistry against the astrocytic glutamate transporter Glt1, which is expressed in the fine processes in all astrocytes. Large image scans were taken of the cortex and/or hippocampus using a $20 x$ objective and $2 x$ line averaging at a single step position. Images were stitched together using optimal path stitching with 5\% overlap. Line averaging was crucial to reduce grid lines where images overlap. Three to five sagittal slices per animal and 3 mice per group were imaged for quantification. Areas that lacked Glt1 labeling were identified after binarization of the image using set thresholding parameters in ImageJ. The binarized image was then processed using the "fill holes" feature to consolidate Glt1 loss areas into discrete shapes. Finally, Glt1 loss regions were found by setting consistent size and circularity parameters that excluded spaces covered by blood vessels and neurons from being recognized as "Glt1-free". (Suppl. Fig. 1). Glt1 loss was calculated as a percentage of the total cortex area in each slice and was plotted with each data point representing one slice. Data points of slices from the same animal were plotted using the same color, different colors represent data points from different mice.

\subsubsection{Quantification of Cadaverine leakage}

Cadaverine is coupled to the fluorescent dye Alexa Fluor 550 (A550) and is excluded from the brain parenchyma by the functional BBB. BBB leakiness permits the dye to cross into the 
brain, where neurons take it up. Large image scans of the cortex were taken using a 10x objective and images were stitched together using optimal path stitching with $5 \%$ overlap. Five slices were imaged per animal. Cadaverine ${ }^{+}$regions were included in quantification upon meeting the following criteria: 1) Cadaverine cells were brighter than the background, 2) were clustered in close proximity to each other, and 3) each drawn ROI consisted of at least 10 Cadaverine $^{+}$cells. Cadaverine leakage area was calculated as a percentage of the total cortex area in each slice and was plotted by animal.

\subsubsection{Quantification of astrocyte process length and volume}

To determine if astrocytes adjacent to ablated neighbors respond by changing their morphology, we employed the Simple Neurite Tracer (Longair, Baker, \& Armstrong, 2011) in $\mathrm{Fiji} /$ ImageJ in order to create a $3 \mathrm{D}$ representation of an astrocyte and its processes. Total process length and volume of $\mathrm{GFAP}^{+}$astrocyte processes were measured and compared, and Sholl analysis was employed to determine astrocyte process complexity. Early (1 dpa), middle (11 dpa) and late (28 dpa) timepoints were examined in three mice per timepoint. Sample size for each group was $n=15$ astrocytes. Five astrocytes were located across at least three different slices for each animal, and these three slices were chosen to represent different areas of the cortex. GFAP expression was used to analyze astrocytes and their major process length and thickness, and Glt-1 was used to confirm loss areas in the experimental mice.

\subsubsection{Polarity quantification}

To investigate the polarity of the astrocytes adjacent to areas of loss, we first identified the relevant area of loss and drew a line between the two ends of this loss (Line 1) (Fig. 5e). From the center of Line 1, Line 2 (the bisector) was drawn through the center of the soma of the astrocyte and extended to the end of the longest process in that direction. Next, Line 3 was drawn perpendicular to Line 2, and it also went through the center of the soma of the astrocyte and extended to the end of the longest process in that direction. Line 2 and Line 3 served to 
divide the astrocyte into quadrants, with the more proximal quadrants being the ones directly adjacent to the relevant loss area while the distal quadrants were the ones further removed from the loss.

Additional lines were added to enclose the quadrants, which were all centered at the astrocyte soma. The area of the two proximal quadrants and the area of the two distal quadrants was determined. The ratio of the distal area to the proximal area was then calculated, in order to provide us with information about the polarity of the astrocyte in relation to the relevant area of loss. The ratio of width (Line 3) to length (Line 2) was also calculated, in order to provide further polarity information.

For sham astrocytes, without a relevant area of loss to draw Line 1, a random number generator between 1 and 360 was used to determine the angle at which Line 1 would be drawn. From there, the same protocol from above was followed in order to divide the sham astrocytes into four quadrants. The ratio of the proximal area to the distal area and the ratio of width to length was calculated for these astrocytes as well.

\subsubsection{Quantification of astrocyte proliferation}

Astrocyte proliferation was quantified using immunohistochemistry against the cell cycle protein Ki67 across all timepoints or BrdU labeling at 2 hpa, 6 hpa, 1 dpa, 3 dpa, and 5 dpa. To quantify the number of $\mathrm{Ki} 67^{+}$astrocytes, 1 confocal image was taken in 3-5 different slices per animal, 3 mice per group. To quantify the number of $\mathrm{BrdU}^{+}$astrocytes, 1 confocal image was taken in 3-5 different slices per animal, 3 mice per group. For experimental mice, images were taken in areas adjacent to Glt1 loss. For control mice, one image each was taken in the frontal, medial, and lateral regions of cortex. Regions surrounding large penetrating arteries were avoided in both groups because Glt1 expression levels are sometimes reduced in directly adjacent astrocytes, even in controls. Confocal images had a z-step size of $1 \mu \mathrm{m}$. Stacks spanned the entire slice and were quantified step-by-step using the cell counter tool in ImageJ. 
Cells that co-labeled for S100ß, DAPI and Ki67 or S100ß, DAPI and BrdU were considered proliferating astrocytes.

\subsubsection{Quantification of ZO-1 expression}

Expression of the tight junction protein ZO-1 was quantified in ImageJ. ZO-1 images were binarized based on intensity and size and resulting masks were overlaid onto corresponding images of the marker CD31 that labels endothelial cells. A line was drawn along the CD31+ blood vessels, and the generated plot profile represented ZO-1-positive pixels as "1", and pixels lacking ZO-1 as "0". The plot profile data was used to calculate the percent of pixels in the drawn line that lacked ZO-1. Using the known pixel dimensions, this measurement could be converted into length of ZO-1 coverage in micrometers and was reported per animal as percent of vessel lacking ZO-1. 3-5 confocal images were taken in 3-5 different slices, 3 mice per group. The experimental mice were examined along early (6 hpa), middle (11 dpa) and late (28 dpa) timepoints. Images for experimental mice were taken in regions lacking Glt1. For the same ZO-1 images, fluorescence intensity was also measured and was reported per animal.

\subsubsection{Quantification of GLUT1 expression}

We measured fluorescence intensity of the protein Glucose Transporter 1 (GLUT1) expression in blood vessels within regions of astrocyte ablation. Mean fluorescence intensity of GLUT1 was measured using ImageJ. As above, Glt1 was used to confirm regions of astrocyte ablation. Images for experimental mice were taken in areas lacking Glt1. 3 confocal images were taken in 3-5 different slices, 3 mice per group. The experimental mice were examined along early ( $1 \mathrm{dpa})$, middle (11 dpa) and late (28 dpa) timepoints.

\subsection{Statistics}

Statistics were calculated and graphed using GraphPad Prism 8 (GraphPad Software). Statistics not reported in text can be found in Table 3. Data groups were considered significantly 
different at $p \leq 0.05$. Data were tested for Gaussian distribution using the Kolmogorov-Smirnov (KS) normality test. Statistical tests were chosen accordingly and are specified in the results section or figure legends. Data values are reported as mean with standard error of the mean (SEM). Scatter plots reflect individual values and bar graphs reflect the mean with SEM. In graphs with slices plotted, slices from the same animal were plotted as dots of the same color, and different colors represent data points from different mice. Statistical significance is indicated with ${ }^{*} p \leq 0.05,{ }^{* *} p \leq 0.01,{ }^{* * *} p \leq 0.001,{ }^{* * *} p \leq 0.0001$. 


\section{Results}

\subsection{Astrocyte ablation occurs within hours after Tamoxifen administration}

To determine if astrocytes are necessary for blood-brain barrier (BBB) maintenance, we genetically ablated a small number of astrocytes in adult mice using a conditional and inducible approach. Mice expressing the diphtheria toxin subunit A (DTA) behind a stop cassette flanked by loxP sites were bred with mice expressing CreERT behind the promoter of the astrocytic glutamate transporter Glast. This restricted expression of CreERT to astrocytes and enabled induction of astrocyte ablation in adult mice upon administration of Tamoxifen, which causes translocation of the Cre recombinase to the nucleus. There, Cre recombinase excised the stop cassette enabling expression of DTA (Fig. 1a). We chose Glast-CreERT specifically because of its limited recombination efficiency in the adult forebrain (Mori et al., 2006), which allowed for sparse astrocyte ablation and confirmed that no astrocyte ablation took place in experimental

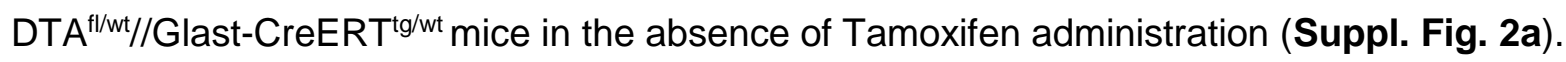

We first determined the time course of astrocyte ablation by harvesting brain tissue $2 \mathrm{~h}, 6 \mathrm{~h}$, 24h, 3d, 5d, 11d and 28d after a single dose of Tamoxifen (Tx) or carrier solution (10\% ethanol in corn oil) (Fig. 1b). At 6 hpa and 1 dpa, we observed overlap between the astrocyte marker S100 $\beta$ and the apoptosis marker cleaved caspase 3 , suggesting that astrocytes underwent apoptosis at these timepoints (Fig. 1c). The nuclei in these astrocytes were pyknotic and highly condensed, an additional indication that these cells were undergoing apoptosis. We did not find any cleaved caspase 3-positive cells at later timepoints ( $3 \mathrm{dpa}, 5 \mathrm{dpa}, 11 \mathrm{dpa}, 28 \mathrm{dpa}$ ), suggesting that by those timepoints, the recombined astrocytes had died.

We confirmed astrocyte loss across all timepoints using the astrocyte membrane-associated protein glutamate transporter 1 (Glt1). Tissues from control mice were characterized by a mostly even and continuous Glt1 staining pattern (Fig. 1d), though astrocytes close to the midline sometimes had reduced Glt1 levels in both control and experimental groups (Fig. 1e). After 


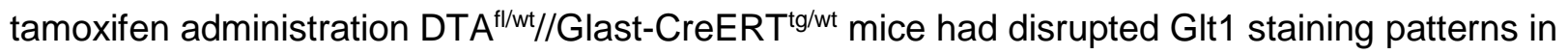
distinct regions resembling single astrocyte domains or groups of astrocytes throughout the cortical gray matter (Fig. 1d-e) and other brain regions, including the hippocampus, striatum and cerebellum (Suppl. Fig. 2b-d).

Areas lacking Glt1 were also characterized by lack of expression of other astrocyte proteins including S100ß, and Aquaporin4 (AQ4) (Suppl. Fig. 3a-b). This occurred, in single domains, as early as 2 hours post ablation (hpa, refers to administration of Tx) (Fig. 1d-e). At this timepoint we did not detect cleaved caspase-3 possibly due to the small number of apoptotic astrocytes at this early timepoint.

Quantification of Glt1-negative area size was not sensitive enough to detect significant differences between control and experimental mice at 2 hpa and 6 hpa (Fig. 1f), even though small areas with missing astrocytes were clearly present, even at these early timepoints. Cortical area size lacking Glt1 increased at $1 \mathrm{dpa}$ and was maximal at approximately $12 \%$ at 5 dpa. At 11 and $28 \mathrm{dpa}$, areas without Glt1 appeared slightly reduced in size when compared to $5 \mathrm{dpa}$, but this difference was not statistically significant. For each experimental animal, the largest cortical Glt1 loss areas were consistently located closer to the midline, while smaller loss areas were found primarily in lateral sections. When these regions were plotted separately, medial slices (Allen Brain Atlas slices 8-21) showed significantly larger Glt1 loss areas compared to lateral slices (Allen Brain Atlas slices 1-7) in experimental but not in control mice (Fig. 1g).

In conclusion, astrocyte ablation was initiated in DTA ${ }^{\mathrm{f} / \mathrm{wt} / / G l a s t-C r e E R} T^{\mathrm{tg} / \mathrm{wt}}$ mice within hours after Tx administration and peaked at $5 \mathrm{dpa}$. Approximately $12 \%$ of the cortical surface area lacked Glt1 coverage. 


\subsection{Astrocyte ablation triggers early and sustained blood-brain barrier dysfunction}

It is unclear if pericytes are sufficient to maintain the adult BBB or if astrocytes are indeed necessary, possibly upstream of pericytes, to maintain BBB function in vivo. To determine whether genetic ablation of astrocytes in the adult mouse brain interferes with BBB integrity, we used the small fluorescently labeled molecule Cadaverine $(<1 \mathrm{kDa})$. We chose Cadaverine as opposed to larger molecular size tracers as a starting point to detect even small disturbances in BBB function. A recent study reported Cadaverine leakage into the brain parenchyma to be indicative of impaired tight junctions even in the absence of leakage of larger plasma proteins ( 70kDa) or Dextran-coupled fluorescent tracers (10kDa) (Yanagida et al., 2017).

Cadaverine leakage was observed as early as 2 hpa and was typically associated with areas of astrocyte ablation (Fig. 2a) suggesting that BBB integrity was affected very quickly once astrocytes become dysfunctional as a result of DTA expression, which inhibits protein synthesis ultimately leading to cell death. Cadaverine was injected 30 minutes before mice were euthanized, thus leakage of the tracer represents the dysfunction of the barrier at this particular time point.

As an approximation of the extent of BBB dysfunction after astrocyte ablation, we quantified the percentage of cortical area covered by cells that took up Cadaverine in large image scans (Fig. 2b, Suppl. Fig. 4a). At 6 hpa about $5 \%$ of the cortical gray matter was covered by Cadaverine $^{+}$cells. This area fraction tripled by 5-11dpa. While Cadaverine spread throughout the tissue appeared diffuse at early timepoints after ablation ( $6 \mathrm{hpa}, 1 \mathrm{dpa}$ ) it was found to be more restricted to areas of ablation one month after ablation ( $28 \mathrm{dpa}$ ) signified by a significantly reduced area covered by Cadaverine ${ }^{+}$cells. We also occasionally found some Cadaverine leakage, albeit at much smaller extent, in control mice. Interestingly, leakages colocalized with areas along the midline where we found astrocytes with reduced Glt1 levels even in controls. 
Sometimes leakage of Cadaverine occurred in controls surrounding large penetrating arteries with adjacent astrocytes lacking Glt1.

We next sought to determine if greater Cadaverine leakage correlated with greater Glt1 loss by plotting these values from all experimental and control mice. The r value of 0.71 (two-tailed Pearson's correlation test) reflects a moderate correlation but suggests that Cadaverine leakage is not necessarily larger in mice with larger Glt1 loss regions. This might be due to the small size of the dye, which might easily diffuse within the tissue.

To further determine the extent and severity of BBB dysfunction after astrocyte ablation, we stained for the large molecular size blood plasma protein fibrinogen ( 340 kDa). Fibrinogen accumulates outside of blood vessels and acts as part of the coagulation cascade that stops bleeding, and is indicative of damage to blood vessels resulting in entrance of larger bloodborne molecules and erythrocytes. While not as widespread as Cadaverine leakage, we observed several regions with fibrinogen deposition in the cortex as early as $1 \mathrm{dpa}$ (Fig. 2c). In the 14 experimental mice examined for fibrinogen, 7 of the 80 slices examined showed fibrinogen deposition. These regions were consistently surrounded by large zones depleted of Glt $1^{+}$astrocytes and Cadaverine leakage. However, most areas with Glt1 loss and Cadaverine leakage lacked fibrinogen deposits.

Taken together, these findings suggest that astrocyte ablation interferes with BBB integrity, that larger areas of loss result in more extensive damage to the BBB, allowing entrance of molecules as large as fibrinogen into the brain, and that BBB integrity is disturbed for at least 4 weeks post ablation.

\subsection{Astrocyte ablation interferes with tight junction function but does not affect expression of endothelial glucose transporter Glut1.}

We next asked whether Cadaverine and fibrinogen leakage occurred due to dysfunctional tight junctions in astrocyte ablated areas. We examined the tight junction protein zonula occludens-1 
(ZO-1) using immunohistochemistry at $6 \mathrm{hpa}, 11 \mathrm{dpa}$ and $28 \mathrm{dpa}$. In control mice, we observed continuous labeling of ZO-1 that overlapped with the endothelial cell marker CD31 (Fig. 3a). We observed mostly intact ZO-1 labeling in ablation regions at $6 \mathrm{hpa}$. These areas did not show Cadaverine leakage. In contrast, the few areas that had disrupted ZO-1 labeling also presented with Cadaverine leakage (Fig. 3a). We observed frequent ZO-1 disruption and reduced expression at $11 \mathrm{dpa}$ and $28 \mathrm{dpa}$, and some vessels lacked ZO-1 almost completely (Fig. 3a, yellow arrowhead). Quantifications for ZO-1 intensity and continuity along CD31 vessels at 6 hpa, when we observed only few missing astrocytes domains, showed no changes from controls (Fig. 3b-c). At $11 \mathrm{dpa}$ and $28 \mathrm{dpa}$, the percentage of CD31 vessels lacking ZO-1 labeling was increased and ZO-1 signal intensity was decreased.

Increased permeability due to BBB dysfunction can occur through several mechanisms beyond loosening of physical tightness of the junctions, including dysregulation of proteins that govern its metabolic barrier properties. The endothelial glucose transporter Glut1 is responsible for over $90 \%$ of all glucose transport into the brain, and is thus often used as a readout for metabolic barrier function (Boado \& Pardridge, 1993; Pardridge, Boado, \& Farrell, 1990). We labeled blood vessels with the glucose transporter Glut1 to determine if glucose transporter levels were affected by astrocyte ablation. We found no changes in Glut1 expression pattern at 6 hpa, 11 dpa or 28 dpa (Fig. 3d). Quantification of average fluorescence intensity of Glut1 in vessels adjacent to astrocyte ablation regions revealed no differences among groups (Fig. 3e).

Together, this suggests that astrocyte ablation interferes with specific aspects of barrier function such as expression and/or localization of tight junction proteins.

\subsection{Astrocytes adjacent to ablated areas respond with molecular changes characteristic for glial scar formation}

In response to injury and disease, astrocytes undergo context-dependent molecular and morphological changes in a process called astrogliosis. In the event of a focal traumatic brain or 
spinal cord injury, astrocytes can form glial scars to seal off injured areas and protect from further damage. Here, we asked if astrocyte loss and opening of the BBB is sufficient to induce a scar-forming response in astrocytes adjacent to ablated regions. We first tested for the phosphorylation of the cytokine and growth factor signal transducer and activator of transcription 3 (pSTAT3), which is essential for scar formation (Herrmann et al., 2008). The promoter for glial fibrillary acidic protein (GFAP) is a downstream target of STAT3 (Ito et al., 2016). GFAP is typically upregulated after injury and is intensely increased in scar-forming astrocytes.

While we found $\mathrm{GFAP}^{+}$astrocytes adjacent to regions of astrocyte ablation and Cadaverine leakage at $1 \mathrm{dpa}, 3 \mathrm{dpa}$, and $5 \mathrm{dpa}$, at these timepoints none labeled for pSTAT3. Several pockets of pSTAT3 ${ }^{+} / \mathrm{GFAP}^{+}$astrocytes were detected at $11 \mathrm{dpa}$. By $28 \mathrm{dpa}, \mathrm{pSTAT3}^{+} / \mathrm{GFAP}^{+}$ astrocytes were more numerous and appeared to surround areas of ablation (Fig. 4a). These astrocytes had increased GFAP levels when compared to those at earlier timepoints. These regions were observed across the cortex and were found in all experimental mice at $28 \mathrm{dpa}$ $(n=3)$.

We next assessed if astrocyte ablation activated microglia and if this might affect timing of astrocytic STAT3 phosphorylation. At $3 \mathrm{dpa}$, some microglia had increased levels of lba1 appeared changed in morphology, with many membrane-rich processes. At 11dpa, many more microglia within areas of astrocyte ablation were clearly activated with Iba1 upregulation, hypertrophy of cell bodies and main processes. At this timepoint, classic morphological changes reminiscent of microglia activation dominated while "membrane-rich" microglia were no longer observed. At 28dpa, microglia activation within the areas of astrocyte ablation was even more pronounced. Some microglia were de-ramified while others had an increased number of processes (Suppl. Fig. 5). Given that phosphorylation of STAT3 in astrocytes aligned in severity with the severity of microglia activation is possible that astrocytes and microglia close to ablation areas respond to each other's activation state. 
The transcription factor Sox9 is expressed primarily by astrocytes and is upregulated in reactive astrocytes in models of stroke and Parkinson's disease (Choi et al., 2018; Sun et al., 2017). We tested for Sox9 expression in astrocytes adjacent to regions of ablation but found that Sox9 expression remained unchanged in all groups (Fig. $\mathbf{4 b )}$.

\subsection{Astrocytes adjacent to ablated areas respond with morphological changes}

After focal brain injury, astrocytes become hypertrophic with swollen $\mathrm{GFAP}^{+}$cell bodies and processes. Astrocytes extend their processes toward the site of injury (Oberheim, Wang, Goldman, \& Nedergaard, 2006; Robel, Bardehle, Lepier, Brakebusch, \& Götz, 2011). This results, in conjunction with the response of other glia, in a physical boundary sealing the injured area off from the uninjured parts of the brain. To determine if astrocytes adjacent to ablated astrocytes respond in a similar fashion, we employed the Simple Neurite Tracer in Fiji/lmageJ in order to create a 3D projection of $\mathrm{GFAP}^{+}$astrocytes and their processes. Length and thickness of astrocytes' major GFAP-expressing processes were traced, and Sholl analysis was used to determine process complexity. In control mice, sparse numbers of $\mathrm{GFAP}^{+}$astrocytes were located along blood vessels. These astrocytes were traced as controls. After astrocyte ablation, astrocytes neighboring the ablated regions changed over time in the number, length and volume of their $\mathrm{GFAP}^{+}$processes (Fig. 5a). Total process length of neighboring astrocytes increased by 43.4 percent from $1 \mathrm{dpa}(815.919 \mu \mathrm{m} \pm 77.147 \mu \mathrm{m}, \mathrm{n}=15)$ to $28 \mathrm{dpa}(1170.540 \pm 116.179 \mu \mathrm{m}$, $\mathrm{n}=15$ ) (Fig. 5b). Total process volume of these astrocytes more than doubled, increasing by 140.0 percent from $1 \mathrm{dpa}\left(928.828 \mu \mathrm{m} \pm 110.830 \mu \mathrm{m}^{3}, \mathrm{n}=15\right)$ to $28 \mathrm{dpa}(2229.636 \pm 110.830$ $\left.\mu m^{3} n=15\right)$ (Fig. c). Sholl analysis comparing astrocytes neighboring ablation regions at $1 \mathrm{dpa}$ and 28 dpa showed a significant increase in process arborization (Two-way ANOVA for number of intersections versus timepoint, $p<0.0001, n=15$ astrocytes per timepoint) (Fig. $5 d$ ), suggesting that more astrocyte processes expressed GFAP over time.

To determine if astrocytes extend processes into the areas of astrocyte ablation, we 
examined the dimensions of astrocyte domains by drawing quadrants, using the location of the ablation region as a guide (Fig. 5e). We did not find changes in length to width ratio at any timepoint compared to controls (Fig. 5f). When looking at the area of the quadrants, we also found no changes in proximal to distal area at any timepoint compared to controls (Fig. $\mathbf{5 g}$ ). This suggests that longer GFAP+ processes result from GFAP-filaments stretching farther into already present processes rather than processes stretching into areas of loss to replace lost astrocytes. Alternatively, our approach to measuring astrocyte shape based on GFAP-tracing might not be sensitive enough to detect small polarizations toward areas of loss.

In all, these data suggest that loss of astrocytes initiates mild morphological changes in their neighbors characterized by presence of GFAP filaments in a larger number of processes and increase in process volume, yet we could not detect directional polarity to these changes. Thus, loss of contact to a neighbor might either not be a signal inducing astrocyte polarity or diffuse BBB leakage, other ablation regions in close proximity, and additional cellular and molecular triggers may be present that overwrite a strong polarization toward the lost astrocyte.

\subsection{Astrocytes adjacent to ablated areas do not proliferate to replace ablated neighbors}

Astrocytes in the healthy mature brain are post-mitotic, but a subset of astrocytes re-enter the cell cycle after focal brain or spinal cord injury. We next asked if astrocyte ablation triggers a proliferative response in neighboring astrocytes geared toward replacing lost cells. In order to assess astrocyte proliferation, we chose two approaches. First, we labeled brain slices of experimental and control mice with Ki67, which is expressed during active phases of the cell cycle but is absent in resting non-mitotic cells (Scholzen \& Gerdes, 2000). As expected, a small number of $\mathrm{Ki} 67^{+}$cells were present throughout the cortical gray matter and a higher number was found within adult neurogenic zones in all groups (Suppl. Fig. 6a). However, S100 $\beta^{+}$ astrocytes adjacent to ablated astrocytes did not co-label with Ki67 within the cortical gray

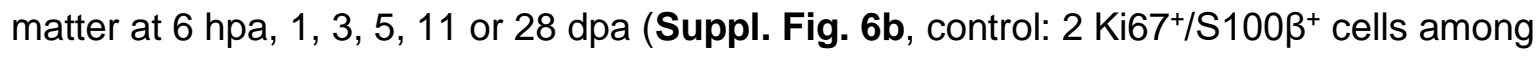


$10,088 \mathrm{~S} 100 \beta^{+}$cells, $\mathrm{n}=10$ mice; experimental: $1 \mathrm{Ki67/S} 100 \beta^{+}$cell among $3,684 \mathrm{~S} 100 \beta^{+}$cells, $\mathrm{n}=3-5$ mice per timepoint)

Secondly, we labeled all cells that proliferated using the base analog Bromodeoxyuridine (BrdU), which was administered twice daily after Tx administration for 1, 3 and 5 days to cumulatively label all cells that proliferated during this time. BrdU is incorporated during S-phase and can later be detected by immunohistochemistry, even if the cells were not actively proliferating at the time of the tissue harvest. Similar to the findings using the acute proliferation marker Ki67, we did not find $\mathrm{S} 100 \beta^{+}$astrocytes that co-labeled for BrdU at 1, 3, or 5 dpa (Suppl. Fig. 7, control: $1 \mathrm{BrdU}+/ S 100 \beta^{+}$cell among 1319 S100 $\beta^{+}$cells, $n=9$ mice; experimental: $1 \mathrm{BrdU}^{+} / \mathrm{S} 100 \beta^{+}$cell among $2865 \mathrm{~S} 100 \beta^{+}$cells, $\mathrm{n}=3$ mice per timepoint). Together, astrocyte loss did not initiate proliferation of adjacent astrocytes early or late after ablation. 


\section{Discussion}

\subsection{Astrocyte loss in the adult brain causes BBB damage of variable extent}

Here, we demonstrate a necessary and non-redundant role for astrocytes in BBB maintenance in vivo using a mouse model of astrocyte ablation via tamoxifen-inducible conditional expression of the non-toxic DTA subunit, which inhibits protein synthesis. Astrocyte apoptosis occurred as early as 2 hours after tamoxifen administration. Cadaverine ( 900 Da) leakage indicative of damage to the BBB occurred just as early around ablated astrocytes. In addition to penetration of the smaller molecular weight Cadaverine into the brain parenchyma, deposition of fibrinogen $(340 \mathrm{kDa})$ had taken place in a small subset of the areas with Cadaverine leakage. This suggests varying extents of BBB damage, possibly due to differing numbers of ablated astrocytes. Three recent studies ablating astrocytes have suggested that astrocytes are not needed for maintenance of the BBB in vivo. In the spinal cord, astrocyte ablation using a similar genetic DTA ablation system, no obvious lack of BBB integrity was observed (Schreiner et al., 2015; Tsai et al., 2012). Differences in CNS region (cortical gray matter versus spinal cord) or in the genetic approach (Glast-CreERT versus GFAP-CreERT2 or Aldh1l1-loxP-eGFP-STOP-loxP-DTA x Pax3-Cre) could account for the differences. Additionally, these studies only tested for large size damage to the BBB including presence of erythrocytes, lymphocytes and fibrinogen. It would be easy to overlook the small number of areas with BBB damage large enough to permit entry of fibrinogen or cells from the periphery. In our hands, detection of the larger-size breaches required screening of entire brains. The aforementioned studies did not assess smaller size BBB damage. Yet, small openings of the BBB permitting markers below 3 kDa still indicate significant dysfunction in the BBB (Yanagida et al., 2017).

One study concluded that there were no changes to the BBB based on the absence of leakage of Evans Blue (960 Da when unbound and 65-70 kDa when bound to albumin) and dextran $(4 \mathrm{kDa})$ after laser ablation of astrocytes or endfeet followed by 2-photon imaging 
(Kubotera et al., 2019). Yet cell death was only confirmed by lack of a fluorescent eGFP signal, which can occur as a result of photobleaching after which the still-alive cell is no longer visible. The authors observed recovery of the GFP signal on vessels over the course of minutes to hours but no consequence of the intervention even though free Evans Blue is similar in size as Cadaverine. In our experience, GFP-labeled astrocytes photobleach readily while it is difficult to fully ablate the entire astrocyte or parts of it. It is also possible that 2-photon in vivo imaging is not sensitive enough to detect leakage of small amounts of dye. The advantage of Cadaverine is its uptake into neurons, which makes detection of even small leakages easy in tissue processed for immunohistochemistry when compared to detection of diffuse fluorescence in 2photon imaging. Alternatively, it is possible that ablation of a single astrocyte or single endfoot is not sufficient to induce BBB damage and that secreted factors by neighboring cells are sufficient to maintain barrier integrity. Integrity of tight junctions and other barrier properties were not assessed in this study (Kubotera et al., 2019).

\subsection{Do astrocyte-secreted factors maintain the blood-brain barrier?}

We tested for tight junction integrity by examining the essential tight junction protein ZO-1, a transmembrane protein needed for assembly of the tight junction complex. In order to anchor the tight junctional complex to the cell's actin cytoskeleton it must be localized correctly (Katsuno et al., 2008) and any abnormal localization of ZO-1 is indicative of defective tight junctions. Endothelial tight junctions were impaired hours after astrocyte ablation. In areas where astrocytes were ablated but Cadaverine leakage had not yet occurred, tight junctions appeared intact suggesting that astrocyte ablation caused damage to tight junctions, which then resulted in dye leakage. The mechanisms by which astrocytes maintain the BBB need to be resolved in future studies.

Of the secreted factors reported to modulate BBB function, only angiotensinogen is highly expressed in mature astrocytes. Angiotensinogen found in the CNS is produced primarily 
by astrocytes (Stornetta, Hawelu-Johnson, Guyenet, \& Lynch, 1988) and is an essential component of the brain renin-angiotensin system (RAS) that maintains blood pressure homeostasis(Tanimoto et al., 1994). The enzymatic cleavage of angiotensinogen produces angiotensin-II (Ang-II), which binds to BBB endothelial cells and is considered to be a central player in regulating blood pressure, yet there is significant controversy whether Ang-II promotes or disrupts BBB integrity. Studies performed in vitro have shown that Ang-II reduces BBB permeability and promotes tight junction expression in developing BBB endothelial cell monolayers (Wosik et al., 2007), but increases permeability when added to already established monolayers (Fleegal-DeMotta, Doghu, \& Banks, 2009). BBB-disruptive effects of Ang-II were also found in vivo, though in the context of injury, disease (Takane et al., 2017), or pre-induced hypertension. In these models, Ang-II was introduced either directly into the CNS via infusion (Li et al., 2016) or indirectly via BBB disruption (Biancardi, Son, Ahmadi, Filosa, \& Stern, 2014)that permitted entry of Ang-II (alongside other blood-borne factors) from circulation. Both scenarios resulted in higher than physiological-levels of Ang-II that are not solely derived from astrocytes, and are thus insufficient models for studying roles of Ang-II mediated astrocyte maintenance of the BBB.

Complete lack of angiotensinogen and thus Ang-II also results in BBB disruption, evidenced by diffuse BBB leakage and decreased tight junction expression found in angiotensinogen knockout mice (Kakinuma et al., 1998; Wosik et al., 2007). Although tight junctions were not assessed thoroughly in this study, the BBB dysfunction bears similarities to our data. However, the lack of angiotensinogen throughout the body and during development creates a pre-existing hypertensive environment (Tanimoto et al., 1994) that prevents definitive conclusions about the role of angiotensinogen/ Ang-II in maintenance of the healthy adult BBB. 


\subsection{Astrocyte loss triggers partial and delayed scar formation in neighboring astrocytes}

In areas surrounding astrocyte ablation, neighboring astrocytes responded with mild to moderate GFAP increase within the first week after ablation. This occurred in conjunction with microglia activation, which occurred around 3 days after ablation and was pronounced in areas of astrocyte loss at $28 \mathrm{dpa}$. Phosphorylation of the transcriptional activator STAT3, which has a binding site within the GFAP promoter and occurs 1-5 days after spinal cord injury, is responsible for scar formation after spinal cord injury (Wanner et al., 2013). Interestingly, STAT3 phosphorylation did not occur until 11 days after astrocyte ablation, well after we noted an increase in GFAP. This is in contrast to other reports demonstrating that phosphorylation of STAT3 precedes GFAP upregulation in striatal neurotoxicity (O'Callaghan, Kelly, VanGilder, Sofroniew, \& Miller, 2014) and after spinal cord injury. In the latter injury paradigm, STAT3 phosphorylation subsides 7-14 days later (Herrmann et al., 2008). However, 2-4 weeks after astrocyte ablation an increasing number of astrocytes were positive for pSTAT3 which correlated with increased numbers of $\mathrm{GFAP}^{+}$processes and morphological changes including cellular hypertrophy. This delayed timeline for STAT3 phosphorylation might be explained by the gradual astrocyte loss and reduced extent of BBB damage, compared to an acute large invasive injury with hemorrhage and infiltration of immune cells. Whether astrocyte cell death or BBB leakage triggered the response of neighboring astrocytes was difficult to determine given that BBB damage occurred quickly after astrocyte ablation.

\subsection{Astrocyte loss does not induce proliferation of neighboring astrocytes}

Astrocytes adjacent to ablated areas did not re-enter the cell cycle suggesting that loss of a neighbor is not sufficient to trigger re-entry into the cell cycle. This is surprising as culture studies suggest that contact inhibition is a prominent signal suppressing cell proliferation and exit from the cell cycle (Pavel et al., 2018). The lack of proliferation after astrocyte ablation in 
the adult brain suggests that other signals trigger re-entry of astrocytes into the cell cycle after CNS injury. In the context of severe focal brain or spinal cord injury, a 30-70 percent of scarforming astrocytes proliferate (Bardehle et al., 2013; Buffo et al., 2008; Wanner et al., 2013), while proliferation is not initiated after genetically induced neuronal cell death, in mouse models of Alzheimer disease (Behrendt et al., 2013), or in a mouse model of chronic astrogliosis (Robel et al., 2009). Based on these observations, exposure of the brain to blood-borne substances might be a possible trigger initiating proliferation after acute injury. However, we did not observe proliferating astrocytes in areas with Cadaverine or fibrinogen leakage. This does not exclude the possibility that rapid exposure to or higher concentrations of blood-borne factors would induce astrocyte proliferation. Alternatively, different factors or a combination of factors absent after astrocyte ablation are necessary for astrocytes to re-enter the cell cycle.

\subsection{The blood-brain barrier fails to repair in areas of astrocyte ablation}

We observed BBB damage across all timepoints, suggesting a lack of barrier repair. However, the area covered by Cadaverine leakage was reduced by half and appeared restricted to areas of astrocyte ablation at $28 \mathrm{dpa}$, suggesting that the response of adjacent astrocytes might restrict diffusion of blood-borne factors. In the context of CNS injury, a dual role for astrocytes at the BBB is documented by many studies: In some injury paradigms, astrocytes upregulate factors that increase BBB permeability via downregulation of tight junctions. Among these factors are vascular endothelial growth factor, matrix metalloproteinases, and nitric oxides (Gu et al., 2012; Jiang, Xia, Jiang, Wang, \& Gao, 2014; Yang, Estrada, Thompson, Liu, \& Rosenberg, 2007). Conversely, increased expression of glial derived neurotrophic factor and retinoic acid promote tight junction expression and reduce permeability after stroke (Kong et al., 2015; Liu et al., 2016) and in multiple sclerosis (Mizee et al., 2014). Lack of angiotensinogen has also been associated with failure of BBB repair after cold injury. While the BBB was repaired and not permissive to Evans Blue in wildtype mice within 5 days of the injury, Evans 
Blue still leaked into the brain parenchyma of angiotensinogen $\mathrm{KO}$ mice 2 weeks post injury (Kakinuma et al., 1998). Thus dependent on disease context, age and surrounding microenvironment, astrocytes may lose their ability to maintain the $\mathrm{BBB}$, contribute to $\mathrm{BBB}$ repair or even cause barrier damage. 


\section{References}

Anderson, M. A., Burda, J. E., Ren, Y., Ao, Y., O'Shea, T. M., Kawaguchi, R., . . Sofroniew, M. V. (2016). Astrocyte scar formation aids central nervous system axon regeneration. Nature, 532(7598), 195-200. doi:10.1038/nature17623

Argaw, A. T., Asp, L., Zhang, J., Navrazhina, K., Pham, T., Mariani, J. N., . . John, G. R. (2012). Astrocyte-derived VEGF-A drives blood-brain barrier disruption in CNS inflammatory disease. The Journal of clinical investigation, 122(7), 2454-2468. doi:10.1172/JCI60842

Armulik, A., Genové, G., Mäe, M., Nisancioglu, M. H., Wallgard, E., Niaudet, C., . . Betsholtz, C. (2010). Pericytes regulate the blood-brain barrier. Nature, 468(7323), 557-561. doi:10.1038/nature09522

Bardehle, S., Krüger, M., Buggenthin, F., Schwausch, J., Ninkovic, J., Clevers, H., . . Götz, M. (2013). Live imaging of astrocyte responses to acute injury reveals selective juxtavascular proliferation. Nature neuroscience, 16(5), 580-586. doi:10.1038/nn.3371

Behrendt, G., Baer, K., Buffo, A., Curtis, M. A., Faull, R. L., Rees, M. I., . . Dimou, L. (2013). Dynamic changes in myelin aberrations and oligodendrocyte generation in chronic amyloidosis in mice and men. Glia, 61(2), 273-286. doi:10.1002/glia.22432

Biancardi, V. C., Son, S. J., Ahmadi, S., Filosa, J. A., \& Stern, J. E. (2014). Circulating angiotensin II gains access to the hypothalamus and brain stem during hypertension via breakdown of the blood-brain barrier. Hypertension (Dallas, Tex. : 1979), 63(3), 572-579. doi:10.1161/HYPERTENSIONAHA.113.01743

Boado, R. J., \& Pardridge, W. M. (1993). Glucose Deprivation Causes Posttranscriptional Enhancement of Brain Capillary Endothelial Glucose Transporter Gene Expression via GLUT1 mRNA Stabilization. Journal of neurochemistry, 60(6), 2290-2296. doi:10.1111/j.1471-4159.1993.tb03516.x

Boulay, A.-C., Saubaméa, B., Adam, N., Chasseigneaux, S., Mazaré, N., Gilbert, A., . . CohenSalmon, M. (2017). Translation in astrocyte distal processes sets molecular heterogeneity at the gliovascular interface. Cell Discovery, 3(1), 17005. doi:10.1038/celldisc.2017.5

Buffo, A., Rite, I., Tripathi, P., Lepier, A., Colak, D., Horn, A.-P., . . Götz, M. (2008). Origin and progeny of reactive gliosis: A source of multipotent cells in the injured brain. Proceedings of the National Academy of Sciences of the United States of America, 105(9), 35813586. doi:10.1073/pnas.0709002105

Canfield, S. G., Stebbins, M. J., Morales, B. S., Asai, S. W., Vatine, G. D., Svendsen, C. N., . . Shusta, E. V. (2017). An isogenic blood-brain barrier model comprising brain endothelial cells, astrocytes, and neurons derived from human induced pluripotent stem cells. Journal of neurochemistry, 140(6), 874-888. doi:10.1111/jnc.13923 
Choi, D.-J., Eun, J.-H., Kim, B. G., Jou, I., Park, S. M., \& Joe, E.-H. (2018). A Parkinson's disease gene, DJ-1, repairs brain injury through Sox9 stabilization and astrogliosis. Glia, 66(2), 445-458. doi:10.1002/glia.23258

Daneman, R., Zhou, L., Kebede, A. A., \& Barres, B. A. (2010). Pericytes are required for bloodbrain barrier integrity during embryogenesis. Nature, 468(7323), 562-566. doi:10.1038/nature09513

Fleegal-DeMotta, M. A., Doghu, S., \& Banks, W. A. (2009). Angiotensin II Modulates BBB Permeability via Activation of the AT1 Receptor in Brain Endothelial Cells. Journal of Cerebral Blood Flow \& Metabolism, 29(3), 640-647. doi:10.1038/jcbfm.2008.158

Gu, Y., Zheng, G., Xu, M., Li, Y., Chen, X., Zhu, W., . . Shen, J. (2012). Caveolin-1 regulates nitric oxide-mediated matrix metalloproteinases activity and blood-brain barrier permeability in focal cerebral ischemia and reperfusion injury. Journal of neurochemistry, 120(1), 147-156. doi:10.1111/j.1471-4159.2011.07542.x

Herrmann, J. E., Imura, T., Song, B., Qi, J., Ao, Y., Nguyen, T. K., . . Sofroniew, M. V. (2008). STAT3 is a critical regulator of astrogliosis and scar formation after spinal cord injury. The Journal of neuroscience : the official journal of the Society for Neuroscience, 28(28), 7231-7243. doi:10.1523/JNEUROSCI.1709-08.2008

Huang, B., Krafft, P. R., Ma, Q., Rolland, W. B., Caner, B., Lekic, T., . . Zhang, J. H. (2012). Fibroblast growth factors preserve blood-brain barrier integrity through RhoA inhibition after intracerebral hemorrhage in mice. Neurobiology of disease, 46(1), 204-214. doi:10.1016/j.nbd.2012.01.008

Igarashi, Y., Utsumi, H., Chiba, H., Yamada-Sasamori, Y., Tobioka, H., Kamimura, Y., ... Sawada, N. (1999). Glial Cell Line-Derived Neurotrophic Factor Induces Barrier Function of Endothelial Cells Forming the Blood-Brain Barrier. Biochemical and Biophysical Research Communications, 261(1), 108-112. doi:https://doi.org/10.1006/bbrc.1999.0992

Ito, K., Sanosaka, T., Igarashi, K., Ideta-Otsuka, M., Aizawa, A., Uosaki, Y., . . Takizawa, T. (2016). Identification of genes associated with the astrocyte-specific gene Gfap during astrocyte differentiation. Scientific reports, 6(1), 23903. doi:10.1038/srep23903

Janzer, R. C., \& Raff, M. C. (1987). Astrocytes induce blood-brain barrier properties in endothelial cells. Nature, 325(6101), 253-257. doi:10.1038/325253a0

Jiang, S., Xia, R., Jiang, Y., Wang, L., \& Gao, F. (2014). Vascular endothelial growth factors enhance the permeability of the mouse blood-brain barrier. PloS one, 9(2), e86407e86407. doi:10.1371/journal.pone.0086407

Kakinuma, Y., Hama, H., Sugiyama, F., Yagami, K.-i., Goto, K., Murakami, K., \& Fukamizu, A. (1998). Impaired blood-brain barrier function in angiotensinogen-deficient mice. Nature Medicine, 4(9), 1078-1080. doi:10.1038/2070

Katsuno, T., Umeda, K., Matsui, T., Hata, M., Tamura, A., Itoh, M., . . Tsukita, S. (2008). Deficiency of zonula occludens-1 causes embryonic lethal phenotype associated with defected yolk sac angiogenesis and apoptosis of embryonic cells. Molecular biology of the cell, 19(6), 2465-2475. doi:10.1091/mbc.e07-12-1215 
Kong, L., Wang, Y., Wang, X.-J., Wang, X.-T., Zhao, Y., Wang, L.-M., \& Chen, Z.-Y. (2015). Retinoic acid ameliorates blood-brain barrier disruption following ischemic stroke in rats. Pharmacological Research, 99, 125-136. doi:https://doi.org/10.1016/j.phrs.2015.05.014

Kubotera, H., Ikeshima-Kataoka, H., Hatashita, Y., Allegra Mascaro, A. L., Pavone, F. S., \& Inoue, T. (2019). Astrocytic endfeet re-cover blood vessels after removal by laser ablation. Scientific reports, 9(1), 1263-1263. doi:10.1038/s41598-018-37419-4

Lee, S.-W., Kim, W. J., Choi, Y. K., Song, H. S., Son, M. J., Gelman, I. H., . . Kim, K.-W. (2003). SSeCKS regulates angiogenesis and tight junction formation in blood-brain barrier. Nature Medicine, 9(7), 900-906. doi:10.1038/nm889

Li, Z., Mo, N., Li, L., Cao, Y., Wang, W., Liang, Y., . . Guo, X. (2016). Surgery-Induced Hippocampal Angiotensin II Elevation Causes Blood-Brain Barrier Disruption via MMP/TIMP in Aged Rats. Frontiers in cellular neuroscience, 10, 105-105. doi:10.3389/fncel.2016.00105

Liu, Y., Wang, S., Luo, S., Li, Z., Liang, F., Zhu, Y., . . Huang, R. (2016). Intravenous PEP-1GDNF is protective after focal cerebral ischemia in rats. Neuroscience Letters, 617, 150155. doi:https://doi.org/10.1016/..neulet.2016.02.017

Longair, M. H., Baker, D. A., \& Armstrong, J. D. (2011). Simple Neurite Tracer: open source software for reconstruction, visualization and analysis of neuronal processes. Bioinformatics, 27(17), 2453-2454. doi:10.1093/bioinformatics/btr390

Min, H., Hong, J., Cho, I.-H., Jang, Y. H., Lee, H., Kim, D., . . Lee, S. J. (2015). TLR2-induced astrocyte MMP9 activation compromises the blood brain barrier and exacerbates intracerebral hemorrhage in animal models. Molecular brain, 8, 23-23. doi:10.1186/s13041-015-0116-z

Mizee, M. R., Nijland, P. G., van der Pol, S. M. A., Drexhage, J. A. R., van het Hof, B., Mebius, R., . . de Vries, H. E. (2014). Astrocyte-derived retinoic acid: a novel regulator of bloodbrain barrier function in multiple sclerosis. Acta Neuropathologica, 128(5), 691-703. doi:10.1007/s00401-014-1335-6

Mori, T., Tanaka, K., Buffo, A., Wurst, W., Kühn, R., \& Götz, M. (2006). Inducible gene deletion in astroglia and radial glia-A valuable tool for functional and lineage analysis. Glia, 54(1), 21-34. doi:10.1002/glia.20350

Nathans, J. (2010). Generation of an inducible Slc1a3-cre/ERT transgenic allele. MGI Direct Submission.

O'Callaghan, J. P., Kelly, K. A., VanGilder, R. L., Sofroniew, M. V., \& Miller, D. B. (2014). Early activation of STAT3 regulates reactive astrogliosis induced by diverse forms of neurotoxicity. PloS one, 9(7), e102003-e102003. doi:10.1371/journal.pone.0102003

Oberheim, N. A., Wang, X., Goldman, S., \& Nedergaard, M. (2006). Astrocytic complexity distinguishes the human brain. Trends in Neurosciences, 29(10), 547-553. doi:https://doi.org/10.1016/..tins.2006.08.004 
Pardridge, W., Boado, R., \& Farrell, C. (1990). Brain-type glucose transporter (GLUT-1) is selectively localized to the blood-brain barrier: Studies with quantitative Western blotting and in situ hybridization. The Journal of biological chemistry, 265, 18035-18040.

Pavel, M., Renna, M., Park, S. J., Menzies, F. M., Ricketts, T., Füllgrabe, J., . . Rubinsztein, D. C. (2018). Contact inhibition controls cell survival and proliferation via YAP/TAZautophagy axis. Nature communications, 9(1), 2961. doi:10.1038/s41467-018-05388-x

Reuss, B., Dono, R., \& Unsicker, K. (2003). Functions of fibroblast growth factor (FGF)-2 and FGF-5 in astroglial differentiation and blood-brain barrier permeability: evidence from mouse mutants. The Journal of neuroscience : the official journal of the Society for Neuroscience, 23(16), 6404-6412. doi:10.1523/JNEUROSCI.23-16-06404.2003

Robel, S., Bardehle, S., Lepier, A., Brakebusch, C., \& Götz, M. (2011). Genetic deletion of cdc42 reveals a crucial role for astrocyte recruitment to the injury site in vitro and in vivo. The Journal of neuroscience : the official journal of the Society for Neuroscience, 31(35), 12471-12482. doi:10.1523/JNEUROSCI.2696-11.2011

Robel, S., Mori, T., Zoubaa, S., Schlegel, J., Sirko, S., Faissner, A., . . Götz, M. (2009). Conditional deletion of $\beta 1$-integrin in astroglia causes partial reactive gliosis. Glia, 57(15), 1630-1647. doi:10.1002/glia.20876

Rubin, L. L., Hall, D. E., Porter, S., Barbu, K., Cannon, C., Horner, H. C., . . Morales, J. (1991). A cell culture model of the blood-brain barrier. The Journal of cell biology, 115(6), 17251735. doi:10.1083/jcb.115.6.1725

Scholzen, T., \& Gerdes, J. (2000). The Ki-67 protein: From the known and the unknown. Journal of Cellular Physiology, 182(3), 311-322. doi:10.1002/(SICI)10974652(200003)182:3<311::AID-JCP1>3.0.CO;2-9

Schreiner, B., Romanelli, E., Liberski, P., Ingold-Heppner, B., Sobottka-Brillout, B., Hartwig, T., . .. Becher, B. (2015). Astrocyte Depletion Impairs Redox Homeostasis and Triggers Neuronal Loss in the Adult CNS. Cell Reports, 12(9), 1377-1384. doi:https://doi.org/10.1016/i.celrep.2015.07.051

Sharma, K., Schmitt, S., Bergner, C. G., Tyanova, S., Kannaiyan, N., Manrique-Hoyos, N., .. . Simons, M. (2015). Cell type- and brain region-resolved mouse brain proteome. Nature neuroscience, 18(12), 1819-1831. doi:10.1038/nn.4160

Siddharthan, V., Kim, Y. V., Liu, S., \& Kim, K. S. (2007). Human astrocytes/astrocyteconditioned medium and shear stress enhance the barrier properties of human brain microvascular endothelial cells. Brain research, 1147, 39-50. doi:10.1016/j.brainres.2007.02.029

Sirko, S., Behrendt, G., Johansson, Pia A., Tripathi, P., Costa, M. R., Bek, S., . . Götz, M. (2013). Reactive Glia in the Injured Brain Acquire Stem Cell Properties in Response to Sonic Hedgehog. Cell Stem Cell, 12(4), 426-439. doi:https://doi.org/10.1016/i.stem.2013.01.019

Srinivasan, R., Lu, T.-Y., Chai, H., Xu, J., Huang, B. S., Golshani, P., . . Khakh, B. S. (2016). New Transgenic Mouse Lines for Selectively Targeting Astrocytes and Studying Calcium 
Signals in Astrocyte Processes In Situ and In Vivo. Neuron, 92(6), 1181-1195. doi:10.1016/j.neuron.2016.11.030

Stewart, P. A., \& Wiley, M. J. (1981). Developing nervous tissue induces formation of bloodbrain barrier characteristics in invading endothelial cells: A study using quail-chick transplantation chimeras. Developmental Biology, 84(1), 183-192. doi:https://doi.org/10.1016/0012-1606(81)90382-1

Stornetta, R. L., Hawelu-Johnson, C. L., Guyenet, P. G., \& Lynch, K. R. (1988). Astrocytes Synthesize Angiotensinogen in Brain. Science, 242(4884), 1444-1446.

Sun, W., Cornwell, A., Li, J., Peng, S., Osorio, M. J., Aalling, N., . . Nedergaard, M. (2017). SOX9 Is an Astrocyte-Specific Nuclear Marker in the Adult Brain Outside the Neurogenic Regions. The Journal of neuroscience : the official journal of the Society for Neuroscience, 37(17), 4493-4507. doi:10.1523/JNEUROSCI.3199-16.2017

Takane, K., Hasegawa, Y., Lin, B., Koibuchi, N., Cao, C., Yokoo, T., \& Kim-Mitsuyama, S. (2017). Detrimental Effects of Centrally Administered Angiotensin II are Enhanced in a Mouse Model of Alzheimer Disease Independently of\&\#xa0;Blood Pressure. Journal of the American Heart Association, 6(4), e004897. doi:doi:10.1161/JAHA.116.004897

Tanimoto, K., Sugiyama, F., Goto, Y., Ishida, J., Takimoto, E., Yagami, K., . . Murakami, K. (1994). Angiotensinogen-deficient mice with hypotension. Journal of Biological Chemistry, 269(50), 31334-31337.

Tao-Cheng, J. H., Nagy, Z., \& Brightman, M. W. (1987). Tight junctions of brain endothelium in vitro are enhanced by astroglia. The Journal of neuroscience : the official journal of the Society for Neuroscience, 7(10), 3293-3299. doi:10.1523/JNEUROSCI.07-1003293.1987

Tsai, H.-H., Li, H., Fuentealba, L. C., Molofsky, A. V., Taveira-Marques, R., Zhuang, H., .. . Rowitch, D. H. (2012). Regional Astrocyte Allocation Regulates CNS Synaptogenesis and Repair. Science, 337(6092), 358. doi:10.1126/science.1222381

Wanner, I. B., Anderson, M. A., Song, B., Levine, J., Fernandez, A., Gray-Thompson, Z., . . Sofroniew, M. V. (2013). Glial scar borders are formed by newly proliferated, elongated astrocytes that interact to corral inflammatory and fibrotic cells via STAT3-dependent mechanisms after spinal cord injury. The Journal of neuroscience : the official journal of the Society for Neuroscience, 33(31), 12870-12886. doi:10.1523/JNEUROSCI.212113.2013

Wolburg, H., Neuhaus, J., Kniesel, U., Krauss, B., Schmid, E. M., Ocalan, M., . . Risau, W. (1994). Modulation of tight junction structure in blood-brain barrier endothelial cells. Effects of tissue culture, second messengers and cocultured astrocytes. Journal of Cell Science, 107(5), 1347-1357.

Wosik, K., Cayrol, R., Dodelet-Devillers, A., Berthelet, F., Bernard, M., Moumdjian, R., ... Prat, A. (2007). Angiotensin II Controls Occludin Function and Is Required for Blood-Brain Barrier Maintenance: Relevance to Multiple Sclerosis. The Journal of Neuroscience, 27(34), 9032-9042. doi:10.1523/jneurosci.2088-07.2007 
Xia, Y.-p., He, Q.-w., Li, Y.-n., Chen, S.-c., Huang, M., Wang, Y., . . . Hu, B. (2013). Recombinant human sonic hedgehog protein regulates the expression of ZO-1 and occludin by activating angiopoietin-1 in stroke damage. PloS one, 8(7), e68891-e68891. doi:10.1371/journal.pone.0068891

Yanagida, K., Liu, C. H., Faraco, G., Galvani, S., Smith, H. K., Burg, N., . . Hla, T. (2017). Sizeselective opening of the blood-brain barrier by targeting endothelial sphingosine 1phosphate receptor 1. Proceedings of the National Academy of Sciences of the United States of America, 114(17), 4531-4536. doi:10.1073/pnas.1618659114

Yang, Y., Estrada, E. Y., Thompson, J. F., Liu, W., \& Rosenberg, G. A. (2007). Matrix Metalloproteinase-Mediated Disruption of Tight Junction Proteins in Cerebral Vessels is Reversed by Synthetic Matrix Metalloproteinase Inhibitor in Focal Ischemia in Rat. Journal of Cerebral Blood Flow \& Metabolism, 27(4), 697-709. doi:10.1038/sj.jcbfm.9600375

Zhang, Y., Chen, K., Sloan, S. A., Bennett, M. L., Scholze, A. R., O'Keeffe, S., . . Wu, J. Q. (2014). An RNA-sequencing transcriptome and splicing database of glia, neurons, and vascular cells of the cerebral cortex. The Journal of neuroscience : the official journal of the Society for Neuroscience, 34(36), 11929-11947. doi:10.1523/JNEUROSCI.186014.2014

Zhang, Z. G., Zhang, L., Croll, S. D., \& Chopp, M. (2002). Angiopoietin-1 reduces cerebral blood vessel leakage and ischemic lesion volume after focal cerebral embolic ischemia in mice. Neuroscience, 113(3), 683-687. doi:https://doi.org/10.1016/S0306-4522(02)00175$\underline{6}$

Zhang, Z. G., Zhang, L., Jiang, Q., Zhang, R., Davies, K., Powers, C., . . Chopp, M. (2000). VEGF enhances angiogenesis and promotes blood-brain barrier leakage in the ischemic brain. The Journal of clinical investigation, 106(7), 829-838. doi:10.1172/JCI9369

Zheng, Y., Vertuani, S., Nyström, S., Audebert, S., Meijer, I., Tegnebratt, T., . . Holmgren, L. (2009). Angiomotin-Like Protein 1 Controls Endothelial Polarity and Junction Stability During Sprouting Angiogenesis. Circulation Research, 105(3), 260-270. doi:doi:10.1161/CIRCRESAHA.109.195156 
bioRxiv preprint doi: https://doi.org/10.1101/2020.03.16.993691; this version posted March 18,2020 . The copyright holder for this preprint (which was not certified by peer review) is the author/funder. All rights reserved. No reuse allowed without permission.

Table 1. Sex and genotype of mice used in experiments.

\begin{tabular}{|c|c|c|c|c|c|c|}
\hline Figure 1 & Panel & Animal \# & Sex & Experimental Group & Timepoint & Total $n$ \\
\hline & c & 0046 & M & DTA $^{\mathrm{fl} / \mathrm{wt}} / /$ Glast-CreERT ${ }^{\mathrm{tg} / \mathrm{wt}}+$ Tamoxifen & $1 \mathrm{dpa}$ & \\
\hline & $d$ & 4520 & $\mathrm{~F}$ & DTA $^{\text {wt/wt }} / /$ Glast-CreERT $T^{\mathrm{t} /} / \mathrm{wt}+$ Tamoxifen & $3 \mathrm{dpa}$ & \\
\hline & & 309 & $\mathrm{~F}$ & $\mathrm{DTA}^{\mathrm{f} / \mathrm{wt}} / /$ Glast-CreERT $\mathrm{Tg}^{\mathrm{t} / \mathrm{wt}}+$ Tamoxifen & $6 \mathrm{hpa}$ & \\
\hline & & 305 & M & $\mathrm{DTA}^{\mathrm{f} / \mathrm{wt}} / /$ Glast-CreERT $\mathrm{Tt}^{\mathrm{tg} / \mathrm{wt}}+$ Tamoxifen & $11 \mathrm{dpa}$ & \\
\hline & & 4624 & $\mathrm{M}$ & $\mathrm{DTA}^{\mathrm{fl} / \mathrm{wt} / / \text { Glast-CreERT }}{ }^{\mathrm{tg} / \mathrm{wt}}+$ Tamoxifen & $28 \mathrm{dpa}$ & \\
\hline & e & 4864 & $\mathrm{~F}$ & 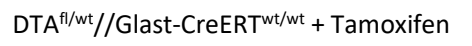 & $28 \mathrm{dpa}$ & \\
\hline & & 315 & M & DTA $^{\mathrm{f} / / \mathrm{wt}} / /$ Glast-CreERT ${ }^{\mathrm{tg} / \mathrm{wt}}+$ Tamoxifen & $11 \mathrm{dpa}$ & \\
\hline & $f, g$ & 528 & $\mathrm{~F}$ & DTwt/wt//Glast-CreER ${ }^{\mathrm{tg} / \mathrm{wt}}+$ Tamoxifen & $6 \mathrm{hpa}$ & $\mathrm{n}=15$ (control) \\
\hline & & 532 & $\mathrm{~F}$ & DTA $^{\text {wt/wt }} / /$ Glast-CreERT ${ }^{\mathrm{t} /} / \mathrm{wt}+$ Tamoxifen & $6 \mathrm{hpa}$ & \\
\hline & & 319 & $\mathrm{~F}$ & DTA $^{\text {wt } / w t} / /$ Glast-CreERT $T^{\mathrm{tg} / \mathrm{wt}}+$ Tamoxifen & $6 \mathrm{hpa}$ & \\
\hline & & 4902 & M & DTA $^{\text {wt/wt }} / /$ Glast-CreERT ${ }^{\mathrm{tg} / \mathrm{wt}}+$ Tamoxifen & $1 \mathrm{dpa}$ & \\
\hline & & 292 & $\mathrm{~F}$ & $\mathrm{DTA}^{\mathrm{f} / \mathrm{wt}} / /$ Glast-CreERTwt/wt + Tamoxifen & $1 \mathrm{dpa}$ & \\
\hline & & 526 & $\mathrm{~F}$ & 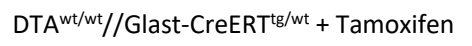 & $1 \mathrm{dpa}$ & \\
\hline & & 0043 & $\mathrm{~F}$ & $\mathrm{DTA}^{\mathrm{f} / \mathrm{wt}} / /$ Glast-CreERTwt/wt + Tamoxifen & $1 \mathrm{dpa}$ & \\
\hline & & 4287 & $\mathrm{~F}$ & $\mathrm{DTA}^{\mathrm{f} / \mathrm{wt}} / /$ Glast-CreERTwt/wt + Tamoxifen & $1 \mathrm{dpa}$ & \\
\hline & & 4520 & $\mathrm{~F}$ & DTA ${ }^{\mathrm{f} / \mathrm{wt}} / /$ Glast-CreERTwt/wt + Tamoxifen & $3 \mathrm{dpa}$ & \\
\hline & & 3358 & M & $\mathrm{DTA}^{\mathrm{f} / \mathrm{wt}} / /$ Glast-CreERT ${ }^{\mathrm{wt} / \mathrm{wt}}+$ Tamoxifen & $3 \mathrm{dpa}$ & \\
\hline & & 313 & M & DTA $^{\text {wt/wt}} / /$ Glast-CreERT ${ }^{\mathrm{tg} / \mathrm{wt}}+$ Tamoxifen & $11 \mathrm{dpa}$ & \\
\hline & & 4864 & $M$ & DTA $^{\mathrm{f} / / \mathrm{wt}} / /$ Glast-CreERTwt/wt + Tamoxifen & $28 \mathrm{dpa}$ & \\
\hline & & 4862 & M & $\mathrm{DTA}^{\mathrm{f} / \mathrm{wt}} / /$ Glast-CreERT ${ }^{\mathrm{wt} / \mathrm{wt}}+$ Tamoxifen & $28 \mathrm{dpa}$ & \\
\hline & & 219 & $\mathrm{~F}$ & DTA $^{\text {wt } / w t} / /$ Glast-CreERTwt/wt + Tamoxifen & $28 \mathrm{dpa}$ & \\
\hline & & 4995 & $\mathrm{~F}$ & $\mathrm{DTA}^{\mathrm{f} / \mathrm{wt}} / /$ Glast-CreERTwt/wt + Tamoxifen & $28 \mathrm{dpa}$ & \\
\hline & & 893 & $\mathrm{~F}$ & $\mathrm{DTA}^{\mathrm{fl} / \mathrm{wt} / / \text { Glast-CreERT }} \mathrm{Tg}^{\mathrm{tg} / \mathrm{wt}}+$ Tamoxifen & $2 \mathrm{hpa}$ & $\mathrm{n}=3(2 \mathrm{hpa})$ \\
\hline & & 895 & M & $\mathrm{DTA}^{\mathrm{fl} / \mathrm{wt} / / \text { Glast-CreERT }} \mathrm{tg} / \mathrm{wt}+$ Tamoxifen & $2 \mathrm{hpa}$ & \\
\hline & & 892 & M & DTA ${ }^{\mathrm{f} / / \mathrm{wt}} / /$ Glast-CreERT $\mathrm{T}^{\mathrm{t} / \mathrm{wt}}+$ Tamoxifen & $2 \mathrm{hpa}$ & \\
\hline & & 309 & $\mathrm{~F}$ & DTA $^{\mathrm{fl} / \mathrm{wt}} / /$ Glast-CreERT $\mathrm{tg} / \mathrm{wt}+$ Tamoxifen & $6 \mathrm{hpa}$ & $\mathrm{n}=3(6 \mathrm{hpa})$ \\
\hline & & 868 & M & $\mathrm{DTA}^{\mathrm{f} / \mathrm{wt}} / /$ Glast-CreERT $\mathrm{tg} / \mathrm{wt}+$ Tamoxifen & $6 \mathrm{hpa}$ & \\
\hline & & 723 & $\mathrm{~F}$ & DTA $^{\mathrm{fl} / \mathrm{wt}} / /$ Glast-CreERT ${ }^{\mathrm{tg} / \mathrm{wt}}+$ Tamoxifen & $6 \mathrm{hpa}$ & \\
\hline & & 4901 & M & DTA $^{\mathrm{fl} / \mathrm{wt}} / /$ Glast-CreERT $\mathrm{Tt}^{\mathrm{tg} / \mathrm{wt}}+$ Tamoxifen & $1 \mathrm{dpa}$ & $\mathrm{n}=4(1 \mathrm{dpa})$ \\
\hline
\end{tabular}


bioRxiv preprint doi: https://doi.org/10.1101/2020.03.16.993691; this version posted March 18,2020 . The copyright holder for this preprint (which was not certified by peer review) is the author/funder. All rights reserved. No reuse allowed without permission.

\begin{tabular}{|c|c|c|c|c|c|c|}
\hline & & 294 & $\mathrm{~F}$ & $\mathrm{DTA}^{\mathrm{fl} / \mathrm{wt}} / /$ Glast-CreERT $\mathrm{T}^{\mathrm{tg} / \mathrm{wt}}+$ Tamoxifen & $1 \mathrm{dpa}$ & \\
\hline & & 3497 & $\mathrm{~F}$ & $\mathrm{DTA}^{\mathrm{fl} / \mathrm{wt}} / /$ Glast-CreERTtg/wt + Tamoxifen & $1 \mathrm{dpa}$ & \\
\hline & & 4221 & $\mathrm{~F}$ & $\mathrm{DTA}^{\mathrm{fl} / \mathrm{wt}} / /$ Glast-CreERT $\mathrm{T}^{\mathrm{tg} / \mathrm{wt}}+$ Tamoxifen & $1 \mathrm{dpa}$ & \\
\hline & & 4519 & M & $\mathrm{DTA}^{\mathrm{fl} / \mathrm{wt}} / /$ Glast-CreERT $\mathrm{T}^{\mathrm{tg} / \mathrm{wt}}+$ Tamoxifen & $3 \mathrm{dpa}$ & $n=4(3 \mathrm{dpa})$ \\
\hline & & 4523 & M & $\mathrm{DTA}^{\mathrm{f} / \mathrm{wt}} / /$ Glast-CreERT $T^{\mathrm{tg} / \mathrm{wt}}+$ Tamoxifen & $3 \mathrm{dpa}$ & \\
\hline & & 3351 & M & $\mathrm{DTA}^{\mathrm{f} / \mathrm{wt}} / /$ Glast-CreERT $T^{\mathrm{tg} / \mathrm{wt}}+$ Tamoxifen & $3 \mathrm{dpa}$ & \\
\hline & & 2279 & M & $\mathrm{DTA}^{\mathrm{fl} / \mathrm{wt}} / /$ Glast-CreERT $\mathrm{T}^{\mathrm{tg} / \mathrm{wt}}+$ Tamoxifen & $3 \mathrm{dpa}$ & \\
\hline & & 538 & M & DTA $^{\mathrm{fl} / \mathrm{wt}} / /$ Glast-CreERT tg/wt + Tamoxifen & $5 \mathrm{dpa}$ & $\mathrm{n}=4$ (5 dpa) \\
\hline & & 317 & M & DTA $^{\mathrm{f} / / \mathrm{wt}} / /$ Glast-CreERT $T^{\mathrm{tg} / \mathrm{wt}}+$ Tamoxifen & $5 \mathrm{dpa}$ & \\
\hline & & 535 & $\mathrm{~F}$ & 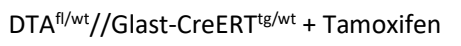 & $5 \mathrm{dpa}$ & \\
\hline & & 536 & $\mathrm{~F}$ & $\mathrm{DTA}^{\mathrm{fl} / \mathrm{wt}} / /$ Glast-CreERT $\mathrm{T}^{\mathrm{tg} / \mathrm{wt}}+$ Tamoxifen & $5 \mathrm{dpa}$ & \\
\hline & & 310 & M & $\mathrm{DTA}^{\mathrm{fl} / \mathrm{wt}} / /$ Glast-CreERTtg/wt + Tamoxifen & $11 \mathrm{dpa}$ & $\mathrm{n}=4(11 \mathrm{dpa})$ \\
\hline & & 305 & M & $\mathrm{DTA}^{\mathrm{fl} / \mathrm{wt}} / /$ Glast-CreERT $\mathrm{tg} / \mathrm{wt}+$ Tamoxifen & $11 \mathrm{dpa}$ & \\
\hline & & 529 & M & 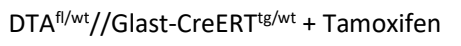 & $11 \mathrm{dpa}$ & \\
\hline & & 314 & $\mathrm{~F}$ & $\mathrm{DTA}^{\mathrm{fl} / \mathrm{wt}} / /$ Glast-CreERT $T^{\mathrm{tg} / \mathrm{wt}}+$ Tamoxifen & $11 \mathrm{dpa}$ & \\
\hline & & 4624 & M & DTA $^{\mathrm{f} / / \mathrm{wt}} / /$ Glast-CreERT $T^{\mathrm{tg} / \mathrm{wt}}+$ Tamoxifen & $28 \mathrm{dpa}$ & $n=5$ (28 dpa) \\
\hline & & 4631 & $\mathrm{~F}$ & $\mathrm{DTA}^{\mathrm{f} / \mathrm{wt}} / /$ Glast-CreERT $\mathrm{T}^{\mathrm{tg} / \mathrm{wt}}+$ Tamoxifen & $28 \mathrm{dpa}$ & \\
\hline & & 220 & $\mathrm{~F}$ & $\mathrm{DTA}^{\mathrm{fl} / \mathrm{wt}} / /$ Glast-CreERTtg/wt + Tamoxifen & $28 \mathrm{dpa}$ & \\
\hline & & 291 & $\mathrm{~F}$ & $\mathrm{DTA}^{\mathrm{fl} / \mathrm{wt}} / /$ Glast-CreERT $\mathrm{tg} / \mathrm{wt}+$ Tamoxifen & $28 \mathrm{dpa}$ & \\
\hline & & 4836 & M & $\mathrm{DTA}^{\mathrm{fl} / \mathrm{wt}} / /$ Glast-CreERT $T^{\mathrm{tg} / \mathrm{wt}}+$ Tamoxifen & $28 \mathrm{dpa}$ & \\
\hline Figure 2 & a & 4518 & $\mathrm{~F}$ & $\mathrm{DTA}^{\mathrm{fl} / \mathrm{wt}} / /$ Glast-CreERT ${ }^{\mathrm{wt} / \mathrm{wt}}+$ Tamoxifen & $3 \mathrm{dpa}$ & \\
\hline & & 309 & $\mathrm{~F}$ & $\mathrm{DTA}^{\mathrm{fl} / \mathrm{wt}} / /$ Glast-CreERT $\mathrm{tg} / \mathrm{wt}+$ Tamoxifen & $6 \mathrm{hpa}$ & \\
\hline & & 314 & $\mathrm{~F}$ & $\mathrm{DTA}^{\mathrm{fl} / \mathrm{wt}} / /$ Glast-CreERT $\mathrm{tg} / \mathrm{wt}+$ Tamoxifen & $11 \mathrm{dpa}$ & \\
\hline & & 4631 & $\mathrm{~F}$ & 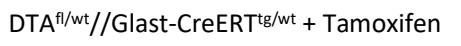 & $28 \mathrm{dpa}$ & \\
\hline & $\mathrm{b}$ & 4902 & M & DTA $^{\text {wt/wt }} / /$ Glast-CreERTtg/wt + Tamoxifen & $1 \mathrm{dpa}$ & \\
\hline & & 305 & M & $\mathrm{DTA}^{\mathrm{f} / \mathrm{wt}} / /$ Glast-CreERTtg/wt + Tamoxifen & $11 \mathrm{dpa}$ & \\
\hline & c & 319 & $\mathrm{~F}$ & DTA $^{\text {wt }} / \mathrm{wt} / /$ Glast-CreERTtg/wt + Tamoxifen & $6 \mathrm{hpa}$ & $\mathrm{n}=16$ (control) \\
\hline & & 528 & $\mathrm{~F}$ & DTA $^{\text {wt/wt }} / /$ Glast-CreERTtg/wt + Tamoxifen & $6 \mathrm{hpa}$ & \\
\hline & & 532 & $\mathrm{~F}$ & DTA $^{\text {wt } / w t} / /$ Glast-CreERTtg/wt + Tamoxifen & $6 \mathrm{hpa}$ & \\
\hline & & 4902 & $M$ & $\mathrm{DTA}^{\mathrm{fl} / \mathrm{wt}} / /$ Glast-CreERT ${ }^{\mathrm{wt} / \mathrm{wt}}+$ Tamoxifen & $1 \mathrm{dpa}$ & \\
\hline
\end{tabular}


bioRxiv preprint doi: https://doi.org/10.1101/2020.03.16.993691; this version posted March 18,2020 . The copyright holder for this preprint (which was not certified by peer review) is the author/funder. All rights reserved. No reuse allowed without permission.

\begin{tabular}{|c|c|c|c|c|c|c|}
\hline & & 292 & $\mathrm{~F}$ & DTA $^{\mathrm{f} / / \mathrm{wt}} / /$ Glast-CreERTwt/wt + Tamoxifen & $1 \mathrm{dpa}$ & \\
\hline & & A8032 & $M$ & DTA $^{\mathrm{f} / / \mathrm{wt}} / /$ Glast-CreERTwt/wt + Tamoxifen & $3 \mathrm{dpa}$ & \\
\hline & & 4518 & $\mathrm{~F}$ & DTA $^{\mathrm{f} / / \mathrm{wt}} / /$ Glast-CreERTwt/wt + Tamoxifen & $3 \mathrm{dpa}$ & \\
\hline & & 4520 & $\mathrm{~F}$ & DTA $^{\text {wt/wt }} / /$ Glast-CreERT $\mathrm{tg} / \mathrm{wt}+$ Tamoxifen & $3 \mathrm{dpa}$ & \\
\hline & & 537 & $M$ & $\mathrm{DTA}^{\mathrm{f} / \mathrm{wt}} / /$ Glast-CreERT ${ }^{\mathrm{wt} / \mathrm{wt}}+$ Tamoxifen & $5 \mathrm{dpa}$ & \\
\hline & & 4862 & $M$ & DTA $^{\mathrm{f} / / \mathrm{wt}} / /$ Glast-CreERT $\mathrm{wt}^{\mathrm{w} / \mathrm{wt}}+$ Tamoxifen & $28 \mathrm{dpa}$ & \\
\hline & & 219 & $\mathrm{~F}$ & DTA $^{\text {wt/wt }} / /$ Glast-CreERT ${ }^{\text {wt }} /$ wt + Tamoxifen & $28 \mathrm{dpa}$ & \\
\hline & & 4629 & $\mathrm{~F}$ & DTA $^{\mathrm{ft} / \mathrm{wt}} / /$ Glast-CreERTwt/wt + Tamoxifen & $28 \mathrm{dpa}$ & \\
\hline & & 272 & $\mathrm{~F}$ & 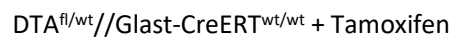 & $28 \mathrm{dpa}$ & \\
\hline & & 273 & $\mathrm{~F}$ & DTA $^{\mathrm{f} / / \mathrm{wt}} / /$ Glast-CreERTwt/wt + Tamoxifen & $28 \mathrm{dpa}$ & \\
\hline & & 4864 & $M$ & DTA $^{\mathrm{f} / / \mathrm{wt}} / /$ Glast-CreERTwt/wt + Tamoxifen & $28 \mathrm{dpa}$ & \\
\hline & & 4995 & $\mathrm{~F}$ & $\mathrm{DTA}^{\mathrm{f} / \mathrm{wt}} / /$ Glast-CreERTwt/wt + Tamoxifen & $28 \mathrm{dpa}$ & \\
\hline & & 893 & $\mathrm{~F}$ & DTA $^{\mathrm{f} / \mathrm{wt}} / /$ Glast-CreERT ${ }^{\mathrm{tg} / \mathrm{wt}}+$ Tamoxifen & $2 \mathrm{hpa}$ & $\mathrm{n}=3$ (2 hpa) \\
\hline & & 895 & $M$ & $\mathrm{DTA}^{\mathrm{f} / \mathrm{wt}} / /$ Glast-CreERT ${ }^{\mathrm{tg} / \mathrm{wt}}+$ Tamoxifen & 2 hpa & \\
\hline & & 892 & $M$ & DTA $^{\mathrm{f} / \mathrm{wt}} / /$ Glast-CreERT ${ }^{\mathrm{tg} / \mathrm{wt}}+$ Tamoxifen & $2 \mathrm{hpa}$ & \\
\hline & & 309 & $\mathrm{~F}$ & $\mathrm{DTA}^{\mathrm{f} / \mathrm{wt}} / /$ Glast-CreERT ${ }^{\mathrm{tg} / \mathrm{wt}}+$ Tamoxifen & $6 \mathrm{hpa}$ & $n=3(6 \mathrm{hpa})$ \\
\hline & & 723 & $\mathrm{~F}$ & $\mathrm{DTA}^{\mathrm{f} / \mathrm{wt}} / /$ Glast-CreERT ${ }^{\mathrm{tg} / \mathrm{wt}}+$ Tamoxifen & $6 \mathrm{hpa}$ & \\
\hline & & 868 & $M$ & DTA $^{\mathrm{ft} / \mathrm{wt}} / /$ Glast-CreERT ${ }^{\mathrm{tg} / \mathrm{wt}}+$ Tamoxifen & $6 \mathrm{hpa}$ & \\
\hline & & 4901 & $M$ & $\mathrm{DTA}^{\mathrm{f} / \mathrm{wt}} / /$ Glast-CreERT ${ }^{\mathrm{tg} / \mathrm{wt}}+$ Tamoxifen & $1 \mathrm{dpa}$ & $\mathrm{n}=3(1 \mathrm{dpa})$ \\
\hline & & 293 & $\mathrm{~F}$ & 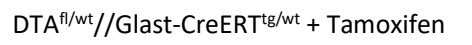 & $1 \mathrm{dpa}$ & \\
\hline & & 294 & $\mathrm{~F}$ & $\mathrm{DTA}^{\mathrm{f} / \mathrm{wt}} / /$ Glast-CreERT ${ }^{\mathrm{tg} / \mathrm{wt}}+$ Tamoxifen & $1 \mathrm{dpa}$ & \\
\hline & & 4519 & $M$ & DTA $^{\mathrm{f} / / \mathrm{wt}} / /$ Glast-CreERT ${ }^{\mathrm{t} / / \mathrm{wt}}+$ Tamoxifen & $3 \mathrm{dpa}$ & $\mathrm{n}=3$ ( $3 \mathrm{dpa})$ \\
\hline & & 4523 & $M$ & $\mathrm{DTA}^{\mathrm{f} / \mathrm{wt}} / /$ Glast-CreERT ${ }^{\mathrm{tg} / \mathrm{wt}}+$ Tamoxifen & $3 \mathrm{dpa}$ & \\
\hline & & A8033 & $M-$ & DTA $^{\mathrm{f} / \mathrm{wt}} / /$ Glast-CreERT ${ }^{\mathrm{tg} / \mathrm{wt}}+$ Tamoxifen & $3 \mathrm{dpa}$ & \\
\hline & & 536 & $\mathrm{~F}$ & $\mathrm{DTA}^{\mathrm{f} / \mathrm{wt} / / \text { Glast-CreERT }} \mathrm{T}^{\mathrm{tg} / \mathrm{wt}}+$ Tamoxifen & $5 \mathrm{dpa}$ & $\mathrm{n}=3(5 \mathrm{dpa})$ \\
\hline & & 535 & $\mathrm{~F}$ & DTA $^{\mathrm{fl} / \mathrm{wt}} / /$ Glast-CreERT ${ }^{\mathrm{tg} / \mathrm{wt}}+$ Tamoxifen & $5 \mathrm{dpa}$ & \\
\hline & & 317 & $M$ & $\mathrm{DTA}^{\mathrm{f} / \mathrm{wt}} / /$ Glast-CreERT $\mathrm{tg} / \mathrm{wt}+$ Tamoxifen & $5 \mathrm{dpa}$ & \\
\hline & & 314 & $\mathrm{~F}$ & $\mathrm{DTA}^{\mathrm{f} / \mathrm{wt}} / /$ Glast-CreERT ${ }^{\mathrm{tg} / \mathrm{wt}}+$ Tamoxifen & $11 \mathrm{dpa}$ & $\mathrm{n}=4(11 \mathrm{dpa})$ \\
\hline & & 305 & $M$ & $\mathrm{DTA}^{\mathrm{f} / \mathrm{wt}} / /$ Glast-CreERT ${ }^{\mathrm{tg} / \mathrm{wt}}+$ Tamoxifen & $11 \mathrm{dpa}$ & \\
\hline & & 310 & $\mathrm{~F}$ & $\mathrm{DTA}^{\mathrm{f} / \mathrm{wt}} / /$ Glast-CreERT ${ }^{\mathrm{tg} / \mathrm{wt}}+$ Tamoxifen & $11 \mathrm{dpa}$ & \\
\hline & & 310 & $M$ & $\mathrm{DTA}^{\mathrm{f} / \mathrm{wt}} / /$ Glast-CreERT ${ }^{\mathrm{tg} / \mathrm{wt}}+$ Tamoxifen & $11 \mathrm{dpa}$ & \\
\hline
\end{tabular}


bioRxiv preprint doi: https://doi.org/10.1101/2020.03.16.993691; this version posted March 18,2020 . The copyright holder for this preprint (which was not certified by peer review) is the author/funder. All rights reserved. No reuse allowed without permission.

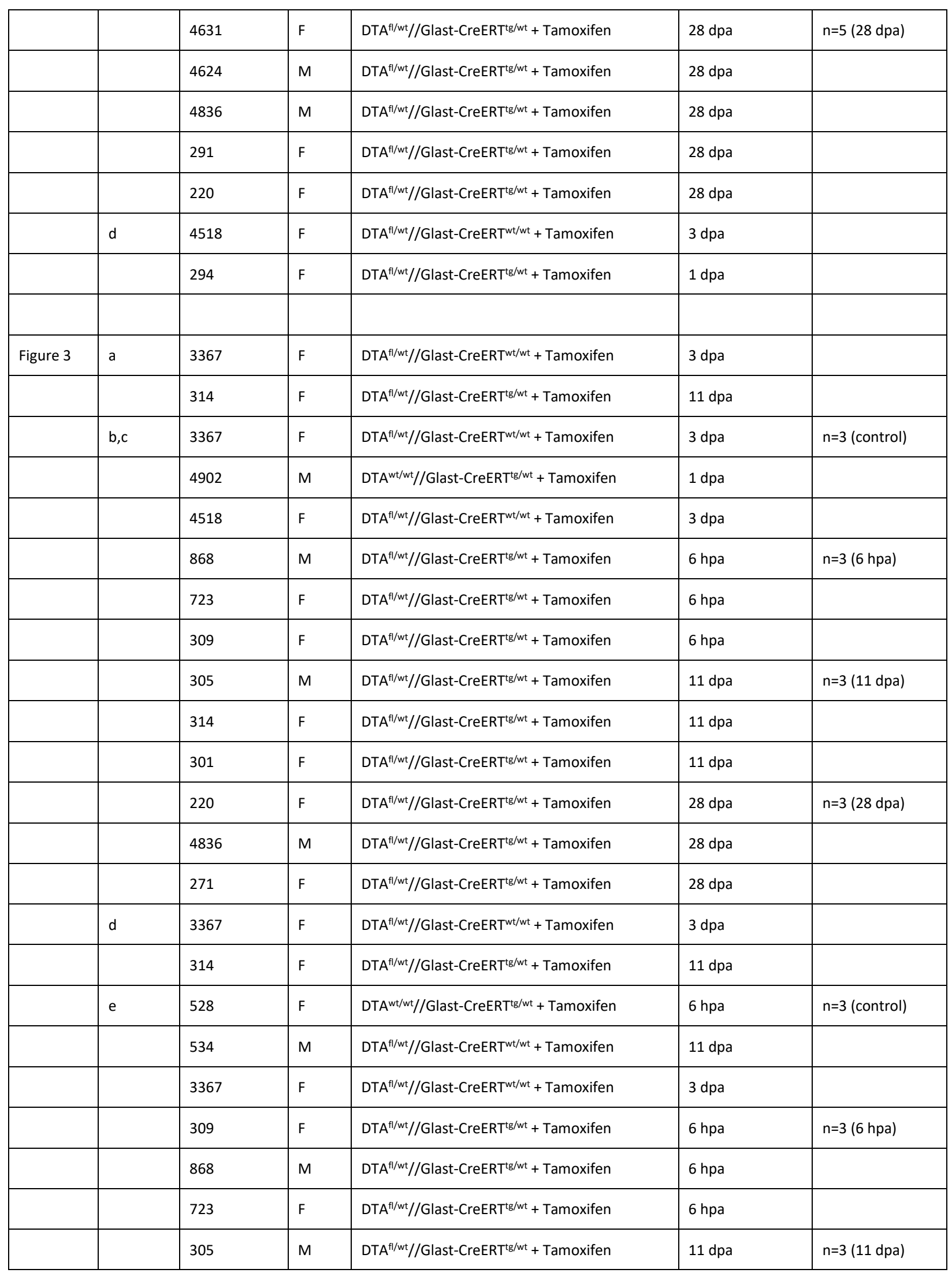


bioRxiv preprint doi: https://doi.org/10.1101/2020.03.16.993691; this version posted March 18,2020 . The copyright holder for this preprint (which was not certified by peer review) is the author/funder. All rights reserved. No reuse allowed without permission.

\begin{tabular}{|c|c|c|c|c|c|c|}
\hline & & 310 & $\mathrm{~F}$ & DTA $^{\mathrm{fl} / \mathrm{wt}} / /$ Glast-CreERT $\mathrm{tg} / \mathrm{wt}+$ Tamoxifen & $11 \mathrm{dpa}$ & \\
\hline & & 314 & $\mathrm{~F}$ & DTA $^{\mathrm{f} / \mathrm{wt}} / /$ Glast-CreERT ${ }^{\mathrm{tg} / \mathrm{wt}}+$ Tamoxifen & $11 \mathrm{dpa}$ & \\
\hline & & 217 & M & DTA $^{\mathrm{fl} / \mathrm{wt}} / /$ Glast-CreERT ${ }^{\mathrm{tg} / \mathrm{wt}}+$ Tamoxifen & $28 \mathrm{dpa}$ & $\mathrm{n}=3(28 \mathrm{dpa})$ \\
\hline & & 4836 & M & 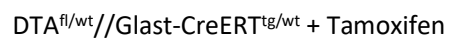 & $28 \mathrm{dpa}$ & \\
\hline & & 4631 & $\mathrm{~F}$ & 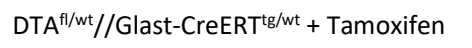 & $28 \mathrm{dpa}$ & \\
\hline \multirow[t]{8}{*}{ Figure 4} & a & 4224 & M & $\mathrm{DTA}^{\mathrm{f} / \mathrm{wt}} / /$ Glast-CreERTwt/wt + Tamoxifen & $3 \mathrm{dpa}$ & \\
\hline & & 294 & $\mathrm{~F}$ & $\mathrm{DTA}^{\mathrm{f} / \mathrm{wt} / / \text { Glast-CreERT } \mathrm{tg} / \mathrm{wt}}+$ Tamoxifen & $1 \mathrm{dpa}$ & \\
\hline & & 314 & $\mathrm{~F}$ & $\mathrm{DTA}^{\mathrm{fl} / \mathrm{wt} / / \text { Glast-CreERT }} \mathrm{tg} / \mathrm{wt}+$ Tamoxifen & $11 \mathrm{dpa}$ & \\
\hline & & 4863 & M & 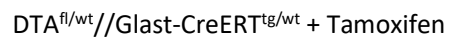 & $28 \mathrm{dpa}$ & \\
\hline & $\mathrm{b}$ & 4862 & M & 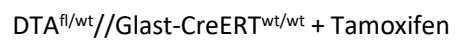 & $28 \mathrm{dpa}$ & \\
\hline & & 293 & $\mathrm{~F}$ & $\mathrm{DTA}^{\mathrm{f} / \mathrm{wt}} / /$ Glast-CreERTtg/wt + Tamoxifen & $1 \mathrm{dpa}$ & \\
\hline & & 310 & M & DTA ${ }^{\mathrm{f} / \mathrm{wt}} / /$ Glast-CreERT $\mathrm{Tg}^{\mathrm{t} / \mathrm{wt}}+$ Tamoxifen & $11 \mathrm{dpa}$ & \\
\hline & & 4624 & M & 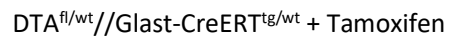 & $28 \mathrm{dpa}$ & \\
\hline \multirow[t]{16}{*}{ Figure 5} & a & 4287 & $\mathrm{~F}$ & $\mathrm{DTA}^{\mathrm{f} / \mathrm{wt}} / /$ Glast-CreERT ${ }^{\mathrm{wt} / \mathrm{wt}}+$ Tamoxifen & $1 \mathrm{dpa}$ & \\
\hline & & 293 & M & $\mathrm{DTA}^{\mathrm{f} / \mathrm{wt}} / /$ Glast-CreERT $\mathrm{t}^{\mathrm{tg} / \mathrm{wt}}+$ Tamoxifen & $1 \mathrm{dpa}$ & \\
\hline & & 314 & $\mathrm{~F}$ & 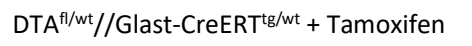 & $11 \mathrm{dpa}$ & \\
\hline & & 4631 & $\mathrm{~F}$ & 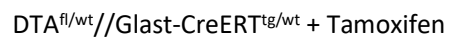 & $28 \mathrm{dpa}$ & \\
\hline & $b-d, f, h$ & 4287 & $\mathrm{~F}$ & DTA $^{\mathrm{f} / / \mathrm{wt}} / /$ Glast-CreERTwt/wt + Tamoxifen & $1 \mathrm{dpa}$ & $\mathrm{n}=3$ (control) \\
\hline & & 301 & $\mathrm{~F}$ & $\mathrm{DTA}^{\mathrm{f} / \mathrm{wt}} / /$ Glast-CreERT ${ }^{\mathrm{wt} / \mathrm{wt}}+$ Tamoxifen & $11 \mathrm{dpa}$ & \\
\hline & & 219 & $\mathrm{~F}$ & DTA $^{\text {wt/wt }} / /$ Glast-CreERTwt/wt + Tamoxifen & $28 \mathrm{dpa}$ & \\
\hline & & 293 & M & $\mathrm{DTA}^{\mathrm{f} / \mathrm{wt}} / /$ Glast-CreERT $\mathrm{tg} / \mathrm{wt}+$ Tamoxifen & $1 \mathrm{dpa}$ & $\mathrm{n}=3(1 \mathrm{dpa})$ \\
\hline & & 4221 & $\mathrm{~F}$ & $\mathrm{DTA}^{\mathrm{f} / \mathrm{wt} / / \text { Glast-CreERT } \mathrm{tg} / \mathrm{wt}}+$ Tamoxifen & $1 \mathrm{dpa}$ & \\
\hline & & 4901 & M & 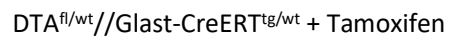 & $1 \mathrm{dpa}$ & \\
\hline & & 271 & $\mathrm{~F}$ & DTA $^{\mathrm{fl} / \mathrm{wt}} / /$ Glast-CreERT ${ }^{\mathrm{tg} / \mathrm{wt}}+$ Tamoxifen & $11 \mathrm{dpa}$ & $\mathrm{n}=3(11 \mathrm{dpa})$ \\
\hline & & 310 & M & $\mathrm{DTA}^{\mathrm{f} / \mathrm{wt}} / /$ Glast-CreERT $\mathrm{tg} / \mathrm{wt}+$ Tamoxifen & $11 \mathrm{dpa}$ & \\
\hline & & 314 & $\mathrm{~F}$ & $\mathrm{DTA}^{\mathrm{f} / \mathrm{wt} / / \text { Glast-CreERT }}$ tg/wt + Tamoxifen & $11 \mathrm{dpa}$ & \\
\hline & & 291 & $\mathrm{~F}$ & 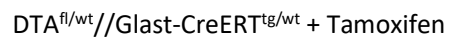 & $28 \mathrm{dpa}$ & $\mathrm{n}=3(28 \mathrm{dpa})$ \\
\hline & & 4631 & $\mathrm{~F}$ & DTA $^{\mathrm{fl} / \mathrm{wt}} / /$ Glast-CreERT $\mathrm{tg} / \mathrm{wt}+$ Tamoxifen & $28 \mathrm{dpa}$ & \\
\hline & & 4865 & M & DTA $^{\mathrm{f} / / \mathrm{wt}} / /$ Glast-CreERT ${ }^{\mathrm{tg} / \mathrm{wt}}+$ Tamoxifen & $28 \mathrm{dpa}$ & \\
\hline
\end{tabular}




\begin{tabular}{|c|c|c|c|c|c|}
\hline \multirow{2}{*}{$\begin{array}{l}\text { Supp. } \\
\text { Fig. } 1\end{array}$} & $a-d$ & 4864 & M & 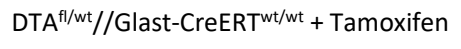 & $28 \mathrm{dpa}$ \\
\hline & & 314 & $\mathrm{~F}$ & $\mathrm{DTA}^{\mathrm{f} / \mathrm{wt}} / /$ Glast-CreERT $T^{\mathrm{tg} / \mathrm{wt}}+$ Tamoxifen & $11 \mathrm{dpa}$ \\
\hline \multirow{8}{*}{$\begin{array}{l}\text { Supp. } \\
\text { Fig. } 2\end{array}$} & a & 381 & M & DTA $^{\mathrm{f} / \mathrm{wt}} / /$ Glast-CreERTt/wt, Naïve & N/A \\
\hline & & 382 & $\mathrm{~F}$ & DTA ${ }^{\mathrm{f} / \mathrm{wt}} / /$ Glast-CreERT ${ }^{\mathrm{tg} / \mathrm{wt}}$, Naïve & N/A \\
\hline & & 4525 & M & 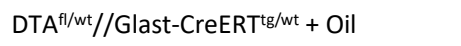 & $3 \mathrm{dpa}$ \\
\hline & $b, c$ & 4862 & M & 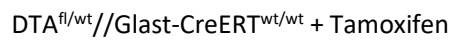 & $28 \mathrm{dpa}$ \\
\hline & & 4864 & M & $\mathrm{DTA}^{\mathrm{f} / \mathrm{wt}} / /$ Glast-CreERT ${ }^{\mathrm{wt} / \mathrm{wt}}+$ Tamoxifen & $28 \mathrm{dpa}$ \\
\hline & & 305 & M & $\mathrm{DTA}^{\mathrm{ft} / \mathrm{wt} / / \text { Glast-CreERT }} \mathrm{Tt}^{\mathrm{tg} / \mathrm{wt}}+$ Tamoxifen & $11 \mathrm{dpa}$ \\
\hline & $d$ & 4862 & M & 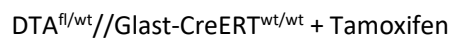 & $28 \mathrm{dpa}$ \\
\hline & & 305 & M & $\mathrm{DTA}^{\mathrm{f} / / \mathrm{wt}} / /$ Glast-CreERT $T^{\mathrm{tg} / \mathrm{wt}}+$ Tamoxifen & $11 \mathrm{dpa}$ \\
\hline \multirow{3}{*}{$\begin{array}{l}\text { Supp. } \\
\text { Fig. } 3\end{array}$} & $a, b$ & 292 & $\mathrm{~F}$ & $\mathrm{DTA}^{\mathrm{fl} / \mathrm{wt}} / /$ Glast-CreERT ${ }^{\mathrm{wt} / \mathrm{wt}}+$ Tamoxifen & $1 \mathrm{dpa}$ \\
\hline & & 892 & M & DTA $^{\mathrm{ft} / \mathrm{wt}} / /$ Glast-CreERT ${ }^{\mathrm{tg} / \mathrm{wt}}+$ Tamoxifen & $2 \mathrm{hpa}$ \\
\hline & & 4624 & M & DTA $^{\mathrm{fl} / \mathrm{wt}} / /$ Glast-CreERT $T^{\mathrm{tg} / \mathrm{wt}}+$ Tamoxifen & $28 \mathrm{dpa}$ \\
\hline \multirow{2}{*}{$\begin{array}{l}\text { Supp. Fig. } \\
4\end{array}$} & a & 4902 & M & DTA ${ }^{w t / w t} / /$ Glast-CreERT ${ }^{\mathrm{t} / \mathrm{wt}}+$ Tamoxifen & $1 \mathrm{dpa}$ \\
\hline & & 4519 & M & 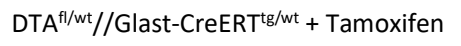 & $3 \mathrm{dpa}$ \\
\hline \multirow{5}{*}{$\begin{array}{l}\text { Supp. Fig. } \\
5\end{array}$} & & 4225 & M & 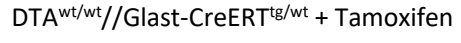 & $1 \mathrm{dpa}$ \\
\hline & & 4223 & $\mathrm{~F}$ & $\mathrm{DTA}^{\mathrm{ft} / \mathrm{wt} / / \text { Glast-CreERT }} \mathrm{T}^{\mathrm{tg} / \mathrm{wt}}+$ Tamoxifen & $1 \mathrm{dpa}$ \\
\hline & & 4519 & M & $\mathrm{DTA}^{\mathrm{ft} / \mathrm{wt} / / \text { Glast-CreERT }} \mathrm{T}^{\mathrm{tg} / \mathrm{wt}}+$ Tamoxifen & $3 \mathrm{dpa}$ \\
\hline & & 314 & $\mathrm{~F}$ & DTA ${ }^{\mathrm{fl} / \mathrm{wt}} / /$ Glast-CreERT $T^{\mathrm{tg} / \mathrm{wt}}+$ Tamoxifen & $11 \mathrm{dpa}$ \\
\hline & & 4863 & M & $\mathrm{DTA}^{\mathrm{ft} / \mathrm{wt} / / \text { Glast-CreERT }} \mathrm{T}^{\mathrm{tg} / \mathrm{wt}}+$ Tamoxifen & $28 \mathrm{dpa}$ \\
\hline \multirow{2}{*}{$\begin{array}{l}\text { Supp. } \\
\text { Fig. } 6\end{array}$} & a & 2794 & M & DTA $^{\text {wt/wt }} / /$ Glast-CreERTtg/wt + Tamoxifen & $3 \mathrm{dpa}$ \\
\hline & $\mathrm{b}$ & 537 & M & $\mathrm{DTA}^{\mathrm{ft} / \mathrm{wt}} / /$ Glast-CreERT ${ }^{\mathrm{wt} / \mathrm{wt}}+$ Tamoxifen & $5 \mathrm{dpa}$ \\
\hline
\end{tabular}


bioRxiv preprint doi: https://doi.org/10.1101/2020.03.16.993691; this version posted March 18,2020 . The copyright holder for this preprint (which was not certified by peer review) is the author/funder. All rights reserved. No reuse allowed without permission.

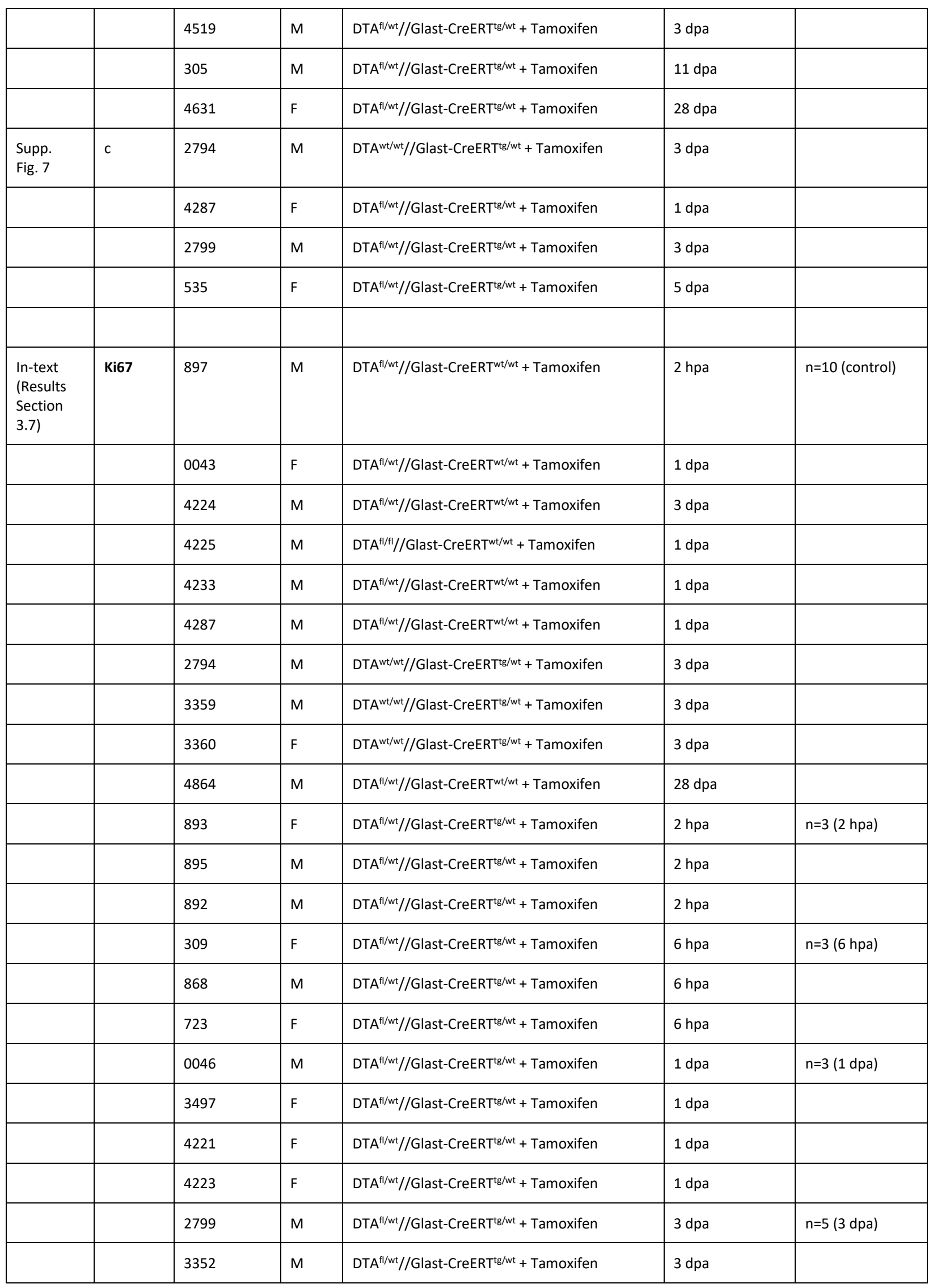


bioRxiv preprint doi: https://doi.org/10.1101/2020.03.16.993691; this version posted March 18,2020 . The copyright holder for this preprint (which was not certified by peer review) is the author/funder. All rights reserved. No reuse allowed without permission.

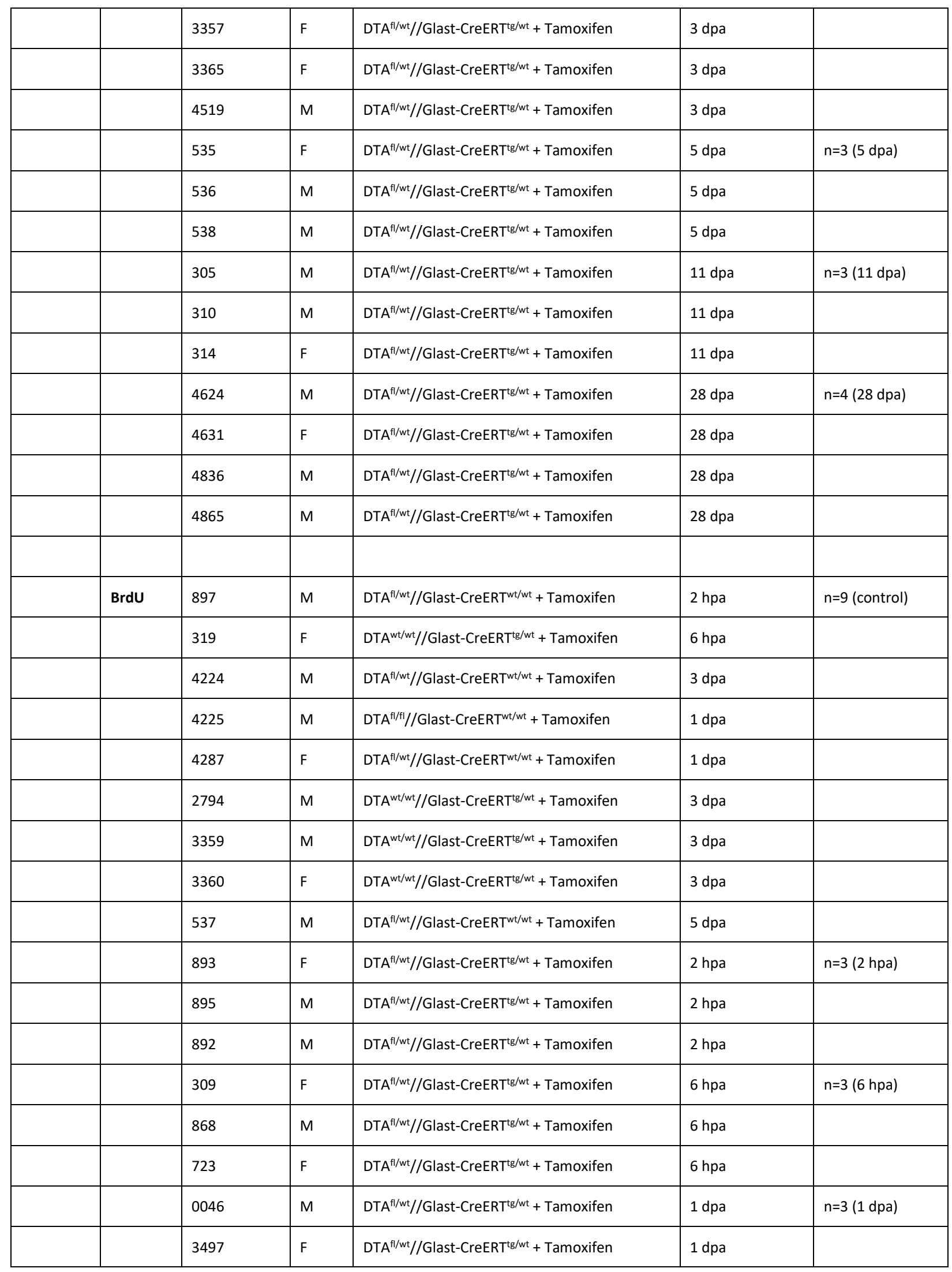


bioRxiv preprint doi: https://doi.org/10.1101/2020.03.16.993691; this version posted March 18, 2020. The copyright holder for this preprint (which was not certified by peer review) is the author/funder. All rights reserved. No reuse allowed without permission.

\begin{tabular}{|c|c|c|c|c|c|c|}
\hline & & 4221 & $\mathrm{~F}$ & $\mathrm{DTA}^{\mathrm{f} / \mathrm{wt} / / \text { Glast-CreERT }} \mathrm{t}^{\mathrm{t} / \mathrm{wt}}+$ Tamoxifen & $1 \mathrm{dpa}$ & \\
\hline & & 4223 & $\mathrm{~F}$ & $\mathrm{DTA}^{\mathrm{f} / \mathrm{wt}} / /$ Glast-CreERT ${ }^{\mathrm{tg} / \mathrm{wt}}+$ Tamoxifen & $1 \mathrm{dpa}$ & \\
\hline & & 2799 & M & $\mathrm{DTA}^{\mathrm{f} / \mathrm{wt} / / \text { Glast-CreERT }} \mathrm{tg}^{\mathrm{t} / \mathrm{wt}}+$ Tamoxifen & $3 \mathrm{dpa}$ & $\mathrm{n}=5(3 \mathrm{dpa})$ \\
\hline & & 3352 & M & DTA $^{\mathrm{f} / \mathrm{wt}} / /$ Glast-CreERT ${ }^{\mathrm{tg} / \mathrm{wt}}+$ Tamoxifen & $3 \mathrm{dpa}$ & \\
\hline & & 3357 & $\mathrm{~F}$ & DTA $^{\mathrm{f} / \mathrm{wt}} / /$ Glast-CreERT ${ }^{\mathrm{tg} / \mathrm{wt}}+$ Tamoxifen & $3 \mathrm{dpa}$ & \\
\hline & & 3365 & $\mathrm{~F}$ & $\mathrm{DTA}^{\mathrm{f} / \mathrm{wt}} / /$ Glast-CreERT $\mathrm{tg} / \mathrm{wt}+$ Tamoxifen & $3 \mathrm{dpa}$ & \\
\hline & & 4519 & M & $\mathrm{DTA}^{\mathrm{f} / \mathrm{wt}} / /$ Glast-CreERT ${ }^{\mathrm{tg} / \mathrm{wt}}+$ Tamoxifen & $3 \mathrm{dpa}$ & \\
\hline & & 535 & $\mathrm{~F}$ & $\mathrm{DTA}^{\mathrm{f} / \mathrm{wt} / / \text { Glast-CreERT }} \mathrm{tg}^{\mathrm{tg} / \mathrm{wt}}+$ Tamoxifen & $5 \mathrm{dpa}$ & $n=3(5 \mathrm{dpa})$ \\
\hline & & 536 & $\mathrm{~F}$ & $\mathrm{DTA}^{\mathrm{f} / \mathrm{wt}} / /$ Glast-CreERT ${ }^{\mathrm{tg} / \mathrm{wt}}+$ Tamoxifen & $5 \mathrm{dpa}$ & \\
\hline & & 538 & M & $\mathrm{DTA}^{\mathrm{f} / \mathrm{wt}} / /$ Glast-CreERT $\mathrm{tg} / \mathrm{wt}+$ Tamoxifen & $5 \mathrm{dpa}$ & \\
\hline
\end{tabular}

Table 2. Antibodies used in experiments.

\begin{tabular}{|c|c|c|c|c|c|c|}
\hline $\begin{array}{l}\text { Primary } \\
\text { Antibodies }\end{array}$ & & & & & & \\
\hline Name & Manufacturer & Catalog \# & RRID & $\begin{array}{l}\text { Species Raised } \\
\text { in }\end{array}$ & $\begin{array}{l}\text { Monoclonal/ } \\
\text { Polyclonal }\end{array}$ & Concentration \\
\hline$S 100 \beta$ & Sigma Aldrich & S2532 & AB_477499 & Mouse & Monoclonal & $1: 1000$ \\
\hline Glt1 & Millipore & AB1783 & AB_90949 & Guinea pig & Polyclonal & $1: 1000$ \\
\hline GFAP & Millipore & AB5541 & AB_177521 & Chicken & Polyclonal & $1: 1000$ \\
\hline Ki67 & Thermo Fisher & RM-9106-S1 & AB_149792 & Rabbit & Monoclonal & $1: 1000$ \\
\hline BrdU & Abcam & ab6326 & AB_305426 & Rat & Monoclonal & $1: 500$ \\
\hline $\begin{array}{l}\text { Cleaved } \\
\text { Caspase } 3\end{array}$ & $\begin{array}{l}\text { Cell Signaling } \\
\text { Technology }\end{array}$ & 9661 & AB_2341188 & Rabbit & Polyclonal & $1: 1000$ \\
\hline Sox-9 & Millipore & AB5535 & AB_2239761 & Rabbit & Polyclonal & $1: 1000$ \\
\hline Fibrinogen & Agilent & A008002 & AB_578481 & Rabbit & Polyclonal & $1: 500$ \\
\hline ZO-1 & Abcam & ab96587 & AB-18.0006 & Rabbit & Polyclonal & $1: 100$ \\
\hline pSTAT3 & $\begin{array}{l}\text { Cell Signaling } \\
\text { Technology }\end{array}$ & \#9145S & AB_2491009 & Rabbit & Monoclonal & $1: 100$ \\
\hline
\end{tabular}




\begin{tabular}{|l|l|l|l|l|l|l|}
\hline Iba1 & Wako & $\# 09-19741$ & AB_839504 & Rabbit & Polyclonal & $1: 1000$ \\
\hline
\end{tabular}

\begin{tabular}{|c|c|c|c|c|c|c|}
\hline $\begin{array}{l}\text { Secondary } \\
\text { Antibodies }\end{array}$ & & & & & & \\
\hline Name & Manufacturer & Catalog \# & RRID & $\begin{array}{l}\text { Species Raised } \\
\text { in }\end{array}$ & $\begin{array}{l}\text { Monoclonal/ } \\
\text { Polyclonal }\end{array}$ & Concentration \\
\hline $\begin{array}{l}\text { Chicken Alexa- } \\
488\end{array}$ & $\begin{array}{l}\text { Jackson Immuno } \\
\text { Research }\end{array}$ & 703-546-155 & AB_2340376 & Donkey & Polyclonal & $1: 1000$ \\
\hline $\begin{array}{l}\text { Rabbit Alexa- } \\
488\end{array}$ & $\begin{array}{l}\text { Jackson Immuno } \\
\text { Research }\end{array}$ & $111-546-144$ & AB_2338057 & Donkey & Polyclonal & $1: 1000$ \\
\hline $\begin{array}{l}\text { Mouse Alexa- } \\
488\end{array}$ & $\begin{array}{l}\text { Jackson Immuno } \\
\text { Research }\end{array}$ & $115-546-003$ & AB_2338859 & Goat & Polyclonal & $1: 1000$ \\
\hline Rat Alexa-488 & $\begin{array}{l}\text { Jackson Immuno } \\
\text { Research }\end{array}$ & $112-546-003$ & AB_2338364 & Goat & Polyclonal & $1: 1000$ \\
\hline $\begin{array}{l}\text { Guinea pig } \\
\text { Alexa-647 }\end{array}$ & $\begin{array}{l}\text { Jackson Immuno } \\
\text { Research }\end{array}$ & $106-606-003$ & AB_2337449 & Goat & Polyclonal & $1: 1000$ \\
\hline
\end{tabular}

\begin{tabular}{|c|c|c|c|c|c|c|}
\hline Dyes & & & & & & \\
\hline Name & Manufacturer & Catalog \# & RRID & $\begin{array}{l}\text { Species Raised } \\
\text { in }\end{array}$ & $\begin{array}{l}\text { Monoclonal/ } \\
\text { Polyclonal }\end{array}$ & Concentration \\
\hline DAPI & ThermoFisher & D1306 & AB_2629482 & $N / A$ & $N / A$ & $1: 1000$ \\
\hline $\begin{array}{l}\text { Alexa-555 } \\
\text { Cadaverine }\end{array}$ & ThermoFisher & A30677 & $\mathrm{N} / \mathrm{A}$ & N/A & N/A & $0.33 \mathrm{mg} / \mathrm{mouse}$ \\
\hline
\end{tabular}

\section{Table 3. Statistics and significance test results}

\begin{tabular}{|c|c|c|c|c|c|c|}
\hline Figure 1f & \multicolumn{6}{|c|}{$\begin{array}{l}\text { Kruskal-Wallis test, significant difference for genotype of animals given tamoxifen and } \\
\text { post-administration timepoint }(p<0.001) . \mathrm{N} \text { is sample number. }\end{array}$} \\
\hline $\begin{array}{l}\text { Dunn's multiple } \\
\text { comparisons test }\end{array}$ & $\begin{array}{l}\text { Mean rank } \\
\text { diff. }\end{array}$ & Significant? & Summary & $\begin{array}{l}\text { Adjusted P } \\
\text { value }\end{array}$ & & \\
\hline Control vs. 2 hpa & -27.54 & No & ns & 0.3851 & & \\
\hline Control vs. 6 hpa & -6.536 & No & ns & $>0.9999$ & & \\
\hline Control vs. $1 \mathrm{dpa}$ & -40.98 & Yes & ** & 0.0044 & & \\
\hline Control vs. 3 dpa & -47.23 & Yes & $\star \star \star *$ & 0.0002 & & \\
\hline Control vs. 5 dpa & -74.43 & Yes & 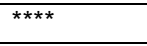 & $<0.0001$ & & \\
\hline Control vs. $11 \mathrm{dpa}$ & -52.05 & Yes & $* * * *$ & $<0.0001$ & & \\
\hline Control vs. $28 \mathrm{dpa}$ & -49.98 & Yes & $* * *$ & 0.0004 & & \\
\hline Test details & Mean 1 & SEM 1 & Mean 2 & SEM 2 & $\mathrm{~N} 1$ & N2 \\
\hline Control vs. 2 hpa & 2.201 & 0.1989 & 4.426 & 0.9110 & 51 & 9 \\
\hline Control vs. 6 hpa & 2.201 & 0.1989 & 2.540 & 0.4053 & 51 & 9 \\
\hline Control vs. 1 dpa & 2.201 & 0.1989 & 6.190 & 1.183 & 51 & 14 \\
\hline
\end{tabular}




\begin{tabular}{|c|c|c|c|c|c|c|}
\hline Control vs. 3 dpa & 2.201 & 0.1989 & 7.051 & 1.157 & 51 & 16 \\
\hline Control vs. 5 dpa & 2.201 & 0.1989 & 12.620 & 2.026 & 51 & 11 \\
\hline Control vs. $11 \mathrm{dpa}$ & 2.201 & 0.1989 & 8.687 & 1.485 & 51 & 14 \\
\hline Control vs. 28 dpa & 2.201 & 0.1989 & 9.219 & 2.360 & 51 & 13 \\
\hline Figure 1g & \multicolumn{6}{|c|}{$\begin{array}{l}\text { Two-way ANOVA, significant difference for genotype of animals given tamoxifen } \\
(p<0.0001) \text { and brain region }(p=0.0008) . N \text { is sample number. }\end{array}$} \\
\hline $\begin{array}{l}\text { Sidak's multiple } \\
\text { comparisons test }\end{array}$ & $\begin{array}{l}\text { Predicted } \\
\text { LS Mean } \\
\text { Diff. } \\
\end{array}$ & Significant? & Summary & $\begin{array}{l}\text { Adjusted } p \\
\text { value }\end{array}$ & & \\
\hline $\begin{array}{l}\text { Medial Control vs. } \\
\text { Medial Experimental }\end{array}$ & -7.296 & Yes & **** & $<0.0001$ & & \\
\hline $\begin{array}{l}\text { Medial Control vs. } \\
\text { Lateral Control }\end{array}$ & -0.1749 & No & Ns & $>0.9999$ & & \\
\hline $\begin{array}{l}\text { Medial Experimental } \\
\text { vs. Lateral } \\
\text { Experimental }\end{array}$ & -0.5990 & Yes & 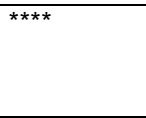 & $<0.0001$ & & \\
\hline $\begin{array}{l}\text { Lateral Control vs. } \\
\text { Lateral Experimental }\end{array}$ & 7.121 & no & ns & 0.9999 & & \\
\hline Test Details & Mean 1 & SEM 1 & Mean 2 & SEM 2 & N1 & N2 \\
\hline $\begin{array}{l}\text { Medial Control vs. } \\
\text { Medial Experimental }\end{array}$ & 2.436 & 0.246 & 9.732 & 0.863 & 30 & 63 \\
\hline $\begin{array}{l}\text { Medial Control vs. } \\
\text { Lateral Control }\end{array}$ & 2.436 & 0.246 & 2.611 & 0.414 & 30 & 22 \\
\hline $\begin{array}{l}\text { Medial Experimental } \\
\text { vs. Lateral } \\
\text { Experimental }\end{array}$ & 9.732 & 0.863 & 3.035 & 0.579 & 63 & 19 \\
\hline $\begin{array}{l}\text { Lateral Control vs. } \\
\text { Lateral Experimental }\end{array}$ & 2.611 & 0.414 & 3.035 & 0.579 & 22 & 19 \\
\hline Figure 2c & \multicolumn{6}{|c|}{$\begin{array}{l}\text { One-way ANOVA, significant difference for genotype and post-administration timepoint } \\
(p<0.0001) . N \text { is sample number. }\end{array}$} \\
\hline $\begin{array}{l}\text { Tukey's multiple } \\
\text { comparisons test }\end{array}$ & Mean Diff & Significant & Summary & $\begin{array}{l}\text { Adjusted } p \\
\text { value }\end{array}$ & & \\
\hline Control vs. 2 hpa & -1.188 & No & Ns & 0.9996 & & \\
\hline Control vs. 6 hpa & -3.659 & No & Ns & 0.6368 & & \\
\hline Control vs. $1 \mathrm{dpa}$ & -7.703 & Yes & ** & 0.0019 & & \\
\hline Control vs. 3 dpa & -12.13 & Yes & 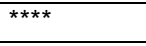 & $<0.0001$ & & \\
\hline Control vs. 5 dpa & -16.84 & Yes & $\star * * *$ & $<0.0001$ & & \\
\hline Control vs. $11 \mathrm{dpa}$ & -16.28 & Yes & $* \star \star \star *$ & $<0.0001$ & & \\
\hline Control vs. 28 dpa & -6.489 & No & Ns & 0.0759 & & \\
\hline 11 dpa vs. 28 dpa & 9.791 & Yes & ** & 0.0034 & & \\
\hline Test Details & Mean 1 & SEM 1 & Mean 2 & SEM 2 & N1 & N2 \\
\hline Control vs. 2 hpa & 0.1322 & 0.08273 & 1.321 & 0.6469 & 48 & 9 \\
\hline Control vs. 6 hpa & 0.1322 & 0.08273 & 3.792 & 0.9597 & 48 & 12 \\
\hline Control vs. $1 \mathrm{dpa}$ & 0.1322 & 0.08273 & 7.835 & 1.395 & 48 & 15 \\
\hline Control vs. 3 dpa & 0.1322 & 0.08273 & 12.26 & 2.724 & 48 & 13 \\
\hline Control vs. 5 dpa & 0.1322 & 0.08273 & 16.97 & 3.001 & 48 & 12 \\
\hline Control vs. $11 \mathrm{dpa}$ & 0.1322 & 0.08273 & 16.41 & 2.466 & 48 & 19 \\
\hline Control vs. 28 dpa & 0.1322 & 0.08273 & 6.621 & 1.799 & 48 & 10 \\
\hline 11 dpa vs. 28 dpa & 16.41 & 2.466 & 6.621 & 1.799 & 19 & 10 \\
\hline Figure 3b & \multicolumn{6}{|c|}{$\begin{array}{l}\text { Kruskal-Wallis test, significant difference for genotype and post-administration } \\
\text { timepoint }(p<0.0001)\end{array}$} \\
\hline $\begin{array}{l}\text { Dunn's multiple } \\
\text { comparisons test }\end{array}$ & $\begin{array}{l}\text { Mean rank } \\
\text { diff. }\end{array}$ & Significant? & Summary & $\begin{array}{l}\text { Adjusted P } \\
\text { value }\end{array}$ & & \\
\hline
\end{tabular}




\begin{tabular}{|c|c|c|c|c|c|c|}
\hline Control vs. 6 hpa & -2.450 & No & ns & $>0.999$ & & \\
\hline Control vs. $11 \mathrm{dpa}$ & -15.98 & Yes & ** & 0.0011 & & \\
\hline Control vs. $28 \mathrm{dpa}$ & -19.39 & Yes & 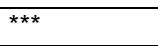 & 0.0004 & & \\
\hline 6 hpa vs. $11 \mathrm{dpa}$ & -13.53 & No & Ns & 0.0863 & & \\
\hline 6 hpa vs. 28 dpa & -16.94 & Yes & * & 0.0285 & & \\
\hline 11 dpa vs. $28 \mathrm{dpa}$ & -3.416 & No & Ns & $>0.9999$ & & \\
\hline Test Details & Mean 1 & SEM 1 & Mean 2 & SEM 2 & N1 & N2 \\
\hline Control vs. 6 hpa & 2.963 & 0.7270 & 6.731 & 4.021 & 12 & 5 \\
\hline Control vs. $11 \mathrm{dpa}$ & 2.963 & 0.7270 & 28.12 & 3.536 & 12 & 11 \\
\hline Control vs. $28 \mathrm{dpa}$ & 2.963 & 0.7270 & 35.35 & 4.207 & 12 & 7 \\
\hline 6 hpa vs. $11 \mathrm{dpa}$ & 6.731 & 4.021 & 28.12 & 3.536 & 5 & 11 \\
\hline 6 hpa vs. 28 dpa & 6.731 & 4.021 & 35.35 & 4.207 & 5 & 7 \\
\hline 11 dpa vs. $28 \mathrm{dpa}$ & 28.12 & 3.536 & 35.35 & 4.207 & 11 & 7 \\
\hline Figure 3c & \multicolumn{6}{|c|}{$\begin{array}{l}\text { Kruskal-Wallis test, significant difference for genotype and post-administration } \\
\text { timepoint }(p=0.0004)\end{array}$} \\
\hline $\begin{array}{l}\text { Dunn's multiple } \\
\text { comparisons test }\end{array}$ & $\begin{array}{l}\text { Mean rank } \\
\text { diff. }\end{array}$ & Significant? & Summary & $\begin{array}{l}\text { Adjusted P } \\
\text { value }\end{array}$ & & \\
\hline Control vs. $6 \mathrm{hpa}$ & 0.6727 & No & Ns & $>0.9999$ & & \\
\hline Control vs. $11 \mathrm{dpa}$ & 12.82 & Yes & * & 0.0152 & & \\
\hline Control vs. $28 \mathrm{dpa}$ & 17.13 & Yes & ** & 0.0022 & & \\
\hline 6 hpa vs. $11 \mathrm{dpa}$ & 12.15 & No & Ns & 0.1425 & & \\
\hline 6 hpa vs. $28 \mathrm{dpa}$ & 16.46 & Yes & * & 0.0286 & & \\
\hline 11 dpa vs. $28 \mathrm{dpa}$ & 4.312 & No & Ns & $>0.9999$ & & \\
\hline Test Details & Mean 1 & SEM 1 & Mean 2 & SEM 2 & N1 & N2 \\
\hline Control vs. 6 hpa & 1109 & 129 & 1001 & 187 & 11 & 5 \\
\hline Control vs. $11 \mathrm{dpa}$ & 1109 & 129 & 457.4 & 55.81 & 11 & 11 \\
\hline Control vs. $28 \mathrm{dpa}$ & 1109 & 129 & 351.9 & 90.11 & 11 & 7 \\
\hline 6 hpa vs. $11 \mathrm{dpa}$ & 1001 & 187 & 457.4 & 55.81 & 5 & 11 \\
\hline 6 hpa vs. $28 \mathrm{dpa}$ & 1001 & 187 & 351.9 & 90.11 & 5 & 7 \\
\hline 11 dpa vs. $28 \mathrm{dpa}$ & 457.4 & 55.81 & 351.9 & 90.11 & 11 & 7 \\
\hline Fig 3e & \multicolumn{6}{|c|}{$\begin{array}{l}\text { One-way ANOVA, no significant difference for genotype and post-administration } \\
\text { timepoint }(p=0.9960)\end{array}$} \\
\hline $\begin{array}{l}\text { Dunnett's multiple } \\
\text { comparisons test }\end{array}$ & Mean Diff & Significant? & Summary & $\begin{array}{l}\text { Adjusted P } \\
\text { value }\end{array}$ & & \\
\hline Control vs. $6 \mathrm{hpa}$ & -11.85 & No & Ns & 0.9996 & & \\
\hline Control vs. 11dpa & -31.08 & No & Ns & 0.9946 & & \\
\hline Control vs. $28 \mathrm{dpa}$ & -33.26 & No & Ns & 0.9934 & & \\
\hline Test Details & Mean 1 & SEM 1 & Mean 2 & SEM 2 & N1 & N2 \\
\hline Control vs. 6 hpa & 423.4 & 171.7 & 435.2 & 106.5 & 3 & 3 \\
\hline Control vs. 11dpa & 423.4 & 171.7 & 454.5 & 29.52 & 3 & 3 \\
\hline Control vs. $28 \mathrm{dpa}$ & 423.4 & 171.7 & 456.7 & 101.3 & 3 & 3 \\
\hline Figure 5b & \multicolumn{6}{|c|}{$\begin{array}{l}\text { One-Way ANOVA, significant difference for post-administration timepoint }(p=0.0273) \\
\mathrm{N} \text { is sample number. }\end{array}$} \\
\hline $\begin{array}{l}\text { Tukey's multiple } \\
\text { comparisons test }\end{array}$ & Significant? & Summary & $\begin{array}{l}\text { Adjusted P } \\
\text { value }\end{array}$ & & & \\
\hline $1 \mathrm{dpa}$ vs. $11 \mathrm{dpa}$ & No & ns & 0.6083 & & & \\
\hline $1 \mathrm{dpa}$ vs. $28 \mathrm{dpa}$ & Yes & * & 0.0228 & & & \\
\hline 11 dpa vs. 28 dpa & No & ns & 0.1810 & & & \\
\hline Test details & Mean 1 & Mean 2 & Mean Diff. & SE of diff. & N1 & N2 \\
\hline $1 \mathrm{dpa}$ vs. $11 \mathrm{dpa}$ & 815.9 & 938.8 & -122.9 & 128.5 & 15 & 15 \\
\hline $1 \mathrm{dpa}$ vs. $28 \mathrm{dpa}$ & 815.9 & 1171 & -354.6 & 128.5 & 15 & 15 \\
\hline
\end{tabular}




\begin{tabular}{|l|l|l|l|l|l|l|}
\hline $11 \mathrm{dpa}$ vs. $28 \mathrm{dpa}$ & 938.8 & 1171 & -231.7 & 128.5 & 15 & 15 \\
\hline & & & & & & \\
\hline
\end{tabular}

\begin{tabular}{|l|l|l|l|l|l|l|}
\hline Figure 5c & \multicolumn{1}{l}{$\begin{array}{l}\text { One-Way ANOVA, significant difference for post-administration timepoint }(\mathrm{p}=0.0013), \\
\text { N is sample number. }\end{array}$} \\
\hline $\begin{array}{l}\text { Tukey's multiple } \\
\text { comparisons test }\end{array}$ & Significant? & Summary & $\begin{array}{l}\text { Adjusted P } \\
\text { value }\end{array}$ & & & \\
\hline 1 dpa vs. 11 dpa & No & ns & 0.6446 & & & \\
\hline 1 dpa vs. 28 dpa & Yes & ${ }^{*}$ & 0.0204 & & & \\
\hline 11 dpa vs. 28 dpa & No & ns & 0.1499 & & & \\
\hline & & & & & & \\
\hline Test details & Mean 1 & Mean 2 & Mean Diff. & SE of diff. & N1 & N2 \\
\hline 1 dpa vs. 11 dpa & 1086 & 1402 & -316.2 & 352.2 & 15 & 15 \\
\hline 1 dpa vs. 28 dpa & 1086 & 2073 & -987.0 & 352.2 & 15 & 15 \\
\hline 11 dpa vs. 28 dpa & 1402 & 2073 & -670.8 & 352.2 & 15 & 15 \\
\hline
\end{tabular}

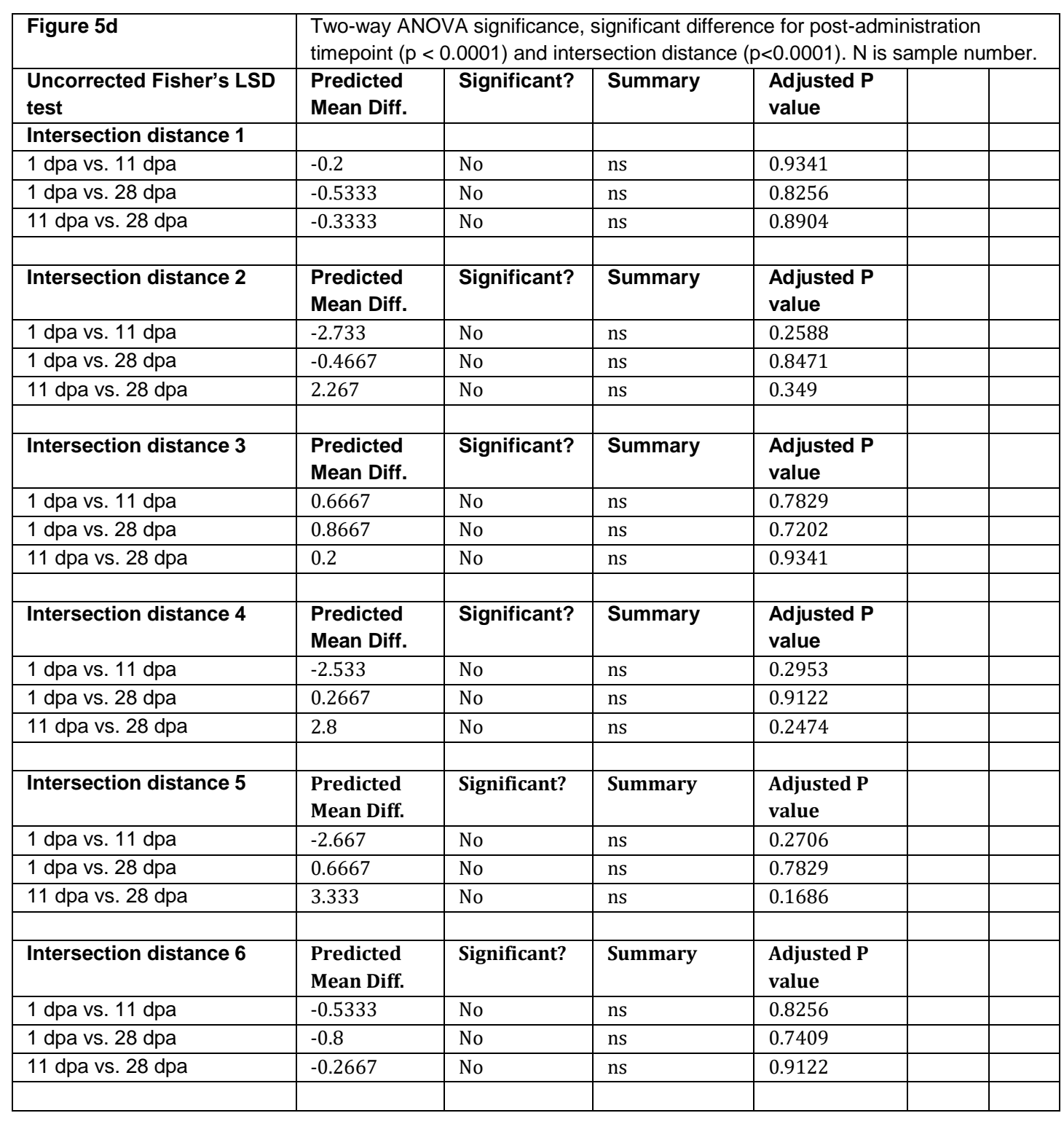




\begin{tabular}{|c|c|c|c|c|c|}
\hline Intersection distance 7 & $\begin{array}{l}\text { Predicted } \\
\text { Mean Diff. }\end{array}$ & Significant? & Summary & $\begin{array}{l}\text { Adjusted P } \\
\text { value }\end{array}$ & \\
\hline $1 \mathrm{dpa}$ vs. $11 \mathrm{dpa}$ & -2.933 & No & ns & 0.2256 & \\
\hline 1 dpa vs. 28 dpa & -5.467 & Yes & $*$ & 0.0241 & \\
\hline 11 dpa vs. 28 dpa & -2.533 & No & ns & 0.2953 & \\
\hline Intersection distance 8 & $\begin{array}{l}\text { Predicted } \\
\text { Mean Diff. }\end{array}$ & Significant? & Summary & $\begin{array}{l}\text { Adjusted P } \\
\text { value }\end{array}$ & \\
\hline 1 dpa vs. 11 dpa & 0 & No & ns & $>0.9999$ & \\
\hline 1 dpa vs. 28 dpa & -5.667 & Yes & * & 0.0194 & \\
\hline 11 dpa vs. 28 dpa & -5.667 & Yes & $*$ & 0.0194 & \\
\hline Intersection distance 9 & $\begin{array}{l}\text { Predicted } \\
\text { Mean Diff. }\end{array}$ & Significant? & Summary & $\begin{array}{l}\text { Adjusted P } \\
\text { value }\end{array}$ & \\
\hline 1 dpa vs. 11 dpa & -2.067 & No & ns & 0.3932 & \\
\hline 1 dpa vs. 28 dpa & -7.2 & Yes & $* *$ & 0.003 & \\
\hline 11 dpa vs. 28 dpa & -5.133 & Yes & $*$ & 0.0341 & \\
\hline Intersection distance 10 & $\begin{array}{l}\text { Predicted } \\
\text { Mean Diff. }\end{array}$ & Significant? & Summary & $\begin{array}{l}\text { Adjusted P } \\
\text { value }\end{array}$ & \\
\hline $1 \mathrm{dpa}$ vs. $11 \mathrm{dpa}$ & -1.6 & No & ns & 0.5085 & \\
\hline 1 dpa vs. 28 dpa & -6.2 & Yes & $*$ & 0.0106 & \\
\hline 11 dpa vs. 28 dpa & -4.6 & No & ns & 0.0576 & \\
\hline Intersection distance 11 & $\begin{array}{l}\text { Predicted } \\
\text { Mean Diff. }\end{array}$ & Significant? & Summary & $\begin{array}{l}\text { Adjusted P } \\
\text { value }\end{array}$ & \\
\hline 1 dpa vs. 11 dpa & -0.8 & No & ns & 0.7409 & \\
\hline 1 dpa vs. 28 dpa & -6.267 & Yes & $* *$ & 0.0098 & \\
\hline 11 dpa vs. 28 dpa & -5.467 & Yes & $*$ & 0.0241 & \\
\hline Intersection distance 12 & $\begin{array}{l}\text { Predicted } \\
\text { Mean Diff. }\end{array}$ & Significant? & Summary & $\begin{array}{l}\text { Adjusted P } \\
\text { value }\end{array}$ & \\
\hline 1 dpa vs. 11 dpa & -0.06667 & No & ns & 0.978 & \\
\hline 1 dpa vs. 28 dpa & -5.533 & Yes & $*$ & 0.0224 & \\
\hline 11 dpa vs. 28 dpa & -5.467 & Yes & $*$ & 0.0241 & \\
\hline Intersection distance 13 & $\begin{array}{l}\text { Predicted } \\
\text { Mean Diff. }\end{array}$ & Significant? & Summary & $\begin{array}{l}\text { Adjusted P } \\
\text { value }\end{array}$ & \\
\hline 1 dpa vs. 11 dpa & -0.3857 & No & ns & 0.8755 & \\
\hline 1 dpa vs. 28 dpa & -5.452 & Yes & $*$ & 0.0271 & \\
\hline 11 dpa vs. 28 dpa & -5.067 & Yes & $*$ & 0.0365 & \\
\hline Intersection distance 14 & $\begin{array}{l}\text { Predicted } \\
\text { Mean Diff. }\end{array}$ & Significant? & Summary & $\begin{array}{l}\text { Adjusted P } \\
\text { value }\end{array}$ & \\
\hline $1 \mathrm{dpa}$ vs. $11 \mathrm{dpa}$ & -0.3333 & No & ns & 0.8904 & \\
\hline 1 dpa vs. 28 dpa & -3.8 & No & ns & 0.1166 & \\
\hline 11 dpa vs. 28 dpa & -3.467 & No & ns & 0.1522 & \\
\hline Intersection distance 15 & $\begin{array}{l}\text { Predicted } \\
\text { Mean Diff. }\end{array}$ & Significant? & Summary & $\begin{array}{l}\text { Adjusted P } \\
\text { value }\end{array}$ & \\
\hline $1 \mathrm{dpa}$ vs. $11 \mathrm{dpa}$ & -0.06667 & No & ns & 0.978 & \\
\hline 1 dpa vs. 28 dpa & -1.6 & No & ns & 0.5085 & \\
\hline 11 dpa vs. 28 dpa & -1.533 & No & ns & 0.5263 & \\
\hline Intersection distance 16 & $\begin{array}{l}\text { Predicted } \\
\text { Mean Diff. }\end{array}$ & Significant? & Summary & $\begin{array}{l}\text { Adjusted P } \\
\text { value }\end{array}$ & \\
\hline 1 dpa vs. 11 dpa & 0 & No & ns & $>0.9999$ & \\
\hline 1 dpa vs. 28 dpa & -0.9333 & No & ns & 0.6997 & \\
\hline
\end{tabular}




\begin{tabular}{|c|c|c|c|c|c|c|}
\hline 11 dpa vs. 28 dpa & -0.9333 & No & ns & 0.6997 & & \\
\hline Intersection distance 17 & $\begin{array}{l}\text { Predicted } \\
\text { Mean Diff. }\end{array}$ & Significant? & Summary & $\begin{array}{l}\text { Adjusted P } \\
\text { value }\end{array}$ & & \\
\hline $1 \mathrm{dpa}$ vs. $11 \mathrm{dpa}$ & 0 & No & ns & $>0.9999$ & & \\
\hline 1 dpa vs. 28 dpa & -0.3333 & No & ns & 0.8904 & & \\
\hline 11 dpa vs. 28 dpa & -0.3333 & No & ns & 0.8904 & & \\
\hline Intersection distance 18 & $\begin{array}{l}\text { Predicted } \\
\text { Mean Diff. }\end{array}$ & Significant? & Summary & $\begin{array}{l}\text { Adjusted P } \\
\text { value }\end{array}$ & & \\
\hline $1 \mathrm{dpa}$ vs. $11 \mathrm{dpa}$ & 0 & No & ns & $>0.9999$ & & \\
\hline 1 dpa vs. $28 \mathrm{dpa}$ & -0.2 & No & ns & 0.9341 & & \\
\hline 11 dpa vs. 28 dpa & -0.2 & No & ns & 0.9341 & & \\
\hline Test Details & Mean 1 & SEM 1 & Mean 2 & SEM 2 & N1 & N2 \\
\hline \multicolumn{7}{|l|}{ Intersection distance 1} \\
\hline 1 dpa vs. 11 dpa & 2.2000 & 0.1745 & 2.4000 & 0.2894 & 15 & 15 \\
\hline $1 \mathrm{dpa}$ vs. $28 \mathrm{dpa}$ & 2.2000 & 0.1745 & 2.7333 & 0.4414 & 15 & 15 \\
\hline 11 dpa vs. 28 dpa & 2.4000 & 0.2894 & 2.7333 & 0.4414 & 15 & 15 \\
\hline Intersection distance 2 & Mean 1 & SEM 1 & Mean 2 & SEM 2 & N1 & N2 \\
\hline $1 \mathrm{dpa}$ vs. $11 \mathrm{dpa}$ & 6.3333 & 0.7411 & 9.0667 & 1.0257 & 15 & 15 \\
\hline 1 dpa vs. 28 dpa & 6.3333 & 0.7411 & 6.800 & 0.8519 & 15 & 15 \\
\hline 11 dpa vs. 28 dpa & 9.0667 & 1.0257 & 6.800 & 0.8519 & 15 & 15 \\
\hline Intersection distance 3 & Mean 1 & SEM 1 & Mean 2 & SEM 2 & N1 & N2 \\
\hline $1 \mathrm{dpa}$ vs. $11 \mathrm{dpa}$ & 12.8000 & 1.8752 & 12.1333 & 0.9354 & 15 & 15 \\
\hline 1 dpa vs. 28 dpa & 12.8000 & 1.8752 & 11.9333 & 1.5568 & 15 & 15 \\
\hline 11 dpa vs. $28 \mathrm{dpa}$ & 12.1333 & 0.9354 & 11.9333 & 1.5568 & 15 & 15 \\
\hline Intersection distance 4 & Mean 1 & SEM 1 & Mean 2 & SEM 2 & N1 & N2 \\
\hline 1 dpa vs. 11 dpa & 16.7333 & 1.8605 & 19.2667 & 1.4879 & 15 & 15 \\
\hline $1 \mathrm{dpa}$ vs. $28 \mathrm{dpa}$ & 16.7333 & 1.8605 & 16.4667 & 2.2988 & 15 & 15 \\
\hline 11 dpa vs. 28 dpa & 19.2667 & 1.4879 & 16.4667 & 2.2988 & 15 & 15 \\
\hline Intersection distance 5 & Mean 1 & SEM 1 & Mean 2 & SEM 2 & N1 & N2 \\
\hline $1 \mathrm{dpa}$ vs. $11 \mathrm{dpa}$ & 21.1333 & 1.9417 & 23.8000 & 2.0775 & 15 & 15 \\
\hline 1 dpa vs. 28 dpa & 21.1333 & 1.9417 & 20.4667 & 2.6147 & 15 & 15 \\
\hline 11 dpa vs. $28 \mathrm{dpa}$ & 23.8000 & 2.0775 & 20.4667 & 2.6147 & 15 & 15 \\
\hline Intersection distance 6 & Mean 1 & SEM 1 & Mean 2 & SEM 2 & N1 & N2 \\
\hline 1 dpa vs. 11 dpa & 22.0667 & 2.2980 & 22.6000 & 2.5219 & 15 & 15 \\
\hline $1 \mathrm{dpa}$ vs. $28 \mathrm{dpa}$ & 22.0667 & 2.2980 & 22.8667 & 3.5144 & 15 & 15 \\
\hline 11 dpa vs. $28 \mathrm{dpa}$ & 22.6000 & 2.5219 & 22.8667 & 3.5144 & 15 & 15 \\
\hline Intersection distance 7 & Mean 1 & SEM 1 & Mean 2 & SEM 2 & N1 & N2 \\
\hline $1 \mathrm{dpa}$ vs. $11 \mathrm{dpa}$ & 18.9333 & 2.5699 & 21.8667 & 2.5799 & 15 & 15 \\
\hline 1 dpa vs. 28 dpa & 18.9333 & 2.5699 & 24.4000 & 3.7299 & 15 & 15 \\
\hline 11 dpa vs. 28 dpa & 21.8667 & 2.5799 & 24.4000 & 3.7299 & 15 & 15 \\
\hline Intersection distance 8 & Mean 1 & SEM 1 & Mean 2 & SEM 2 & N1 & N2 \\
\hline $1 \mathrm{dpa}$ vs. $11 \mathrm{dpa}$ & 14.4000 & 2.3559 & 14.4000 & 1.9019 & 15 & 15 \\
\hline $1 \mathrm{dpa}$ vs. $28 \mathrm{dpa}$ & 14.4000 & 2.3559 & 20.0667 & 3.2870 & 15 & 15 \\
\hline 11 dpa vs. 28 dpa & 14.4000 & 1.9019 & 20.0667 & 3.2870 & 15 & 15 \\
\hline Intersection distance 9 & Mean 1 & SEM 1 & Mean 2 & SEM 2 & N1 & N2 \\
\hline $1 \mathrm{dpa}$ vs. $11 \mathrm{dpa}$ & 7.8000 & 1.5681 & 9.8667 & 1.7206 & 15 & 15 \\
\hline 1 dpa vs. 28 dpa & 7.8000 & 1.5681 & 15.0000 & 2.4708 & 15 & 15 \\
\hline
\end{tabular}




\begin{tabular}{|c|c|c|c|c|c|c|}
\hline 11 dpa vs. $28 \mathrm{dpa}$ & 9.8667 & 1.7206 & 15.0000 & 2.4708 & 15 & 15 \\
\hline Intersection distance 10 & Mean 1 & SEM 1 & Mean 2 & SEM 2 & N1 & N2 \\
\hline 1 dpa vs. 11 dpa & 4.4667 & 1.4305 & 6.0667 & 1.3504 & 15 & 15 \\
\hline 1 dpa vs. 28 dpa & 4.4667 & 1.4305 & 10.6667 & 2.6034 & 15 & 15 \\
\hline 11 dpa vs. 28 dpa & 6.0667 & 1.3504 & 10.6667 & 2.6034 & 15 & 15 \\
\hline Intersection distance 11 & Mean 1 & SEM 1 & Mean 2 & SEM 2 & N1 & N2 \\
\hline 1 dpa vs. 11 dpa & 2.3333 & 1.1819 & 3.1333 & 1.2223 & 15 & 15 \\
\hline 1 dpa vs. 28 dpa & 2.3333 & 1.1819 & 8.6000 & 2.3620 & 15 & 15 \\
\hline 11 dpa vs. 28 dpa & 3.1333 & 1.2223 & 8.6000 & 2.3620 & 15 & 15 \\
\hline Intersection distance 12 & Mean 1 & SEM 1 & Mean 2 & SEM 2 & N1 & N2 \\
\hline 1 dpa vs. 11 dpa & 1.0000 & 0.4781 & 1.0667 & 0.5297 & 15 & 15 \\
\hline $1 \mathrm{dpa}$ vs. $28 \mathrm{dpa}$ & 1.0000 & 0.4781 & 6.5333 & 2.3822 & 15 & 15 \\
\hline 11 dpa vs. 28 dpa & 1.0667 & 0.5297 & 6.5333 & 2.3822 & 15 & 15 \\
\hline Intersection distance 13 & Mean 1 & SEM 1 & Mean 2 & SEM 2 & N1 & N2 \\
\hline 1 dpa vs. 11 dpa & 0.2143 & 0.1547 & 0.6000 & 0.3754 & 15 & 15 \\
\hline 1 dpa vs. 28 dpa & 0.2143 & 0.1547 & 5.6667 & 2.7372 & 15 & 15 \\
\hline 11 dpa vs. 28 dpa & 0.6000 & 0.3754 & 5.6667 & 2.7372 & 15 & 15 \\
\hline Intersection distance 14 & Mean 1 & SEM 1 & Mean 2 & SEM 2 & N1 & N2 \\
\hline 1 dpa vs. 11 dpa & 0.0000 & 0.0000 & 0.3333 & 0.3333 & 15 & 15 \\
\hline 1 dpa vs. 28 dpa & 0.0000 & 0.0000 & 3.8000 & 2.2215 & 15 & 15 \\
\hline 11 dpa vs. 28 dpa & 0.3333 & 0.3333 & 3.8000 & 2.2215 & 15 & 15 \\
\hline Intersection distance 15 & Mean 1 & SEM 1 & Mean 2 & SEM 2 & N1 & N2 \\
\hline $1 \mathrm{dpa}$ vs. $11 \mathrm{dpa}$ & 0.0000 & 0.0000 & 0.0667 & 0.0667 & 15 & 15 \\
\hline 1 dpa vs. 28 dpa & 0.0000 & 0.0000 & 1.6000 & 1.2024 & 15 & 15 \\
\hline 11 dpa vs. 28 dpa & 0.0667 & 0.0667 & 1.6000 & 1.2024 & 15 & 15 \\
\hline Intersection distance 16 & Mean 1 & SEM 1 & Mean 2 & SEM 2 & N1 & N2 \\
\hline 1 dpa vs. 11 dpa & 0.0000 & 0.0000 & 0.0000 & 0.0000 & 15 & 15 \\
\hline 1 dpa vs. 28 dpa & 0.0000 & 0.0000 & 0.9333 & 0.5206 & 15 & 15 \\
\hline 11 dpa vs. 28 dpa & 0.0000 & 0.0000 & 0.9333 & 0.5206 & 15 & 15 \\
\hline Intersection distance 17 & Mean 1 & SEM 1 & Mean 2 & SEM 2 & N1 & N2 \\
\hline 1 dpa vs. 11 dpa & 0.0000 & 0.0000 & 0.0000 & 0.0000 & 15 & 15 \\
\hline 1 dpa vs. 28 dpa & 0.0000 & 0.0000 & 0.3330 & 0.1869 & 15 & 15 \\
\hline 11 dpa vs. 28 dpa & 0.0000 & 0.0000 & 0.3330 & 0.1869 & 15 & 15 \\
\hline Intersection distance 18 & Mean 1 & SEM 1 & Mean 2 & SEM 2 & N1 & N2 \\
\hline $1 \mathrm{dpa}$ vs. $11 \mathrm{dpa}$ & 0.0000 & 0.0000 & 0.0000 & 0.0000 & 15 & 15 \\
\hline 1 dpa vs. 28 dpa & 0.0000 & 0.0000 & 0.2000 & 0.1447 & 15 & 15 \\
\hline 11 dpa vs. 28 dpa & 0.0000 & 0.0000 & 0.2000 & 0.1447 & 15 & 15 \\
\hline Figure $5 f$ & $\begin{array}{l}\text { One-way A } \\
\text { timepoint }(k\end{array}$ & $\begin{array}{l}\text { A, no significal } \\
\text { (382) }\end{array}$ & difference for & otype and pos & $\operatorname{nin}$ & \\
\hline $\begin{array}{l}\text { Tukey's Multiple } \\
\text { Comparisons test }\end{array}$ & Mean Diff & Significant? & Summary & $\begin{array}{l}\text { Adjusted P } \\
\text { value }\end{array}$ & & \\
\hline Control vs. $1 \mathrm{dpa}$ & 0.1601 & No & ns & 0.2119 & & \\
\hline Control vs. $11 \mathrm{dpa}$ & 0.1576 & No & ns & 0.3058 & & \\
\hline Control vs. $28 \mathrm{dpa}$ & 0.1199 & No & ns & 0.4944 & & \\
\hline $1 \mathrm{dpa}$ vs. $11 \mathrm{dpa}$ & -0.002496 & No & ns & $>0.9999$ & & \\
\hline 1 dpa vs. 28 dpa & -0.04018 & No & ns & 0.9758 & & \\
\hline 11 dpa vs. 28 dpa & -0.03768 & No & ns & 0.9836 & & \\
\hline
\end{tabular}


bioRxiv preprint doi: https://doi.org/10.1101/2020.03.16.993691; this version posted March 18,2020 . The copyright holder for this preprint (which was not certified by peer review) is the author/funder. All rights reserved. No reuse allowed without permission.

\begin{tabular}{|c|c|c|c|c|c|c|}
\hline Test Details & Mean 1 & SEM 1 & Mean 2 & SEM 2 & N1 & N2 \\
\hline Control vs. $1 \mathrm{dpa}$ & 1.005 & 0.0429 & 0.8447 & 0.06033 & 17 & 8 \\
\hline Control vs. $11 \mathrm{dpa}$ & 1.005 & 0.0429 & 0.8472 & 0.0732 & 17 & 6 \\
\hline Control vs. $28 \mathrm{dpa}$ & 1.005 & 0.0429 & 0.8849 & 0.08895 & 17 & 7 \\
\hline 1 dpa vs. 11 dpa & 0.8447 & 0.06033 & 0.8472 & 0.0732 & 8 & 6 \\
\hline 1 dpa vs. 28 dpa & 0.8447 & 0.06033 & 0.8849 & 0.08895 & 8 & 7 \\
\hline 11 dpa vs. $28 \mathrm{dpa}$ & 0.8472 & 0.0732 & 0.8849 & 0.08895 & 6 & 7 \\
\hline Figure 5g & \multicolumn{6}{|c|}{$\begin{array}{l}\text { One-way ANOVA, no significant difference for genotype and post-administration } \\
\text { timepoint }(p=0.1896)\end{array}$} \\
\hline $\begin{array}{l}\text { Tukey's Multiple } \\
\text { Comparisons test }\end{array}$ & Mean Diff & Significant? & Summary & $\begin{array}{l}\text { Adjusted P } \\
\text { value }\end{array}$ & & \\
\hline Control vs. 1 dpa & 0.2294 & No & ns & 0.1712 & & \\
\hline Control vs. $11 \mathrm{dpa}$ & -0.007537 & No & ns & $>0.9999$ & & \\
\hline Control vs. 28 dpa & 0.09268 & No & ns & 0.8479 & & \\
\hline 1 dpa vs. 11 dpa & -0.2369 & No & ns & 0.3253 & & \\
\hline 1 dpa vs. 28 dpa & -0.1367 & No & ns & 0.7272 & & \\
\hline 11 dpa vs. 28 dpa & 0.1002 & No & ns & 0.8926 & & \\
\hline Test Details & Mean 1 & SEM 1 & Mean 2 & SEM 2 & N1 & N2 \\
\hline Control vs. $1 \mathrm{dpa}$ & 1.002 & 0.06148 & 0.7728 & 0.09323 & 17 & 8 \\
\hline Control vs. $11 \mathrm{dpa}$ & 1.002 & 0.06148 & 1.01 & 0.1398 & 17 & 6 \\
\hline Control vs. $28 \mathrm{dpa}$ & 1.002 & 0.06148 & 0.9095 & 0.04635 & 17 & 7 \\
\hline $1 \mathrm{dpa}$ vs. $11 \mathrm{dpa}$ & 0.7728 & 0.09323 & 1.01 & 0.1398 & 8 & 6 \\
\hline 1 dpa vs. $28 \mathrm{dpa}$ & 0.7728 & 0.09323 & 0.9095 & 0.04635 & 8 & 7 \\
\hline 11 dpa vs. 28 dpa & 1.01 & 0.1398 & 0.9095 & 0.04635 & 6 & 7 \\
\hline
\end{tabular}




\section{Figure Legends}

Figure 1. Astrocyte ablation occurred within hours after Tamoxifen administration. a. Astrocytes were ablated in mice using a cre-inducible system expressing diptheria toxin fragment fragment a (DTA) after a stop cassette flanked by loxP sites: 1) Cre recombinase coupled to an estrogen receptor was expressed behind the astrocyte glutamate transporter GLAST. 2) Tamoxifen was administered and binded to this estrogen receptor, enabling 3) translocation of cre into the nucleus where 4) recombination at LoxP sites excised the stop sequence in front of DTA and 5) enabled DTA transcription and translation. 6) DTA halted protein translation and led to apoptotic cell death. b. Mice were sacrificed at multiple timepoints between 2 hours and 28 days after tamoxifen administration to determine the timeline and extent of astrocyte ablation. Some animals were also injected with Cadaverine and/or BrdU. c. Some astrocytes in DTA $A^{\mathrm{t} / \mathrm{wt} / / \mathrm{Glast}-}$ CreERT ${ }^{\text {tg/wt }}$ mice colocalized with the apoptotic marker cleaved caspase 3 shortly after tamoxifen administration (arrowhead). d. Loss of the astrocyte marker Glt1 indicating cell ablation occurred only in DTA $\mathrm{A}^{\mathrm{f} / \mathrm{wt} / / G \text { last-CreERT }}{ }^{\mathrm{tg} / \mathrm{wt}}$ mice several hours after tamoxifen administration and continued up to 28 days later, while no Glt1 loss was detected at any

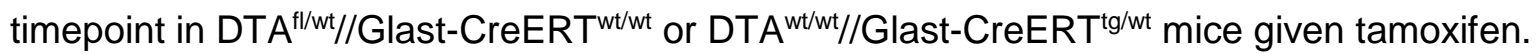
e. Glt1 loss indicative of astrocyte ablation occurred across the cortex in DTA $A^{f / w t} / / G$ last-

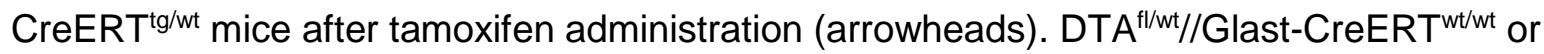
DTA ${ }^{\text {wtwt }} / /$ Glast-CreERTtg/wt $m i c e$ showed few "Glt1-low regions" along the midline or along blood vessels. $\mathbf{f}$. The percentage of Glt1-negative areas were quantified in the cortical gray matter per slice across all timepoints. Slices from the same animal were plotted in the same color. g. Glt1 loss percentage for each slice were plotted in either medial or lateral groups based on location in The Allen Brain Atlas. 
Figure 2. Astrocyte ablation induced BBB dysfunction. a. Leakage of the BBB tracer dye Cadaverine in cortex was observed around regions of astrocyte cell death indicated by lack of Glt1 expression. Cadaverine leakage occurred as early as 2 hpa and was still present at $28 \mathrm{dpa}$. Control mice showed minimal leakage of dye. b. Cadaverine leakage occurred across cortex in experimental mice and was quantified as percent leakage area out of entire cortex area and plotted by slice. c. Some vessels labeled positive for fibrinogen deposition and were surrounded by Glt1 loss and Cadaverine leakage.

Figure 3. Astrocyte ablation of cells adjacent to blood vessels reduced expression of proteins in endothelial cells responsible for maintenance of the BBB. a. Astrocyte ablation of cells next to blood vessels resulted in reduced and discontinuous vessel labeling for the tight junction protein ZO-1 (white arrowheads). ZO-1 expression was examined within Glt-1-lacking areas (circled in yellow). At 6 hpa, few vessels within Glt1-lacking areas showed disrupted ZO-1 labeling, and those that did also presented with Cadaverine leakage. At $11 \mathrm{dpa}$, some vessels in regions of ablation completely lacked ZO-1 (yellow arrowhead) and showed Cadaverine leakage. b. Continuity of ZO-1 labeling in vessels was quantified by binarizing ZO-1 signal and drawing a line along ZO-1 signal, using CD31 as a guide. c. Average fluorescence intensity was quantified for ZO-1 intensity profile measurements of lines drawn along ZO-1 labeling. d. Endothelial glucose transporter GLUT1 expression was unchanged between groups. e. Quantification of average fluorescence intensity of GLUT1 showed no changes in vessels adjacent to Glt1lacking areas.

Figure 4. Astrocytes adjacent to areas of astrocyte ablation had late increased phosphorylation of STAT3 and unchanged Sox9. a. Astrocytes adjacent to regions of Glt1 loss were negative for pSTAT3 at 1, 3 and 5 dpa. GFAP ${ }^{+}$astrocytes close to astrocyte ablation areas labeled positive for phosphorylated STAT3 at $11 \mathrm{dpa}$ and $28 \mathrm{dpa}$. b. Astrocytes adjacent to regions of astrocyte 
ablation indicated by lack of Glt1 did not show changes in their expression of the astrocyte transcription factor Sox9.

Figure 5. Astrocyte ablation induced GFAP upregulation in processes and mild morphological changes in neighboring astrocytes. a. Astrocytes adjacent to regions of astrocyte ablation indicated by lack of Glt1 showed increased expression of GFAP as early as $1 \mathrm{dpa}$ and continued through $28 \mathrm{dpa}$. GFAP labeling was used to trace loss-adjacent astrocyte processes in ImageJ. b. Total length of all GFAP+ processes was quantified for loss-adjacent astrocytes at 1,11 , and 28 days post administration of tamoxifen. c. Total volume of all GFAP+ processes was quantified for loss-adjacent astrocytes at 1,11 , and 28 days post administration of tamoxifen. d. Sholl analysis compared arborization complexity of loss-adjacent astrocytes at 1 and 28 dpa. ${ }^{*} p \leq 0.05,{ }^{* *} p \leq 0.01,{ }^{* *} p<0.001,{ }^{* * *} p \leq 0.0001$. e. Changes in astrocyte polarity were tested by drawing quadrants using astrocyte ablation regions as a reference when present. The two quadrants closest to ablation regions were called proximal, while the two quadrants furthest away were called distal. f. Length to width ratios of drawn quadrants were calculated and compared at 1, 11, and $28 \mathrm{dpa}$. $\mathbf{g}$. The ratio of proximal quadrant areas to distal quadrant areas were calculated and compared among early, middle, and late timepoints.

Supplemental Figure 1. Semi-automatic quantification of Glt1 loss regions using ImageJ. a. Large images of sagittal slices were acquired for both experimental and control mice at all timepoints using line scanning at 20x magnification. b. Images were binarized based using intensity parameters that selected for Glt-1 negative regions. c. Binary images were run through the "fill holes" algorithm to fill in Glt-1 negative regions and create discrete shapes. d. The Glt1 negative regions that are blood vessels and neurons were excluded using consistent size and circularity quantification parameters. The remaining Glt1 negative regions were quantified as regions of astrocyte ablation. 


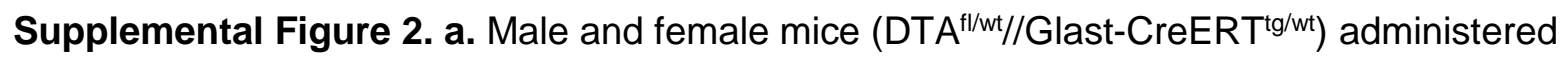
tamoxifen or an oil vehicle only or nothing at all (naïve) did not show astrocyte ablation indicated by no lack of the continuous labeling of astrocyte fine processes with the astrocyte marker membrane-associated astrocyte glutamate transporter Glt1. b-c. In addition to cortical loss of Glt1, Experimental mice showed Glt1 loss in hippocampus and striatum after tamoxifen administration. d. Bergmann glia in the cerebellum that highly express GLAST at high levels in the adult and this in cerebellum showed noticeable depletion in density after tamoxifen administration (arrowheads).]

Supplemental Figure 3. Astrocyte ablation in cortex indicated by lack of expression of astrocyte markers. a. Lack of astrocyte marker $S 100 \beta$ overlaps with lack of Glt1 in experimental mice. b. Lack of astrocyte marker Aquaporin-4 (AQ4) overlaps with lack of Glt1 in experimental mice.

Supplemental Figure 4. Cadaverine leakage occurred after astrocyte ablation across cortex. a. Large area scans of cortex showed minimal Cadaverine leakage in control mice, while diffuse areas of leakage were found in experimental mice.

Supplemental Figure 5. Microglia showed morphology changes and increased lba1 levels in regions of ablated astrocytes.

Supplemental Figure 6. Astrocyte ablation does not induce proliferation of neighboring astrocytes. a. Ki67+cells were present in all mice at the subependymal zone, which contains proliferating cells in adult mice. b. Astrocytes adjacent to loss regions did not express the mitotic marker Ki67 but Ki67+ cells of other cell identity (arrowheads) were present in both 
control and experimental groups.

Supplemental Figure 7. Astrocyte ablation does not induce proliferation of neighboring astrocytes. a. Astrocytes adjacent to loss regions did not express the mitotic marker BrdU but $\mathrm{BrdU}^{+}$cells of other cell identity (arrowheads) were present in both control and experimental groups. 


\section{Control}

a
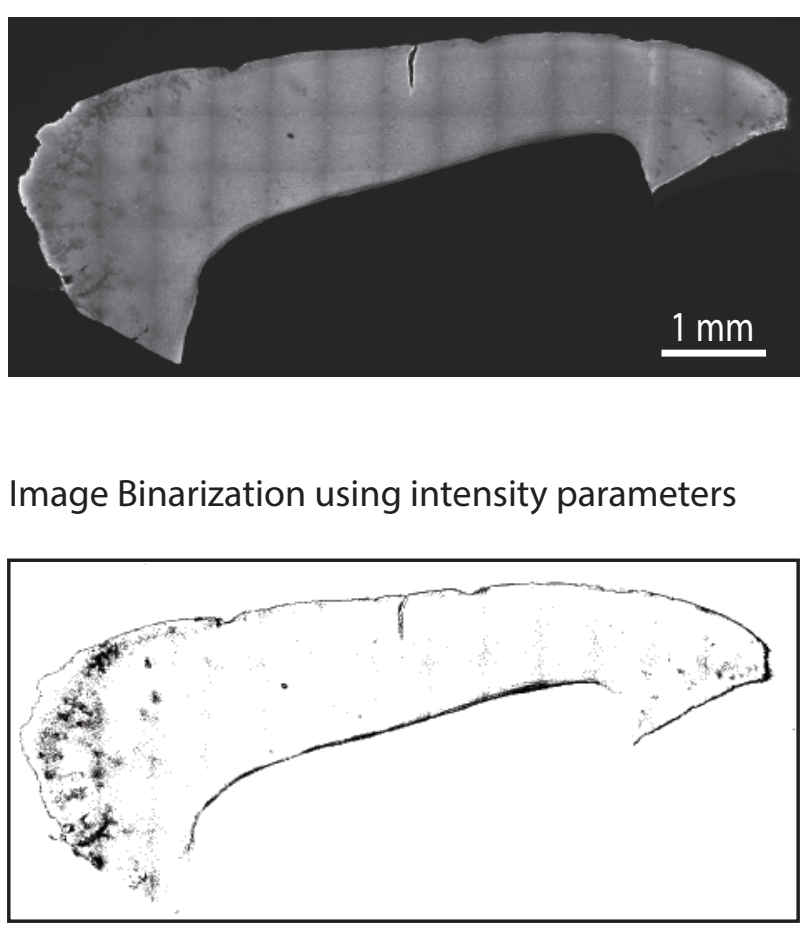

Fill holes algorithim

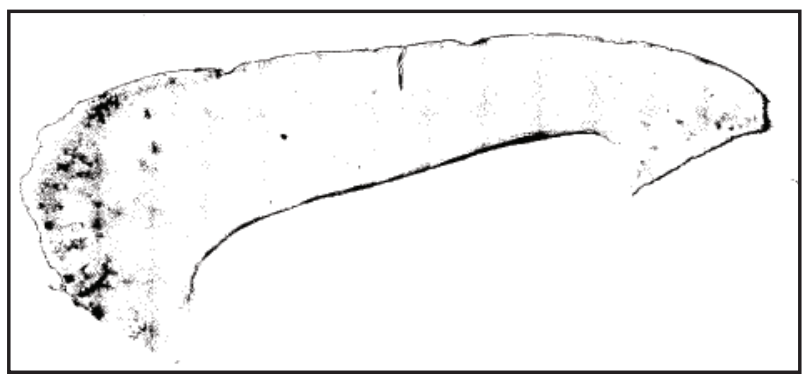

Select for Glt1 loss

d

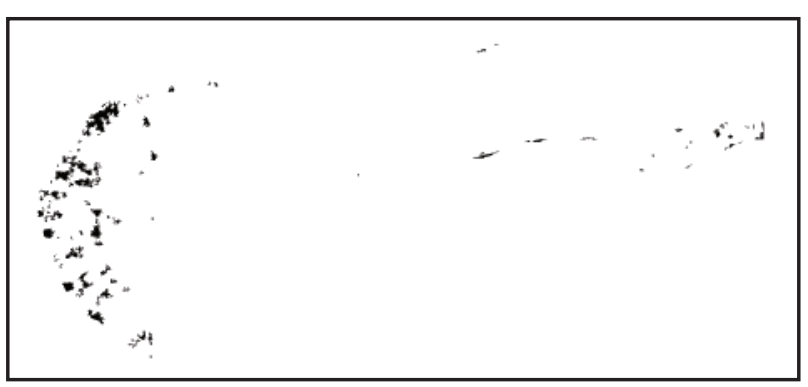

$2.12 \%$ loss
Experimental 11dpa

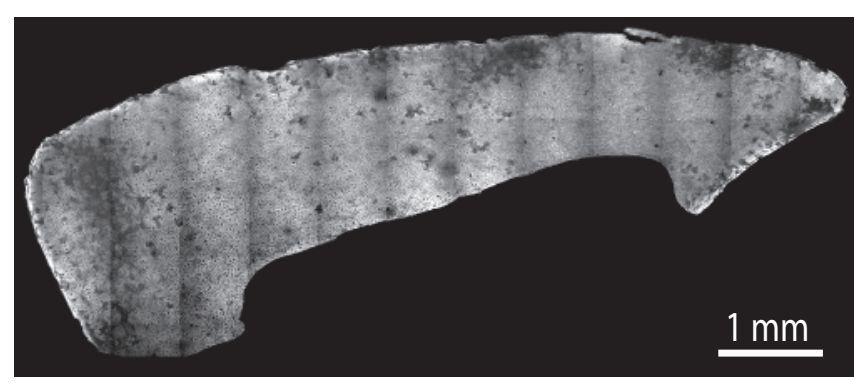

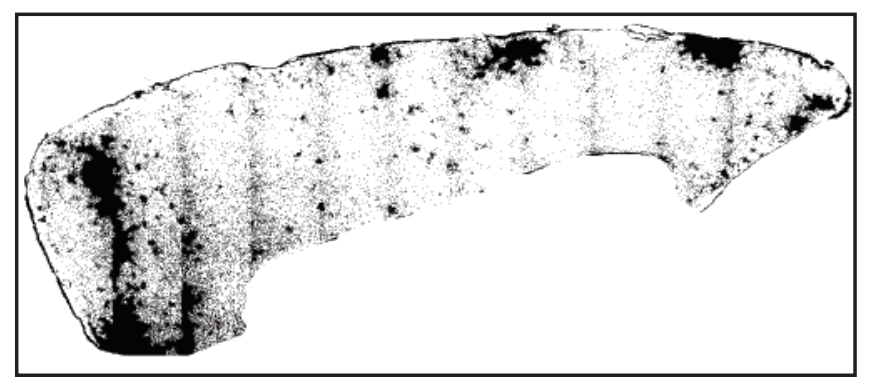

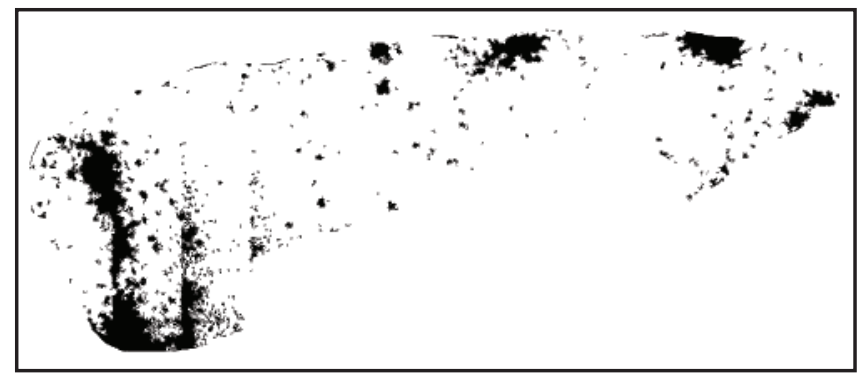

$10.84 \%$ loss 


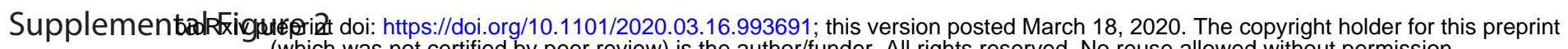
(which was not certified by peer review) is the author/funder. All rights reserved. No reuse allowed without permission.

a

DTA $^{\text {ff/wt }} / /$ GLAST-creERT2 ${ }^{\text {tg/wt }}$ Male

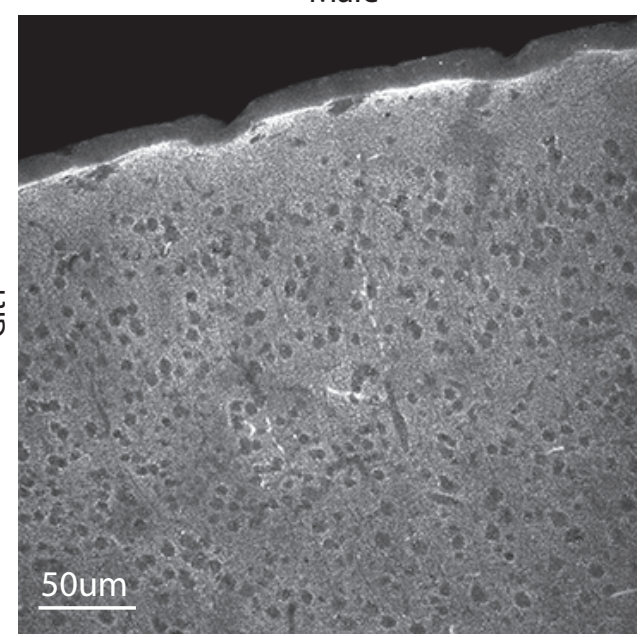

b

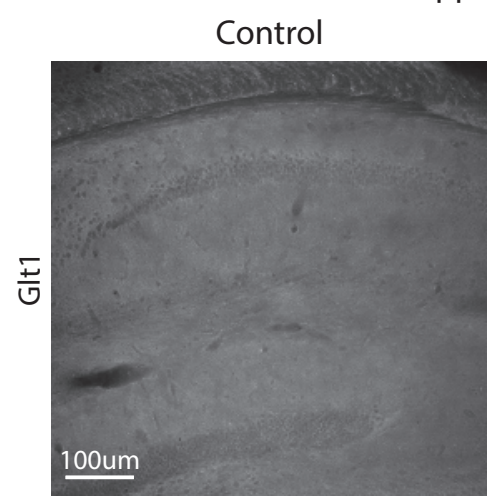

Hippocampus

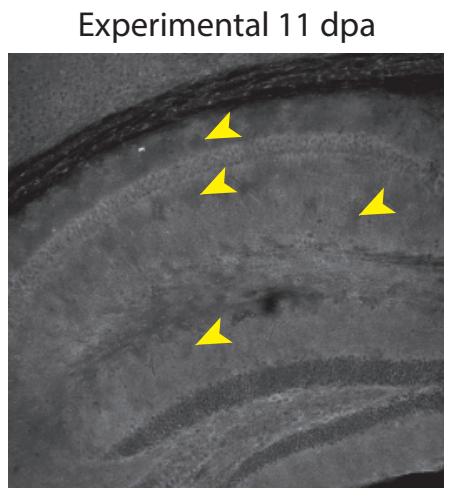

Cerebellum

Control
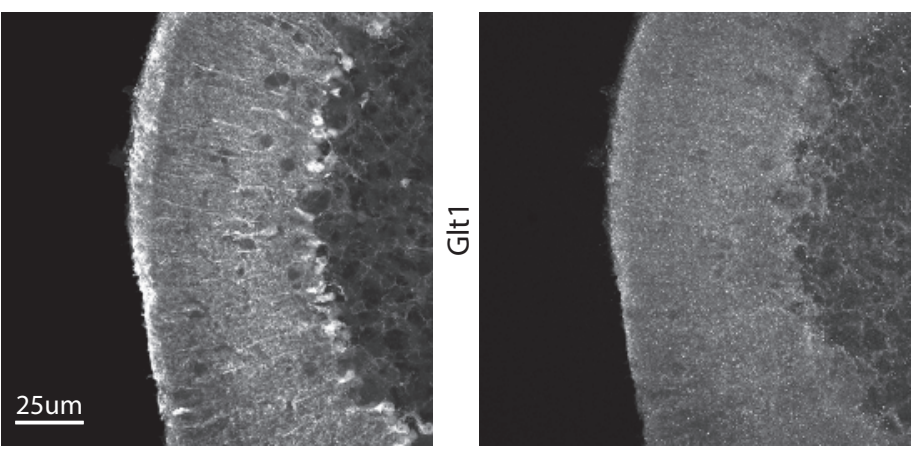

DTA $^{\text {fl/wt }} / /$ GLAST-creERT2 ${ }^{\text {tg/wt }}$

Female

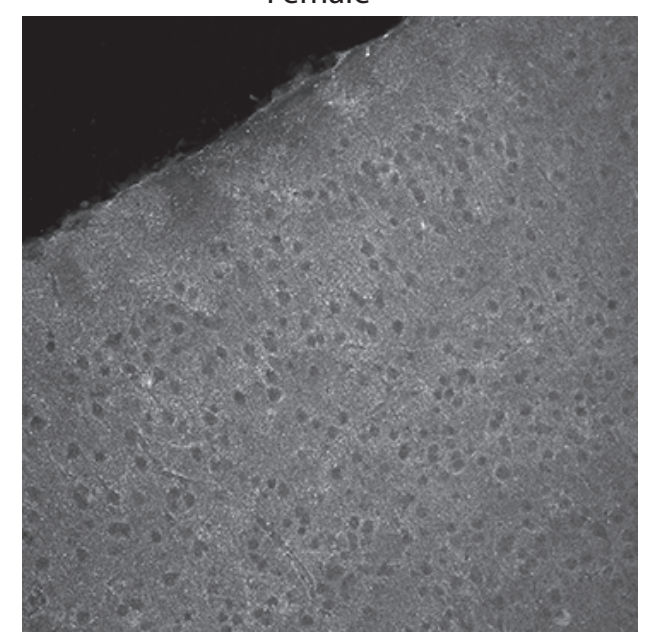

C

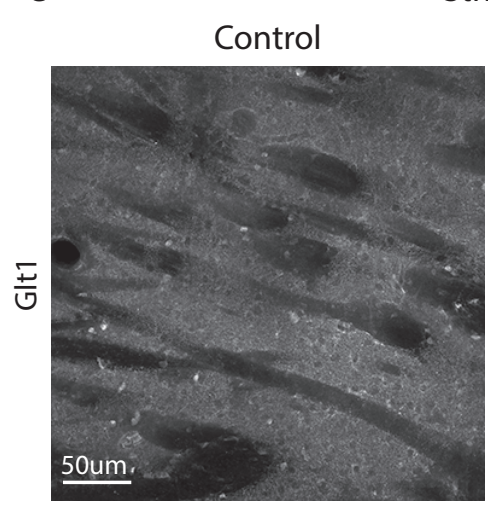

Striatum
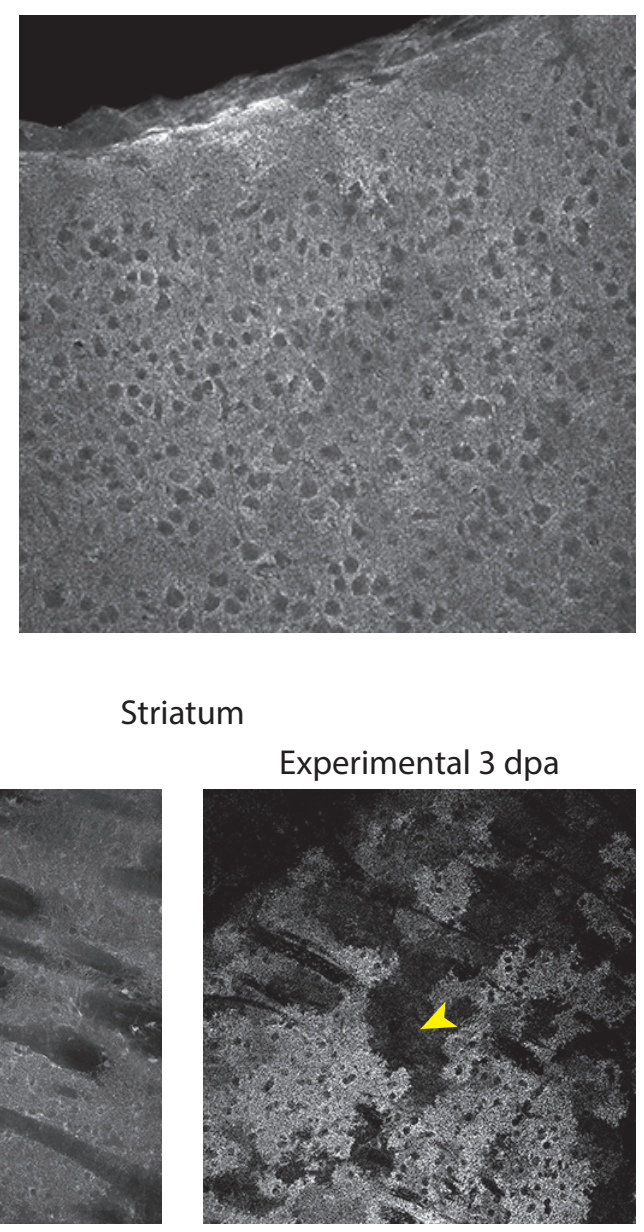

Cerebellum

Experimental $11 \mathrm{dpa}$
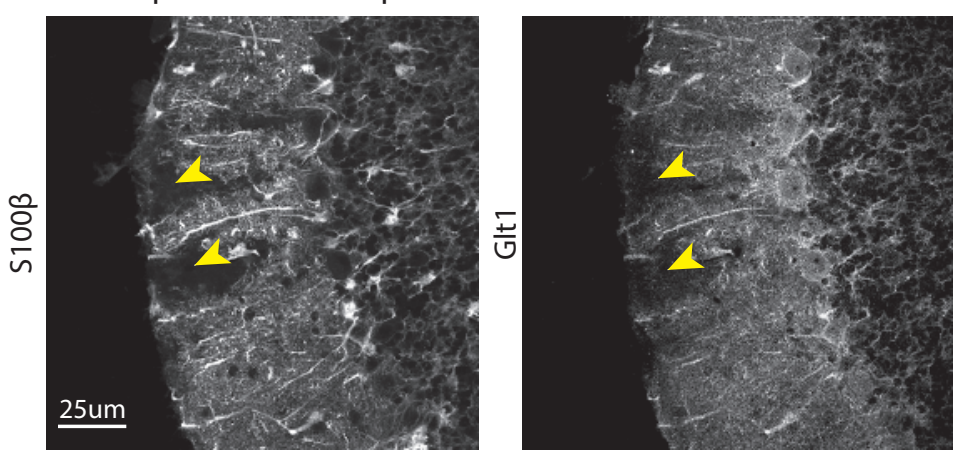


\section{Control}

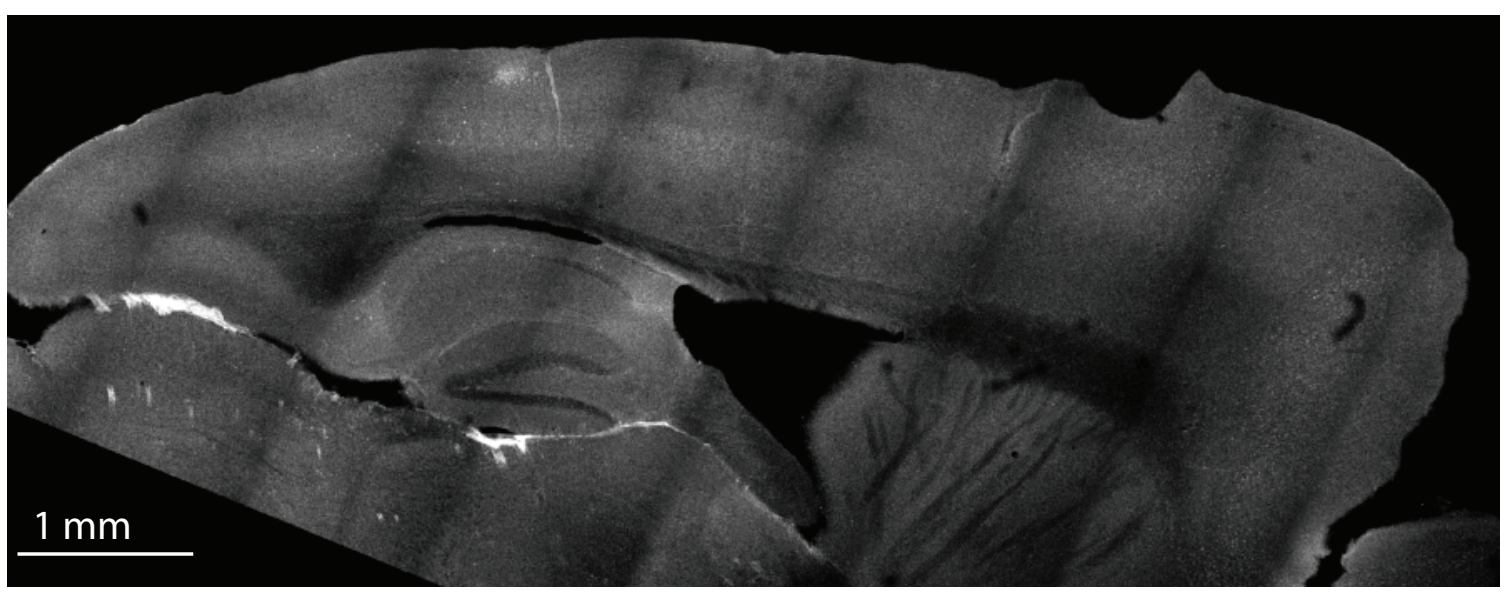

$\frac{\substack{\frac{1}{亠} \\ \frac{0}{0}}}{\frac{0}{0}}$

\section{Experimental $3 \mathrm{dpa}$}

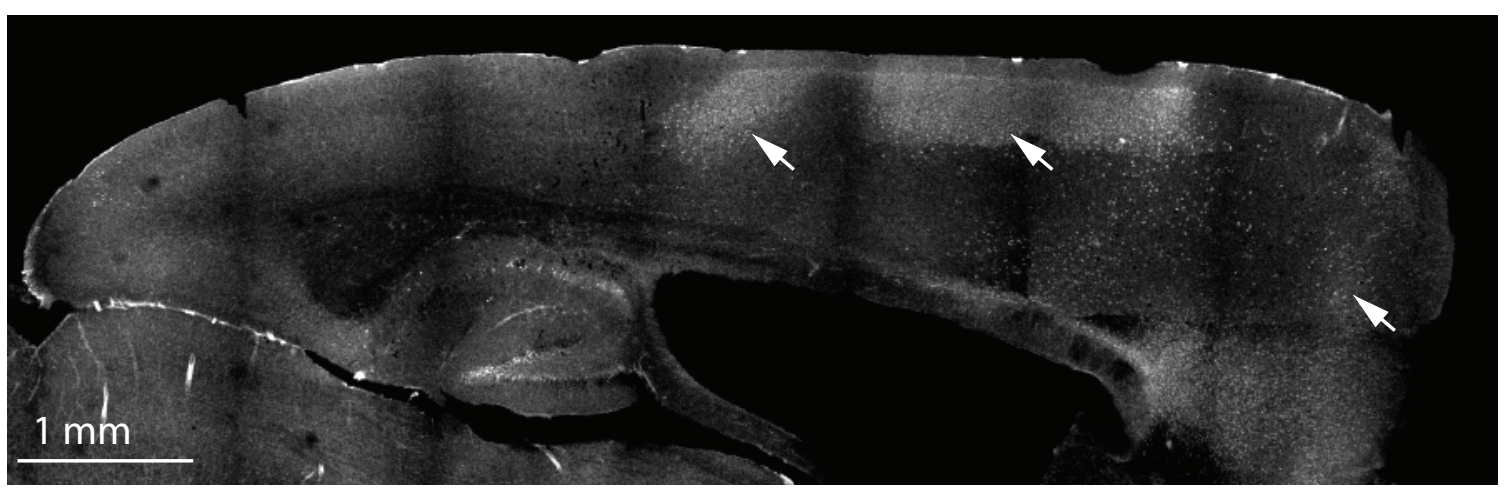


Supplementia RyiFipgapriet Eoi: https://doi.org/10.1101/2020.03.16.993691; this version posted March 18, 2020. The copyright holder for this preprint
fwhich was not certified bv peer review) is the authorffunder. All riahts reserved No reuse allowed without permission. (which was not certified by peer review) is the author/funder. All rights reserved. No reuse allowed without permission.
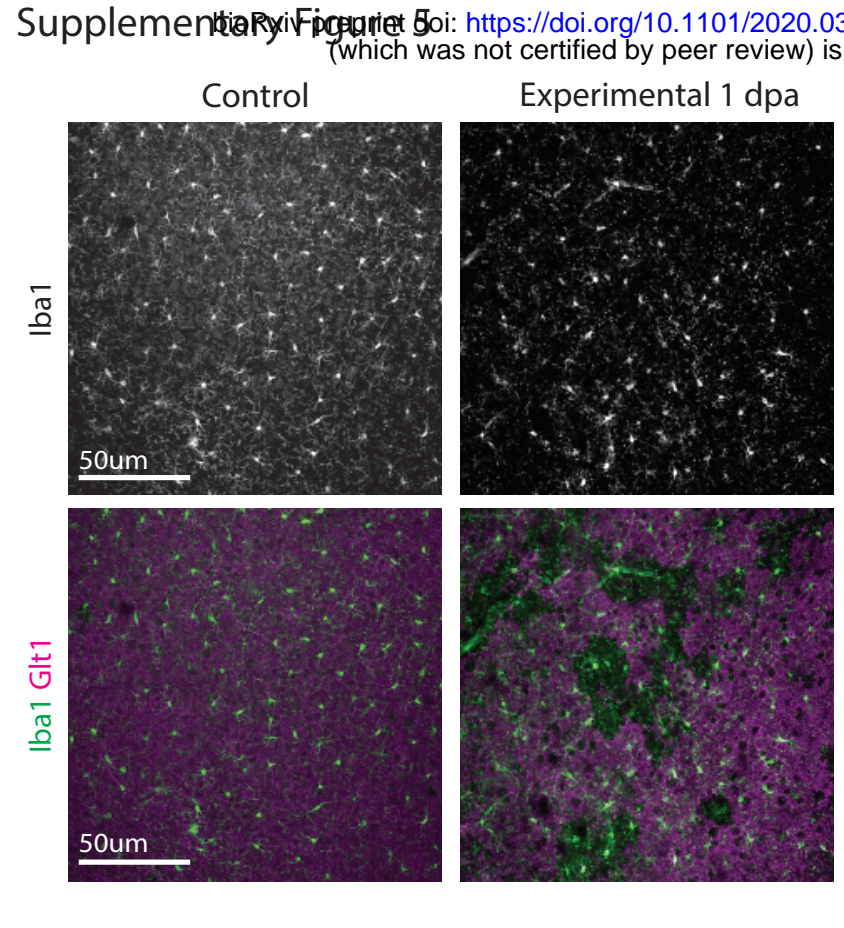

Experimental 3 dpa
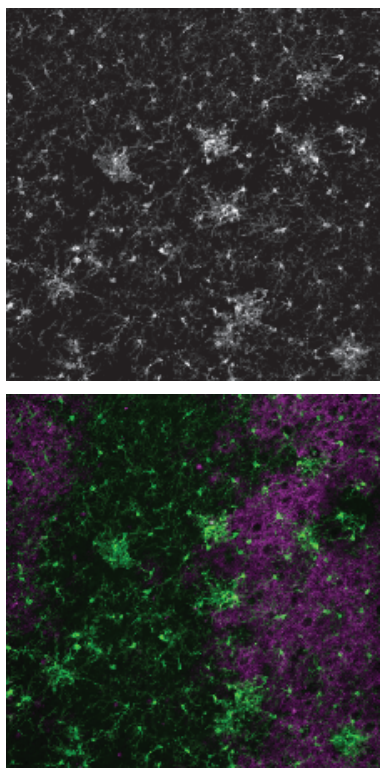

Experimental $11 \mathrm{dpa}$

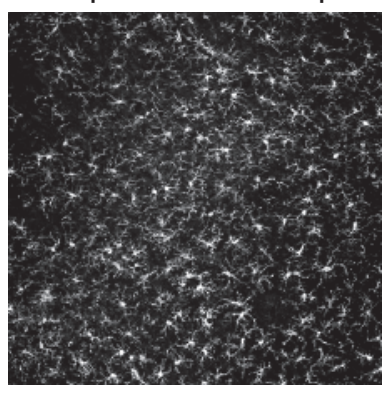

Experimental $28 \mathrm{dpa}$

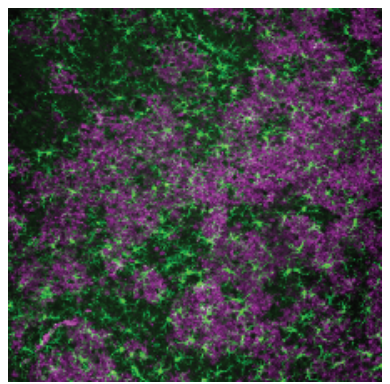

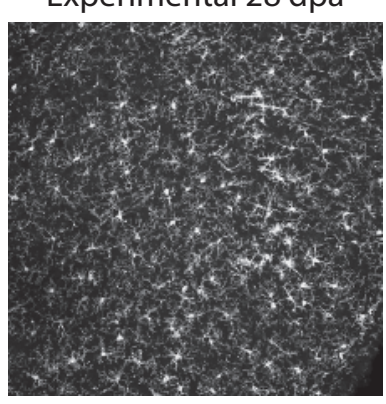

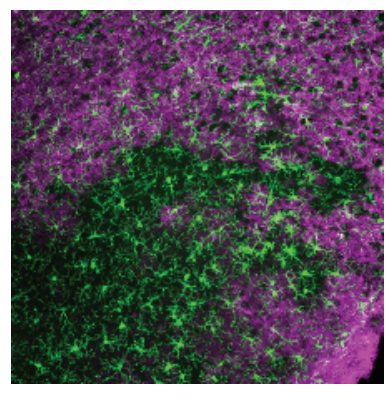

\pm
\pm
$\mathbb{J}$
$\stackrel{0}{=}$

50um
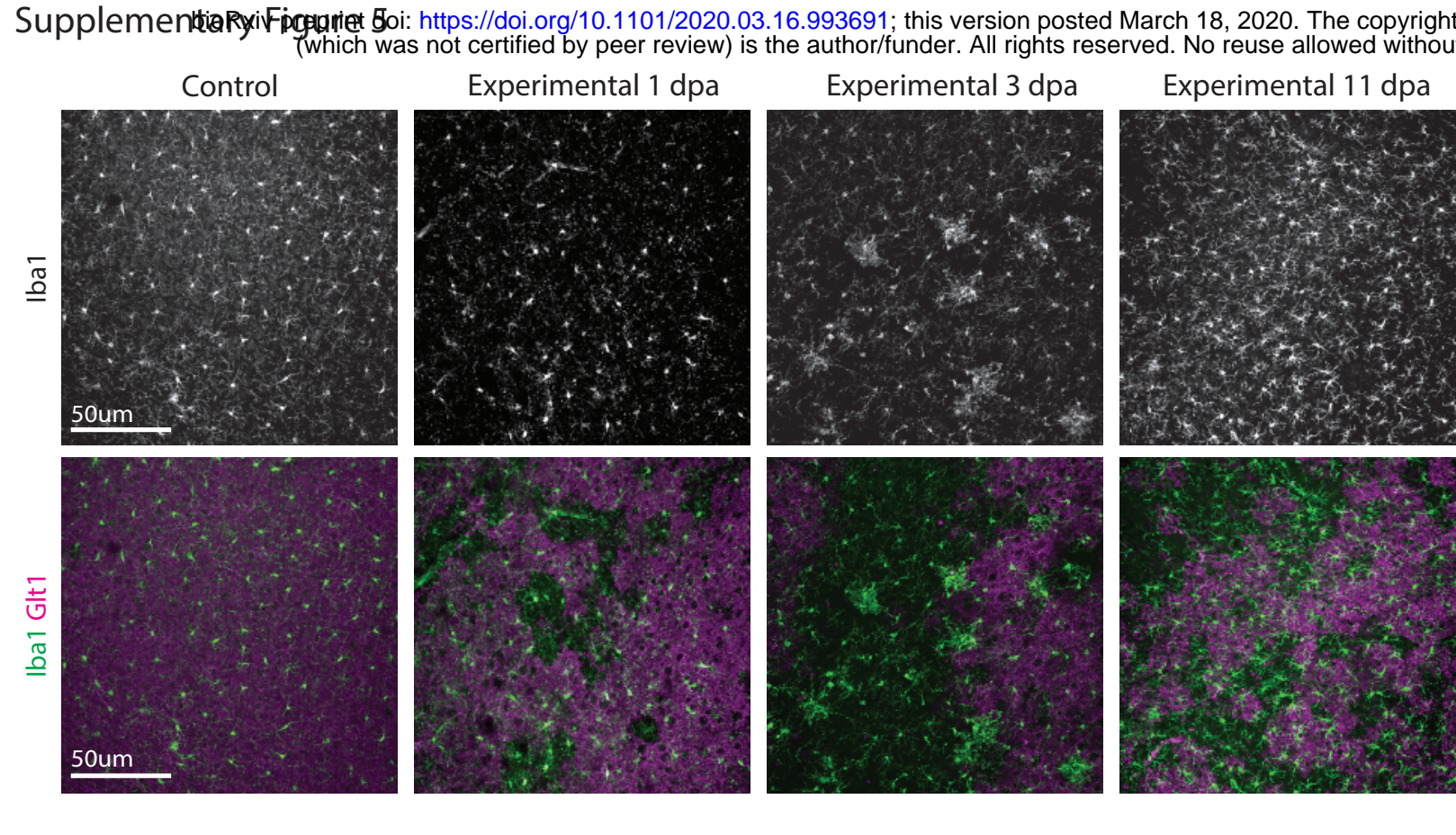
a
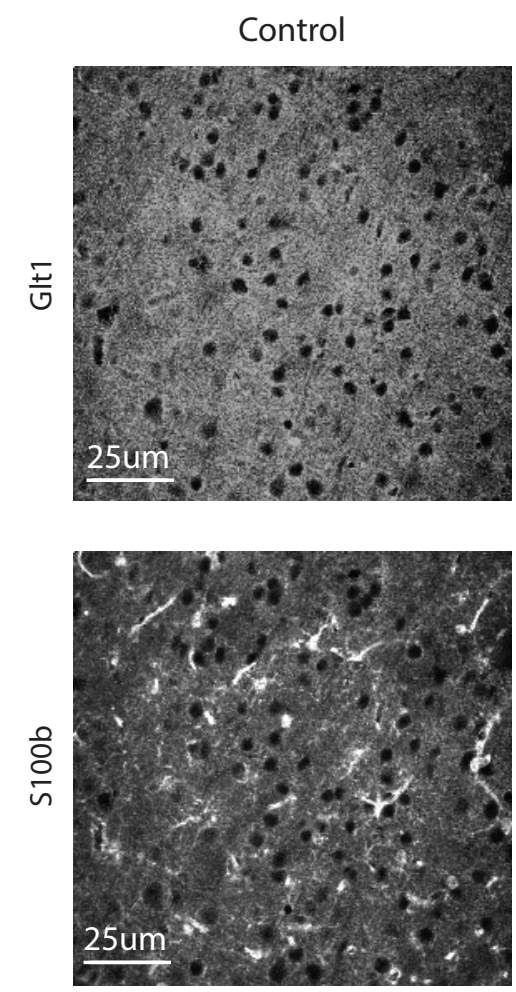

금

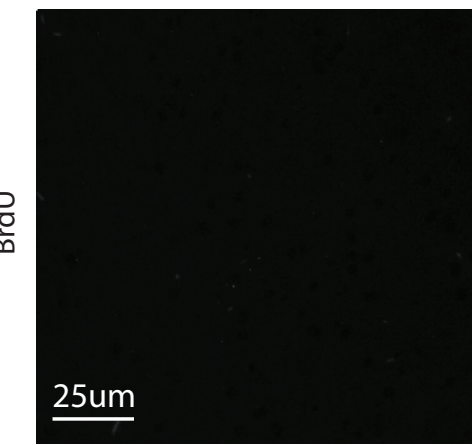

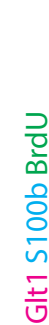

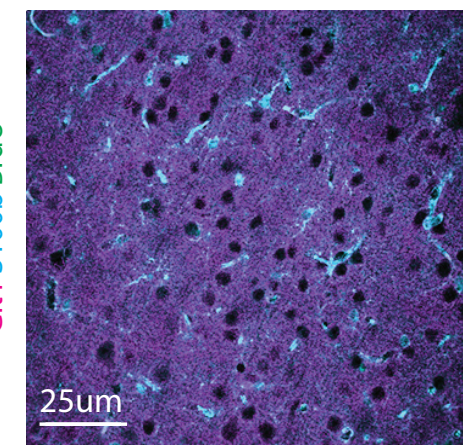

Experimental $1 \mathrm{dpa}$

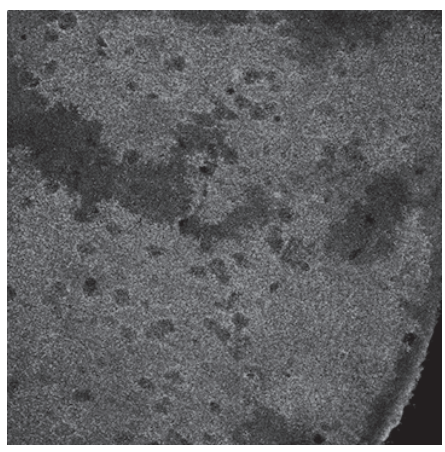

Experimental $3 \mathrm{dpa}$
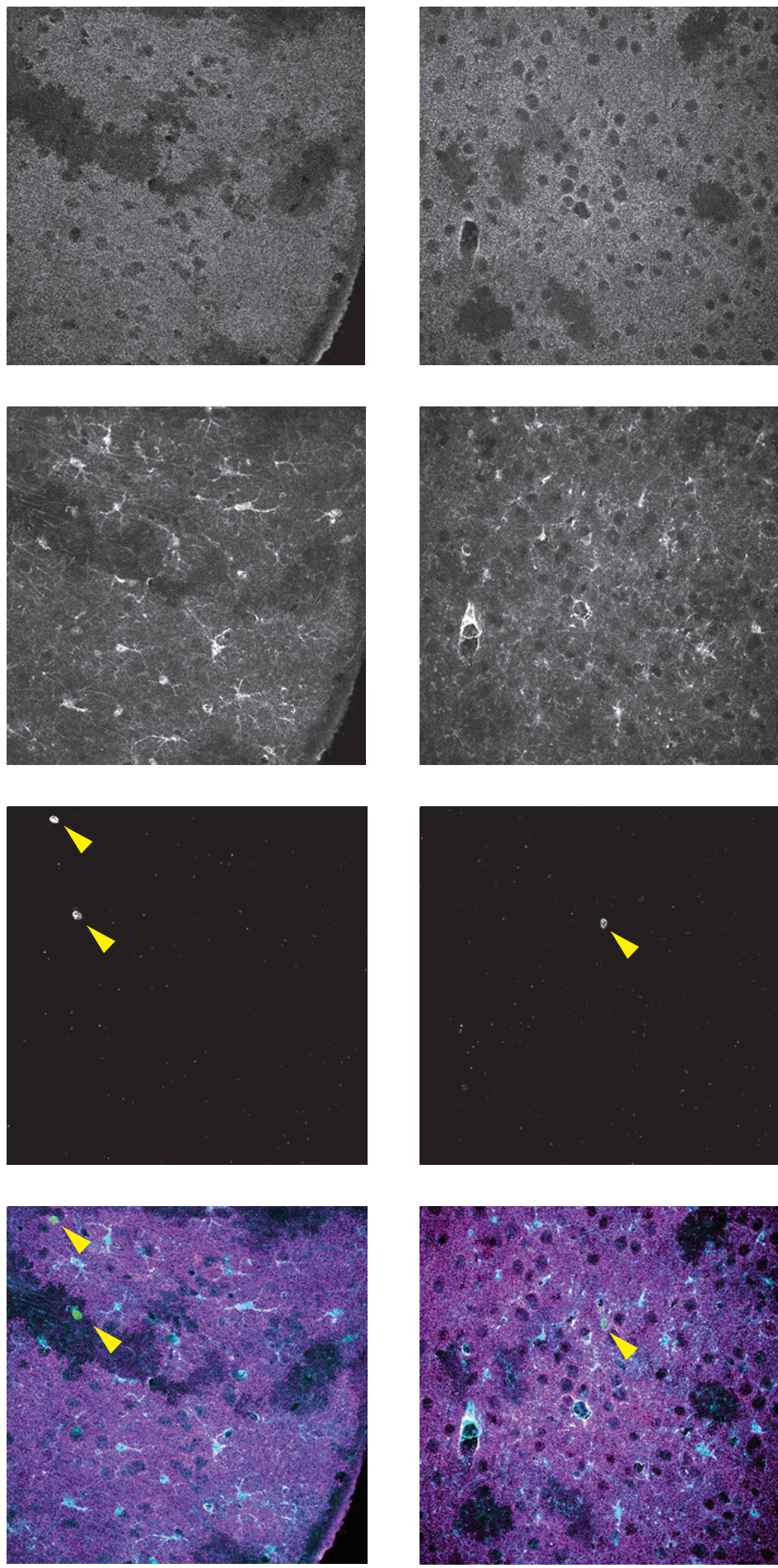
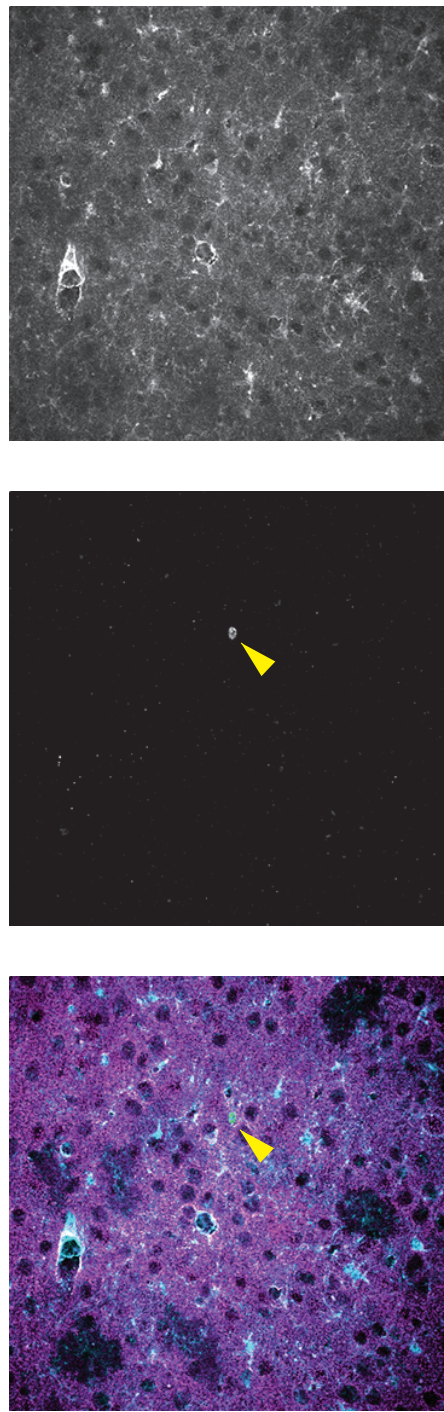

Experimental $5 \mathrm{dpa}$
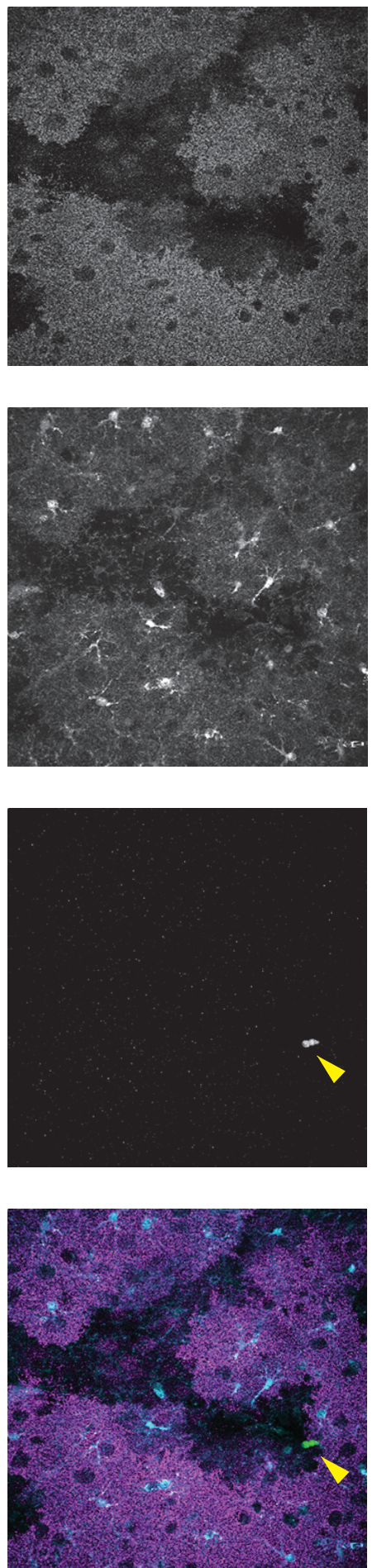